Portland State University

PDXScholar

5-3-1991

\title{
The Burnett Site: a Cascade Phase Camp on the Lower Willamette River
}

Robert M. Burnett

Portland State University

Follow this and additional works at: https://pdxscholar.library.pdx.edu/open_access_etds

Part of the Archaeological Anthropology Commons

Let us know how access to this document benefits you.

\section{Recommended Citation}

Burnett, Robert M., "The Burnett Site: a Cascade Phase Camp on the Lower Willamette River" (1991). Dissertations and Theses. Paper 4171.

https://doi.org/10.15760/etd.6055

This Thesis is brought to you for free and open access. It has been accepted for inclusion in Dissertations and Theses by an authorized administrator of PDXScholar. Please contact us if we can make this document more accessible: pdxscholar@pdx.edu. 
AN ABSTRACT OF THE THESIS OF Robert M. Burnett for the Master of Arts in Anthropology presented May 3, 1991.

Title: The Burnett Site: A Cascade Phase Camp on the Lower Willamette River.

APPROVED BY THE MEMBERS OF THE THESIS COMMITTEE:

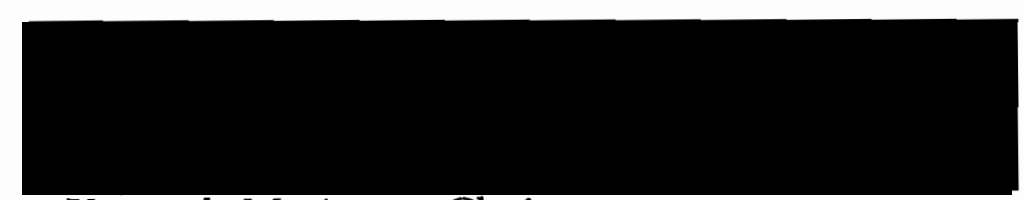

Kenneth M. Ames, Chair
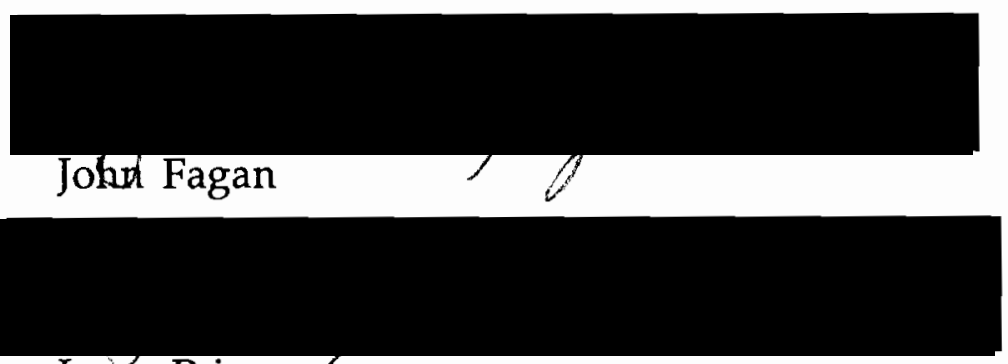

Larry Price

Artifacts recovered from archaeological excavations near the Willamette River in Lake Oswego, Oregon indicate the presence there of a Late Windust-Early Cascade Phase site possibly dating to 9,000 B.P. The assemblage includes 137 projectile points, bifaces or point fragments, nearly all of the Cascade-type. Two stem fragments and one complete point which are similar to those of the 
Windust Phase which dates $10,000-8,000$ B.P. in the southern Columbia Plateau also were found. Stone knives, choppers, scrapers, hammerstones, cores and microblades also are included in the assemblage. No later type notched or stemmed points have been recovered from the site. If the hypothesized dates are valid, the site will be the oldest discovered to date in the Lower Willamette River-Portland Basin area. This thesis reports on the site, its excavation and its artifacts. 
THE BURNETT SITE: A CASCADE PHASE CAMP ON THE LOWER WILLAMETTE RIVER

\author{
by \\ ROBERT M. BURNETT
}

A thesis submitted in partial fulfillment of the requirements for the degree of

MASTER OF ARTS

IN

ANTHROPOLOGY

Portland State University

1991 


\section{TO THE OFFICE OF GRADUATE STUDIES:}

The members of the Committee approve the thesis of Robert M.

Burnett presented May 3, 1991.
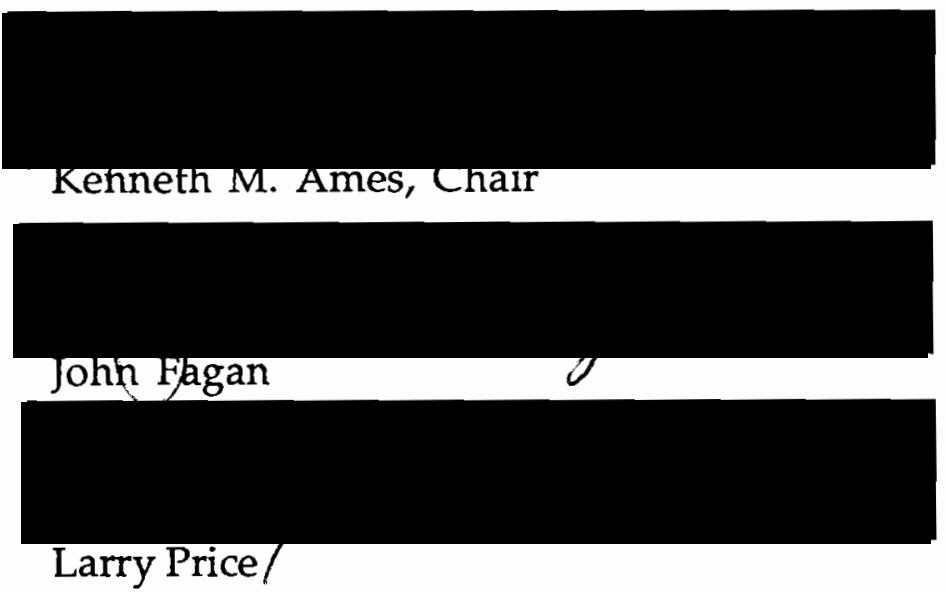

APPROVED

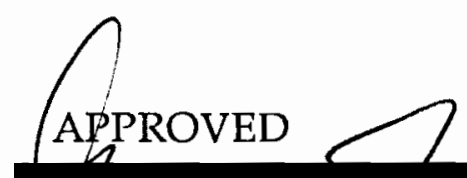

Marc R. Feldesman, Chair, Department of Anthropology

C. William Savery, Interim Vice Provost for Graduate Studies and Research 


\section{ACKNOWLEDGEMENTS}

I would like to express my deep appreciation to all those who made this project possible, including Dr. Kenneth Ames, project supervisor and thesis committee chairman, and Rick Atwell, field director for excavations in 1987 and 1988. Volunteer crew members at 250 Furnace St. were Geoff Kleckner, Ruth Vondracek, Bonnie Mills, Laurine Burnett, Kay Reed, Bob Wagner, Steve Hamilton, Jim Haskett and Robert M. Burnett. Crew members for the 1990 excavation at the Headlee property were Wilda Toussaint, Bonnie Mills, Jo Reese, Shelly Haver, Monique Cushing, Jim Haskett, Robert M. Burnett and Joe Burnett.

Consultants include John Fagan of Archaeological Investigations Northwest, who provided valuable help in lithic analysis and site interpretation; Frank Reckendorf, Jerry Latshaw and Russ Langridge of the U. S. Soil Conservation Service, and Richard Waitt of the U. S. Geological Survey, all of whom advised on soil formation and composition. Thanks also to Larry Price for serving on the thesis committee. This work could not have been completed without the assistance of these friends and helpers and I am sincerely grateful to all of them for their encouragement and support. 


\section{TABLE OF CONTENTS}

\section{PAGE}

ACKNOWLEDGEMENTS................................................................. iii

LIST OF TABLES.

LIST OF FIGURES........................................................................ vii

\section{CHAPTER}

I INTRODUCTION ...........................................................

Physiography-History.................................................. 3

Location

Geology of the Oswego Area

Soil

History

Ethnohistory

II $\quad$ RESEARCH AND FINDINGS............................................ 11

Area Archaeology ........................................................ 11

Project History and Methodology............................ 14

250 Furnace St. Locale

Headlee Property

250 Furnace St. Excavations..................................... 17

Lithic Analysis............................................................ 18

Lithic Raw Materials Used

Distribution of Lithic Items

Fine Screen 
Materials and CCS/Basalt Ratios

Vertical Distribution of Artifacts by Size

Distribution of Technological Artifact Types

Headlee Property Findings.................................. 25

Features, Soil Disturbance....................................... 26

Features

Soil Disturbance

ARTIFACT DESCRIPTIONS........................................... 47

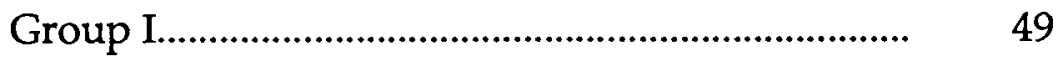

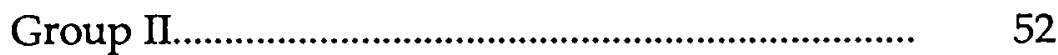

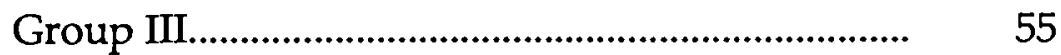

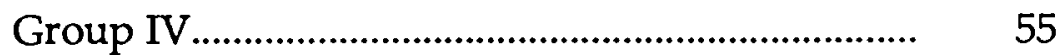

Group V............................................................... 56

Group VI.............................................................. 56

Group VII........................................................... 57

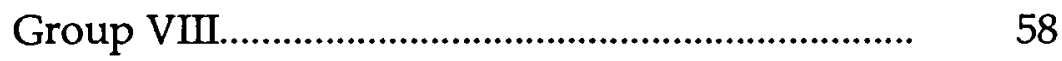

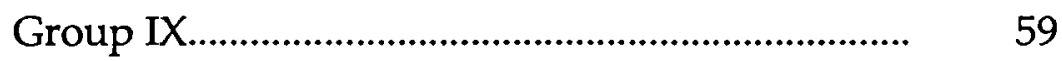

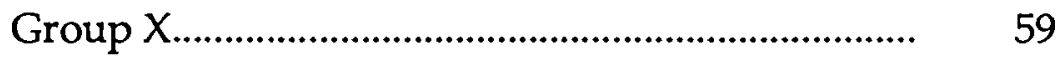

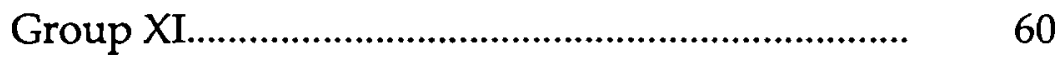

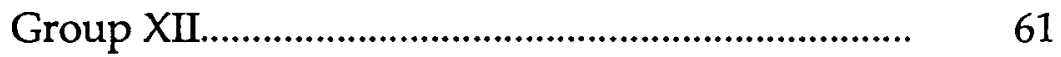

Other Artifact Classes............................................. 62

Flake Blanks

Scrapers

Bifaces

Edge-Modified Cobbles

Utilized Flakes

Hammerstones 
Blade Knife

Net Weight

Cores

IV CASCADE AND WINDUST TYPE

PROJECTILE POINTS................................ $\quad 76$

The Cascade Point in Western Oregon ................ $\quad 78$

Cascadia Cave

Geertz Site

Other Sites

Chronology and Projectile Point Comparisons....

Form

Comparisons: Raw Material

Comparisons: Size

Lithic Technology

Windust

Assemblage Comparisons.

Hypotheses.

Components

One Component

Two Components

Site Function

Material Preference

Artifact Distribution

Soil Formation

Technology

Age Determination

Prehistory

Summary 


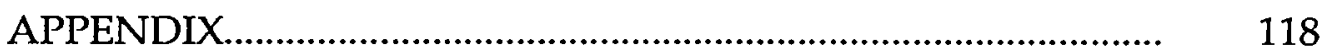




\section{LIST OF TABLES}

I Total Stone Artifacts Including Manufacturing

Debitage in Units A, B, C, D....................................... 30

II $\quad$ Percentages of Basalt, CCS and Obsidian Artifacts

in Units A, B, C, D..................................................... 31

III Numbers of Basalt, CC and Obsidian Artifacts

Recovered From Each Level in

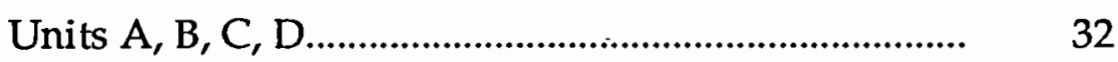

IV Number of Excavated Projectile Points and

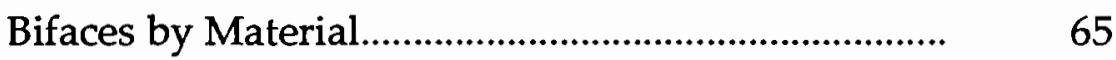

V Percentage of Projectile Points and Bifaces by

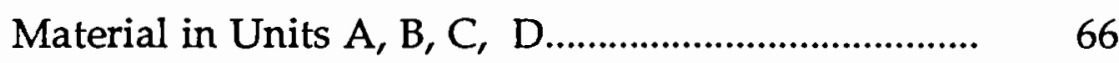

VI Attributes of Cascadia Cave, Geertz and Burnett Sites... 96

VII Projectile Point Material Preferences for

Cascadia Cave, Geertz and Burnett Sites................. 97

VIII Range of Sizes for Complete Points from

Cascadia Cave, Geertz and Burnett Sites.................. 98

IX. Average Length/Width Ratios of Complete Lanceolate

Points. 
X Characteristics of Windust-Type Points from

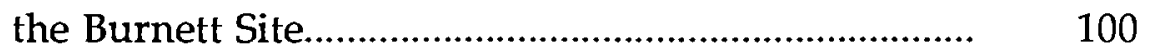




\section{LIST OF FIGURES}

FIGURE

PAGE

1. Relationship of Excavation Units to House and to

Each Other.

2. Vertical Distribution of Artifacts in Units A, B, C, D....... 34

3. Vertical Distribution of All Artifacts, Unit A.................. 35

4. Vertical Distribution of All Artifacts , Unit B................... 35

5. Vertical Distribution of All Artifacts , Unit C................... 35

6. Vertical Distribution of All Artifacts , Unit D.................. 35

7. Distribution Pattern of Unit C Fine Screened Flakes......... 36

8. Unit C Artifacts from $1 / 4$ Inch Screen and

Fine Screen

9. Material Distribution, Fine Screened Soil Sample............ 37

10. Distribution of Material, Units A, B, C, D Combined..... 38

11. Distribution of Artifacts in Unit A by Material............... 39

12. Distribution of Artifacts in Unit B by Material............... 39

13. Distribution of Artifacts in Unit $C$ by Material................. 39

14. Distribution of Artifacts in Unit D by Material................. 39

15. Percentage of Basalt, CCS and Obsidian in Unit A 
16. Percentage of Basalt, CCS and Obsidian in Unit B

Levels.

17. Percentage of Basalt, CCS and Obsidian in Unit C

Levels.

18. Percentage of Basalt, CCS and Obsidian in Unit D

Levels

19. Distribution of .5-1 Centimeter Artifacts.

20. Distribution of Artifacts by Size in Log Scale.

21. Distribution of 4-5 Centimeter Artifacts

22. Distribution of 5-10 Centimeter Artifacts

23. Log Scale Distribution of Large,Small Artifacts..................

24. Distribution of Heated Flakes, Unit C

25. Bipolar Flake and Core Distribution, All Units.................. 44

26. Microblade Distribution, All Units...................................... 44

27. Basalt, CCS Core Distribution............................................. 45

28. Core Distribution, All Units............................................ 45

29. Unimodal Distribution of Artifacts in Headlee Unit........ 46

30. Group I Artifacts--Large, Complete or Near Complete Points Bifaces.

31 Group II Artifacts--Small, Complete Lanceolate Points... 67

32. Group III Artifacts--Complete, Square Base Points With 
33. Group IV Artifacts--A Complete, One -Shouldered

Point.

68

34. Group V Artifacts--Long Narrow Blade or Point Tips...... 69

35. Group VI Artifacts--Long, Medial Sections........................ 69

36. Group VII 'Artifacts-Large Biface Tips and Fragments...... 70

37. Group VIII Artifacts--Medium, Small Point Tips............. 70

38. Group IX Artifacts--Short, Rounded Projectile

Point Tips

71

39. Group X Artifacts--Point Stems. Also Shown is

Complete Windust Type Point.

71

40. Group XI Artifacts--Medial Blade-Point Fragments.......... 72

41. Group XII. Artifacts--Large, Rough Bifaces...................... 72

42. Flake Blanks or Tools....................................................... 73

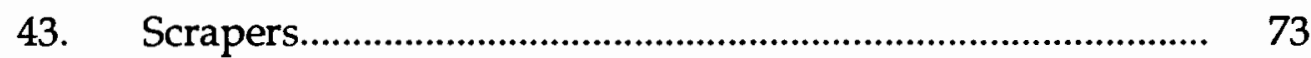

44. Hammerstone, Cobble Chopper....................................... 74

45. Flaked Cobble Tool .............................................................. $\quad 74$

46. Flake Knife........................................................................ 75

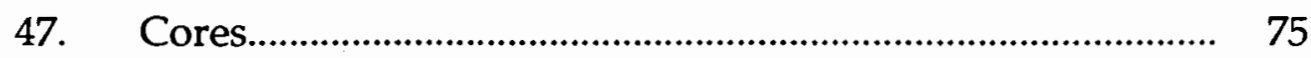

48. Rick Atwell, Field Director in 1987-1988, Records Notes

During Excavation of Units C and D at 250 Furnace $S t$ 


\section{CHAPTER I}

\section{INTRODUCTION}

Archaeological investigation of the Burnett site (35CL96), located in Lake Oswego, a suburb south of Portland, provides a unique opportunity to study the early prehistory of Northwestern Oregon. This site is typologically the oldest reported in the Portland Basin-Lower Willamette River region and is presently the only site of its kind recognized in this area.

Based on the style of the recovered artifacts, the site is probably contemporary with the Late Windust-Early Cascade phases of the Lower Snake River (Leonhardy and Rice 1970; Rice 1972; Bense 1972). The Windust and Cascade Phases are regional culture types proposed primarily for the Lower Snake River region of the Columbia River Plateau, although their manifestations also have been found in western and central Oregon and in southwestern Washington.

East of the Cascades, the Windust Phase spans from 10,000 to 8,000 B.P. and is followed by the Cascade Phase from 8,000 to 5,000 B.P. (Rice 1972). One complete Windust Phase-type point and two Windust-type stem fragments found at the Burnett site relate to the earlier period while all other points recovered are classified here as of the Cascade type. The site is in the Old Town section of the City of Lake Oswego and its survival in a residential area shows that even developed metropolitan areas can have significant archaeological potential. 
Archaeological work at the site has focused on the yard of a residence at 250 Furnace St. and in a nearby vacant half block on Furnace Street between Church and Wilbur Streets (Headlee property). The site area was registered as an archaeological site with the Oregon State Historic Preservation Office in 1987. Teams from the Portland State University Department of Anthropology, under the direction of Dr. Kenneth Ames, excavated four 1X2 meter test units at 250 Furnace St. in 1987 and 1988. Another unit was excavated on the Headlee property in July, 1990. This thesis is based on information and artifacts obtained from these excavations and from surface collections from the site.

This thesis describes the Burnett archaeological site and its artifacts and offers hypotheses relating the site to the prehistory of the Portland Basin and the Northwest. The discovery of only two projectile point types at the site (stemmed and lanceolate) suggests two major hypotheses to be tested in this thesis:

1-- The projectile point assemblage, made up exclusively of lanceolate and stemmed points, represents a two-component occupation of the site during the period of 9,000 to 7,000 B.P. (Late Windust and Early Cascade phases). Under this hypothesis, the site was occupied first by a people using only the older Windust-type points and later by a people who made and used only Cascade-type lanceolate points.

2-- Alternatively, the co-occurrence of stemmed(Windust type) and lanceolate (Cascade type) points indicates a single component occupation during the period when both projectile point types were in use. 
Also discussed are soil formation processes, artifact distribution and site function. Other aspects considered are the relation of the site to regional prehistory and problems of dating.

This thesis contains five parts: Chapter I includes the introduction and background material; Chapter II outlines the distribution of artifacts; Chapter III covers projectile point description; Chapter IV compares the site's lithic materials with those of other sites and Chapter V provides a summary and conclusions.

\section{PHYSIOGRAPHY-HISTÓRY}

\section{Location}

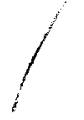

The suburban residential and business community of Lake Oswego is located on the west bank of the Willamette River in Clackamas County about seven miles south of Portland on Highway 43. The Old Town neighborhood is on a terrace above the Willamette River just east of State Street and immediately north of Oswego Creek. The excavations covered by this thesis were conducted on a privately-owned residential lot at 250 Furnace St., Lake Oswego (Township R2S, Range 1E, Section 10, A, D) and in an adjoining block. An old survey stake at the corner of Church and Furnace streets bore the inscription "Elevation 126." The site was discovered in 1985 when the owner at 250 Furnace St. (the author of this thesis) found stone tools while weeding a flower bed.

Surface surveys indicate that the site covers perhaps five or six adjacent blocks in this neighborhood of mostly middle class dwellings. The site may also include all or part of George Rogers Park, a City of Lake 
Oswego public park at the mouth of Oswego Creek, but its precise boundaries have not been determined. In 1989, the Cultural Heritage Foundation of Portland applied to the State Historic Preservation Office for funding of a project that would have established the site boundaries by subsurface testing. The project, designed to prepare a nomination of the site to the National Register of Historic Places, was not approved by SHPO.

\section{Geology of the Oswego Area}

Two factors dominate the geology of the Lake Oswego area: the Columbia River basalt flows and the eroded surface and the deposits of the late Pleistocene Bretz floods. The bedrock underlying the area is Columbia River basalt, formed from lava that flowed into the area from eastern Oregon and Washington some 15 million years ago. In some areas, this basalt is covered by later Boring lava flows from a shield volcano on nearby Mt. Sylvania, where Portland Community College is located (City of Lake Oswego 1976).

The Lake Oswego area is located partially on the southern terminus of the Tualatin Mountains, a plunging anticline of basalt that has been elevated, relative to the adjacent Willamette and Tualatin basins, by faults and minor foldings (City of Lake Oswego 1976). Sediments overlying the basalt were deposited by the last Bretz glacial floods of about 15,000-13,500 years ago. These flood waters from enormous glacier-dammed lakes in Idaho and Montana surged down the Columbia River when the ice barriers were breached. After passing through the Columbia Gorge, the flood waters slowed when they reached the narrows near what is now Kalama, 
Washington, then backed up the Willamette River and swept westward into the Tualatin Valley through a narrow gap in the hills at what is now Oswego Lake. The flood waters filled the Tualatin and Willamette valleys to a depth of nearly 400 feet (Allen 1986). Sediments below the 400 feet elevation level were deposited by flood waters that had scoured the original surface to the basalt bedrock in the Lake Oswego area.

The flood waters dropped much of their sediment load when they spread and slowed as they entered the Tualatin Valley west of Lake Oswego. These gravel deposits changed the course of the Tualatin River which had flowed through the Lake Oswego gap into the Willamette River near the Burnett site (Allen 1986). The Tualatin River now enters the Willamette River south of Oregon City.

West of Lake Oswego, the direction of foreset beds and the size of the material in the deposits suggest westward flowing water of high energy, with a later low energy flow to the east. The early stages of these floods, which must have carried an extremely heavy load of debris, are believed to have scoured the depression which later became Oswego Lake (Trimble 1963).

The Burnett site is located on the edge of a terrace near a steep slope that drops to low bench along the Willamette River. The terrace where the site is located is specifically described in the City of Lake Oswego Physical Resources Inventory (1976):

Terrace deposits consist of fine and coarse grained sediments ranging in elevation from 100 feet to 470 feet above mean sea level. From 100 feet to approximately 260 feet elevation in the terrace deposit area, the surface deposits are boulder and cobble gravels deposited apparently by the Missoula (Bretz) flood. The deposit is divided into two distinct terraces divided by a steep slope. It is believed that the difference in 
elevation of the terraces is due to subsequent erosion either by the receding flood water or by ancestral river erosion. Fault displacement is another possible explanation. Over the Missoula flood deposits are mostly fined grained surface sediments most recently referred to as Willamette silts.

$\underline{\text { Soil }}$

Processes leading to the formation of soils covering the Bretz flood cobbles in the Lake Oswego pose one of the more intriguing questions at the Burnett site. While there is consensus that the boulders and cobbles encountered at 250 Furnace St. at a depth of 120-130 centimeters were left by Bretz flood waters of 15,000-13,000 years ago, theories vary on the origin and nature of the soil covering this cobble layer.

The U. S. Department of Agriculture Soil Map for Clackamas County (1985) lists the soil in the site area as a Woodburn silt loam. It is described as a deep, moderately well-drained soil found on broad valley terraces and formed in stratified glaciolacustrine deposits with slopes of three to eight per cent.

At our request, on July 1, 1988 Russ Langridge and Jerry Latshaw of the U.S. Soil Conservation Service at Albany, Oregon conducted a detailed examination of the sediments exposed in the profile of excavation Unit $B$ at 250 Furnace St. In his report (Appendix), Langridge describes the deposits as correlating with the Hillsboro soil series and the Champoeg geomorphic surface. The Champoeg surface is directly related to Bretz flood deposits of the Portland area and is believed to have been formed by the last major flood of about 13,000 years ago. Langridge states that at the Burnett site, the soil below 87 centimeters from the surface represents the 
Bretz flood deposits. The Hillsboro series is described as representing a soil formed in silty alluvial deposits over a coarse textured discontinuity.

Frank Reckendorf, of the U. S. Soil Conservation Service in Portland, also examined the excavation and described the soil as a Malabon series which formed in sediments deposited by the Bretz floods. The Malabon series is described in the Soil Survey of Clackamas County (1985) as consisting of deep, well-drained soils that formed in mixed silty and clayey alluvium. These soils are on low stream terraces with slopes of zero to three per cent.

Richard Waitt, a geologist with the U. S. Geological Survey, reviewed the site in 1988 and agreed that the gravels and cobbles encountered at 120130 centimeters are debris from the last big Bretz floods. However, in his opinion, the soil above the cobble layer was formed primarily from windblown dust. He theorizes that vast quantities of mud would have been left in the Willamette and Tualatin valleys by the floods, and that as this mud dried, it was picked up as dust by the wind and redeposited through the region by the wind over a long period of time. Waitt believes that the soil could not be the result of water deposits as there is no evidence of any layering. In his opinion, any kind of water deposition, if only a single event, would have left some stratigraphic evidence.

Soil formation and sediment deposition are crucial factors in the creation of the artifact distribution patterns at the Burnett site. If the sediments were deposited by the last Bretz flood slackwater and outflow, they would have been deposited as a single event. The lack of layering in the soil tends to support this single deposition theory. In this case, about 43 centimeters of mud would have been deposited during the time the Bretz 
flood waters covered the site, as Langridge (1987) fixes the Bretz deposits as beginning at about 87 centimeters below the surface. Occupation of the site could not have begun until the mud had hardened sufficiently to support human activities. Major peaks of artifact concentrations are found above 87 centimeters in levels that represent either occupation periods or distribution by disturbance.

Under the windblown dust theory, artifact distribution patterns also could represent either occupation levels or disturbance, or both. The natural accumulation of soil parent material from dust and/or organic material also suggests that this is a single component, multiple occupation site for much the same reasons as outlined for the windblown Bretz flood dust concept.

\section{History}

The lot at 250 Furnace St. is nearly level and there is no evidence of extensive cut or fill in historic times. Judging from the appearance of the land forms, it is probable that only minor surface adjustments were necessary for construction of homes and streets in the Old Town area. In general, the area slopes southerly to Oswego Creek. The area around George Rogers Park probably has been extensively modified by iron works construction and park facility development.

The Lake Oswego area was first settled in 1850 when Albert A. Durham filed a donation land claim on what is now the downtown area and Old Town. The area grew as a transportation center and Oregon's first iron smelter was built in Old Town in the 1860s. Iron was produced in the Old Town facilities, with interruptions, until about 1920 and the original 
iron furnace is now a historical attraction in George Rogers Park. After first becoming popular as a resort and recreation area, Lake Oswego has through the years developed into a mostly upscale suburban residential community (Goodall 1958).

The Old Town neighborhood has been a residential area since the closing and removal of the iron production facilities. Even during its industrial period, much of the neighborhood was devoted to housing for iron workers (Goodall 1958). Use of the area as pasture or for farming in the early settlement period also is probable.

\section{Ethnohistory}

While various groups of Indians lived in the area surrounding Lake Oswego until the arrival of early white settlers and arrowheads reportedly have been found in the vicinity, no latter- day Indian artifacts have been identified at the Burnett site itself. This absence of "arrowheads" is another indicator of the antiquity of the site as use of the bow and arrow is belived to have started about 2,500 years ago.

In the ethnographic period, the lower Willamette River area was home to the Chinook and Kalapuya Indians. The Chinooks, represented by the Clackamas subgroup, dominated the valley of the Clackamas River which enters the Willamette River from the east just north of the Willamette falls at what is now Oregon City-West Linn. The Chinooks also controlled both banks of the Willamette from just above the falls downstream to about the present Portland city limits. Cressman (1977) notes that the Chinooks along the lower Willamette River below the falls had a culture similar to that found among the Chinooks along the 
Columbia River. Woodward (1974) reported a Chinook village at the mouth of the Clackamas River as the only site along the Willamette between Oregon City and Portland. The Saleeby-Pettigrew (1983) list of Indian villages in the Portland area includes three Chinook villages along the Willamette at present day Oregon City, but none in the Lake Oswego area.

The Tualatin subgroup of the Kalapuyans occupied the Tualatin Valley to the south and west of the range of hills that runs along the west side of the Willamette from Oregon City to where it joins the Columbia River. There is some indication (Mackey 1974, Zenk 1976) that the territory of the Tualatin Valley Kalapuyans included the area of Oswego Lake. The Chinooks, who controlled the salmon fishery at Willamette Falls, permitted the Tualatin Indians to pick lampreys from the rocks there without interference (Zenk 1976). The Molala Indians lived on the west slope of the Cascades south of the Clackamas River and probably had little impact on the culture of the Lake Oswego area. 


\section{CHAPTER II}

\section{RESEARCH AND FINDINGS}

\section{AREA ARCHAEOLOGY}

Area archaeology most pertinent to the Burnett site centers on two distinct regions: the Lower Willamette Valley (including the adjacent Cascade foot-hills), and the Portland Basin and nearby Cascade foothills. Included in the chronology of the area are prehistoric sites dating from 8,000 B.P. to the period of Euro-American contact.

In the Willamette Valley and its Cascade foothills, the chronology of early human occupation is encompassed by the Archaic stage which is divided into the Early (8,000-6,000 B.P.), Middle (6,000 B. P.-200 A.D) and Late (200 A. D.-1750) stages (Beckham, Minor, Toepel [1981], Pettigrew [1990]). Cascadia Cave, in the foothills of the Cascade Mountains near Sweet Home, is the only reported Early Archaic site in this area. Charcoal found in the lower levels of this rockshelter has been radiocarbon dated to $7,910+/-280$, or about 8,000 B.P.(Newman 1966).

Early sites in the valley proper include the Hannavan site west of Eugene which is radiocarbon dated to 7,800 B.P. and the Ralston site, also near Eugene and dated to 6,575 B.P.(Pettigrew 1990). Others are the Flanagan site at 5,800 B.P.(Beckham, Minor, Toepel 1981) and the Luckiamute Hearth site radiocarbon dated at 5,300 B.P.(Reckendorf and Parsons 1966). 
Previous archaeological research in the Willamette River Valley has been confined primarily to its upper and middle sections, with only a few sites known to have been studied between Salem and where the valley proper ends just south of Oregon City. At Salem, excavation of the Hager's Grove site (Pettigrew 1980) produced dates as old as 3,850 B.P. Pettigrew (1990) notes that around 3,800 B.P., willowleaf-shaped points were almost the only point found, but that perhaps by 2,900 B. P., corner notched points had become established. He adds that the leaf shaped points continued to be used. White (1979) also notes that the leafshaped points continued to be used "into more recent times."

North of the Willamette Valley proper, in the Oregon City area, the Willamette River cuts through a range of hills and basalt flows, then passes through the broad area of the Portland Basin before entering the Columbia River. Aikens (1986) states that, in general, the older reported sites in the Portland area are linked to the Marybell phase (Pettigrew 1981) dating between about 2,500 B.P. and 1,750 B.P., although he sees scattered evidence as indicating the area along the Lower Columbia River and the Oregon coast was occupied long before that. He notes that this preMarybell period, which has not previously been represented by sites in the Portland area, has as one of its indicators large, lanceolate leaf-shaped and stemmed points, including points similar to those of the Windust and Cascade phases of the Columbia Plateau. However, medium and small-necked notched and stemmed points are the typical types found in sites in the Portland Basin (Aikens 1986).

The scarcity of dated early sites in the lowlands around the Portland Basin is attributed in part to the Cascade Landslide of about 1,250 A.D. which 
caused destructive flooding on the Columbia River below what is now Bonneville Dam. Portland Basin sites from just before and just after the landslide probably were either buried or swept away by the flood and are described by Pettigrew (1990) as either extremely rare or nonexistent.

Subsidence, burial beneath deep alluvium and sea level rise are other factors contributing to the scarcity of very old sites at lower elevations in the Portland area. The Burnett site, located on a terrace above the Willamette River upstream from where it joins the Columbia River, would have been protected from the impact of the landslide flood waters and most other catastrophic events.

In the Cascade foothills east of Portland, the Geertz site produced Cascade-type projectile points only and is given an estimated date of 8,0006,000 B.P. The age is based on the similarities between the Geertz site points and those of Cascadia Cave near Sweet Home, Oregon which has been radiocarbon dated to that period (Woodward 1972). Pettigrew (1990) suggests that the Geertz site may have been used as a hunting camp by groups living on the Clackamas or Columbia rivers. Archaeological works dealing with the Lower Willamette River area north of Salem include a Ph.D. dissertation on the prehistoric antecedents of the Indians of the Clackamas River drainage (Woodward 1974), Pettigrew's Ph.D. dissertation on prehistoric cultural sequence and chronology in the Portland Basin (1977) and a master's thesis on Sauvie Island projectile points (Brown 1960). Saleeby (1983) used archaeological, ethnohistorical and biogeographical data to examine prehistoric settlement patterns for the Portland Basin. In the Lake Oswego area, a survey conducted on the west side of the city in connection with 
construction of a new highway produced no evidence of archaeological sites (Follansbee 1975).

Considerable archaeological work has been performed in Clark County, Washington, across the Columbia River from the Portland area. This area near the Columbia shoreline is particularly rich in prehistoric sites. Nearly 90 of the 200 sites recorded for Clark County are found along the Vancouver Lake shoreline and its environs. Archaeological excavations in this area have produced radiocarbon dates ranging from approximately 3,500 B.P. to 300 B.P. (Fagan, Reese, DeLyria 1991).

Somewhat removed from the Portland area, but important in a regional context, are the Judd Peak and Layser Cave sites in the western foothills of the Cascades in southwestern Washington. These sites produced Windust-type and Cascade-type points and small triangular arrowheads. Radiocarbon dates to 6,650 B.P. were recorded (Daugherty, Flenniken, Welch 1987).

\section{PROJECT HISTORY AND METHODOLOGY}

\section{Furnace St. Locale}

The first indication of the archaeological potential of the site was the discovery in 1985 of several distinctive stone artifacts in a front yard flower bed at the Furnace Street locale. Further investigation produced more stone points, tools and flakes from other garden areas on the property and from beneath the house. Neighbors also reported finding stone artifacts in their yards.

The distinctive, leaf-shaped points and fragments from the yard were examined by archaeologist Charles Hibbs who recognized them as Cascade- 
type points, probably of considerable antiquity. The collection was later reviewed by Dr. Kenneth Ames of Portland State University and the two concluded that the site merited further investigation. A team under the direction of Dr. Ames excavated a 1X2-meter test pit to a depth of 70 centimeters in the front yard at 250 Furnace St. in June, 1987. Numerous stone artifacts were recovered, the integrity of the site was verified and the pit was backfilled pending further investigation.

Excavation was resumed in June, 1988, again by a crew from Portland State University. The original test pit was deepened to 120 centimeters where a layer of cobbles halted excavation. Three other 1X2-meter test pits were excavated to $120-130$ centimeters. (See Figure 1 for location of test pits relative to house and each other.) Because of the lack of surface indicators to suggest study areas of particularly high potential, the pits were located at arbitrary points in the front yard. Pits are designated as Units A, B, C and D.

The datum point for the location of Units A, B, C and D is the corner of the cement foundation on the northeast corner of the house at 250 Furnace St. The northwest corner of Unit A (Figure 1) is six meters from the the house corner. Vertical datum on a stake at the northwest corner of Unit A was at 10.2 centimeters above the surface. This datum also was used for Unit B. A separate datum stake at the northwest corner of Unit C was used for Units C and D. Excavation levels were maintained by line level and tape. Soil excavated from all test pits was screened through 1/4-inch mesh. In addition, a soil sample from Unit $C$ was screened through .055-inch mesh. Bulk soil samples taken from the northeast corner of each 1X2 unit were saved in plastic bags for possible future analysis. A soil sample was taken from a possible pit feature in the east wall of Unit C. Soil samples also were 
taken at five-centimeter levels from the east wall of Unit D. Except for an apparent lawn-plow zone and the Bretz flood cobble deposits encountered at 120-130 centimeters, no cultural or natural stratigraphy was apparent in the field.

Artifacts were plotted for orientation and location when found in situ and recorded by level and unit when recovered from the screens. Most artifacts were washed prior to classification, counting and analysis, but some were preserved unwashed for blood residue analysis which has not yet been performed. Several pieces of charcoal were recovered. One charcoal sample from the 70-centimeter level of Unit A produced a radiocarbon date of about 1,500 B.P. This sample, which probably originated in a burned tree root, was not found associated with any definable feature. Because all points found here appear similar to those of much earlier periods, the radiocarbon date is not considered to represent the earliest occupation of the site.

All artifacts, including flakes, tools, projectile points, cores, lithic debris and flake fragments were counted and the data recorded by excavation level. The term "artifact" is used here to include points, tools and flakes. All artifacts are of stone. No bone was recovered other than that of apparent historical origin found in the upper levels. Historic artifacts of glass, metal and pottery were found generally to a depth of about 35-40 centimeters, with one nail found in the 46-50 centimeter level of Unit D.

\section{Headlee Property}

In the spring of 1990, the planned construction of apartments on the Headlee property on Furnace Street between Church and Wilbur streets under-scored the need to assess its archaeological content before this section 
of the site became inaccessible. The property, which includes about one half of a city block, had been vacant for several years and was heavily overgrown with brush and blackberries.

With the cooperation of Bill Headlee, the developer, seven auger holes were drilled in June and excavation of a 1X2 meter test pit began on July 2. Datum point for location of the Headlee excavation is a large cedar tree on the northeast corner of the property at Furnace and Church streets.

After an initial 20-centimeter level, excavation proceeded at 10centimeter levels. At 40 centimeters below datum, the size of the pit was reduced to $1 \mathrm{X} 1$ meters and excavation continued to a depth of 158 centimeters where a cobble layer was encountered. Soil composition appeared to be similar to that at 250 Furnace St. No prehistoric features were noted. Material was screened through 1/8-inch mesh. Soil samples were taken at 10centimeter intervals. An iron pipe crossed a portion of the pit at 50 centimeters below surface. Findings are discussed elsewhere in this thesis.

\section{FURNACE ST. EXCAVATIONS}

The 1987 and 1988 excavations at 250 Furnace St. recovered 6,651 items, including numerous flaked tools and considerable debitage from tool manufacturing and maintenance. Included in this total are 80 projectile points and point fragments. Another 46 projectile points and fragments and many other bifaces, tools and flakes from a surface collection also were examined. Fine screening of a soil column from Unit $C$ produced an additional 321 flakes. Flakes recovered from the fine screening are treated separately and are not included in the count of artifacts from the $1 / 4$ inch 
screen from Unit C. Except for the plow or lawn zone and the Bretz flood cobble layer, no immediately discernable cultural or natural strata were apparent in the excavation profiles. Because of the lack of discernable strata, units were excavated in arbitrary 5-centimeter levels. For the present analysis, the artifacts from the 5-centimeter levels have been combined into 10-centimeter groupings. Prehistoric artifacts were recovered from the surface to the layer of cobbles deposited by the last Bretz flood.

\section{LITHIC ANALYSIS}

\section{Lithic Raw Materials Used}

The artifacts are separated into three categories on the basis of lithology: basalt, cryptocrystalline silicates (CCS) and obsidian. Basalt is abundant locally in the bluffs and banks on both sides of the Willamette River from above Oregon City downstream to the Sellwood Bridge near the Portland city limits. However, some of the basalt artifacts do not appear to have been manufactured from this generally coarse-grained local material, and may have been shaped from fine-grained basalt cobbles brought in by the Bretz floods. The term "basalt" includes related materials. Cryptocrystalline silicates include, for the purpose of this thesis, chalcedony, agate, quartz, jasper and chert. The origin of the CCS used in the artifacts is unknown, but CCS is found in the nearby Clackamas and Mollalla rivers which flow westward into the Willamette River from their headwaters in the Cascade Range. Battered cortex on many of the flakes suggests that they originated in cobbles that had been transported long distances by water action, such as the Bretz floods. Obsidian is not common locally. It is likely that obsidian found in the Lake Oswego area had its origin in central Oregon. 


\section{Distribution of Lithic Items}

Analysis of lithic items included counting the artifacts and assigning them to various categories of material, technology, size, function and location. The analysis sought to determine what changes, if any, occurred in the manufacturing technology, functional emphasis and intensity of use during the period the site was occupied. Variations, if present, presumably would provide clues to the chronology of the occupation and/or to changes in the culture of the occupants.

No change was evident in the lithic manufacturing techniques of artifacts recovered from the surface to the sterile layer in the Bretz flood cobbles. Core reduction, bipolar flaking, microblade technique and biface manufacture from split cobble flakes are all represented through most of the cultural deposits. This wide distribution could represent a single component of a stable culture. The levels of higher artifact density, on the other hand, may indicate either multiple occupancies or a natural sorting process.

Table I shows that artifacts recovered from each excavation unit range from 21.76 per cent to 27.57 per cent of the total artifacts recovered at 250 Furnace St. This difference of less than six per cent between the number of artifacts found in each unit demonstrates a horizontal uniformity of artifact density in this small portion of the total site. Table II shows the percentages of basalt, CCS and obsidian artifacts found in each unit. Averages for all units are 41.20 per cent basalt, 56.52 per cent CCS and 2.29 per cent obsidian. Artifacts from the Headlee property have not been analyzed for material. 
Figures 2, 3, 4, 5, 6, 7, 8 and 9 and Table III illustrate possible levels of concentrated site use and show how these levels of denser artifact concentration are located at similar elevations in the four excavation units.

All four pits examined at 250 Furnace St. display a very similar bimodal pattern in the vertical distribution of artifacts (Figures 2, 3, 4, 5, and 6). Some irregularity is built into the data in the upper levels as Level I covers 9-20 centimeters below datum in Unit A, 15-34 centimeters below datum in Unit B, 13-30 centimeters in Unit C and 13-30 centimeters in Unit D.

In each unit, artifact density increases sharply from the surface to the 30 centimeter level, then falls off steeply at 40-50 centimeters. This drop is followed by an increase in artifact numbers in the 60-70 centimeter area, and a subsequent rather even decline to almost zero at the 120-130 centimeter level where the Bretz flood cobbles are encountered. This same pattern, with the two marked peaks of concentration, is seen at the same depths in all four excavation units and in all artifact categories studied. In sum, at least two levels of high artifact density are obvious at 250 Furnace St., one near the surface and the other from 50-80 centimeters. These peaks of artifact concentration, located at approximately the same depths in all four units, may represent periods of intense occupation. They also may be the result of movement of artifacts by a natural process not at present understood.

\section{Fine Screen}

A vertical column of soil consisting of .042 cubic meters taken from the northeast corner of Unit C was screened through a .055 inch mesh and produced 321 flakes. These flakes have a vertical distribution pattern somewhat similar to those obtained from the $1 / 4$ inch screen(Figures 4,5 ) 
although it is not as strongly bimodal. Flakes from the fine mesh screen were concentrated at depths of 40-50 centimeters and 60-70 centimeters. The two peaks were separated by a dip at 50-60 centimeters. Recovery declined to the 110-120 level, then rose slightly at the 120-130 mark(Figures 7,8). Figure 9 shows the distribution of fine screened flakes by material. The bimodal pattern is generally similar to that of all other categories plotted.

\section{Materials and CCS/Basalt Ratio}

Cryptocrystalline silicate artifacts are more frequent than basalt in all but four of the 43 excavation levels at this site (Figures 9, 10, 11, 12, 13, 14, Table III). As indicated in Figures 15,16, 17 and 18, the pattern for percentages of basalt and CCS flakes and tools varies somewhat in the four excavation units. In the $1 / 4$ inch screening of material from Unit $\mathrm{C}$, the $\mathrm{CCS} /$ basalt ratio was $1.55 \mathrm{CCS} / 1$ basalt, while in the fine screen material, the average was 1.69 $\mathrm{CCS} / \mathrm{l}$ basalt. (Fine screened flakes are not included in the general data obtained from the 1/4 inch screening of soils from Unit C.)

\section{Vertical Distribution Of Artifacts By Size}

All Unit $C$ artifacts recovered from the the $1 / 4$ inch screens were analyzed by size to determine whether the bimodal pattern of artifact concentrations indicate occupation levels or result from natural forces which have moved flakes and tools vertically through the soil. Pettigrew outlines the use of flake weight to determine the amount of soil disturbance at a site in his Mill Creek Valley report. He theorizes that the greater the mass of an object, the less tendency it will have to be displaced by natural forces acting upon it. At the Mill Creek Valley sites, Pettigrew noted a 
distribution pattern that he believed could be interpreted as containing two major zones of heavy flakes: the first from 0 to 40 centimeters below the surface and the second below about 60 centimeters. Between these two zones was an area with a lower percentage of heavier flakes. This pattern is used to support his theory that the Mill Creek Valley sites contained two components.

Because Pettigrew believes that lighter items will tend to move more than heavier items, he theorizes in the Mill Creek Valley report that a disturbed area of primary deposition will have a relatively higher proportion of heavier flakes.

Flakes at the Burnett site were not weighed, but those from Unit C were sorted by length and when plotted, display a bimodal configuration similar to that which Pettigrew used to suggest two-component sites at Mill Creek Valley.

The Unit $C$ artifacts from the $1 / 4$ inch sample were sorted into the following size categories, measured in centimeters on the long axis: $0-.5, .5-1$, $1-2,2-3,3-4,4-5$ and 5-10 centimeters. Only two flakes in the 0-.5 category were recovered, as one half centimeter is smaller than the $1 / 4$ inch screen mesh. (Artifacts from the fine screening were not graded by size because the soil sample was small compared to the total fill removed from the unit.)

As Figures 19, 20, 21, 22 illustrate, five of the six size categories charted have similar patterns of vertical distribution within the unit. Only one size category (4-5 centimeters) deviated significantly from this pattern. For this size artifact, an initial low count was followed by a steep increase in numbers to the 30-40 centimeter level and a drop to zero at 60-70 centimeters. Recovery increased slightly from 70 centimeters to the cobble layer. 
Pettigrew, in the Mill Creek Valley report, uses the proportion of heavy to light flakes to establish areas of primary deposition. The same procedure was applied to the Burnett size assemblage from Unit C. Artifacts from .5 to 3 centimeters were considered small while those from 4-10 centimeters were considered large. The distribution of large, small and total artifacts is shown in Figure 23. The pattern is basically uniform.

At this site, at least, the Pettigrew theory regarding artifact movement based on weight suggests either that the site is relatively undisturbed or that natural disturbance forces have acted equally upon most artifact sizes.

\section{Distribution of Technological Artifact Types}

Heated Flakes. As concentrations of fire-altered flakes may suggest the location of occupation levels, all artifacts from Unit $C$ were examined for evidence of heat spalling or alteration. The unit produced 53 items which appear to have been subjected to fire. The distribution is shown in Figure 24. Highest concentrations appear near the surface and in the 50-centimeter area. The concentrations are in levels generally corresponding to peaks of all artifacts in Unit $C$ and the other three units.

Bipolar Reduction. The site produced 11 specimens, including cores, of what appear to be examples of the bipolar reduction technique (Figure 25). This number accounts for .17 per cent of total artifacts. A bipolar-type hammerstone was found on the surface. The report on Judd Peak (Daugherty, Flenniken, Welch 1987) states that the small percentage of bipolar materials recovered there (.06 per cent of the entire lithic assemblage) indicates that it was not a major technique employed at that site.

Microblades. Probable microblades recovered from the Burnett site 
total 14, or .21 per cent of the total excavated assemblage (Figure 26), compared to .62 per cent of the assemblage at Judd Peak (Daugherty, Flenniken, Welch 1987). Curiously, 8 of the 14 probable microblades came from Unit D. No microblade cores were found. At Judd Peak, the microblade collection indicates that the technique was in use at that site from at least as early as 7,000 years ago until the late protohistoric period.

Cores. Distribution of cores is illustrated in Figures 27 and 28. All cores from the site were used for the manufacture of flakes. The flakes in turn were either utilized as they came from the core or manufactured into other tools, such as projectile points. Notably, the number of CCS cores is greatest from 50 to 80 centimeters which is the depth with the fewest basalt cores. Also, core numbers do not show the low frequency of other artifacts at 40-50 centimeters although the numbers of basalt cores does drop steeply at the 5060 centimeter level. At this level, the highest frequency of CCS cores corresponds to the lowest frequency of basalt cores.

Ratio of Tools To Total Assemblage. In the report on the Hamilton Island site on the Columbia River, Dunnell and Campbell (1977), state that the ratio of tools to debitage is an important indicator of site usage. At Hamilton Island, debitage totals more than 90 per cent of the assemblage, while tools total about 10 per cent, a ratio that they say suggests that the site was used extensively for manufacturing.

At the Burnett site, cataloged tools account for about 4.15 per cent of the total assemblage. This is even lower than the ratio at Hamilton Island and indicates extensive manufacturing (Table V). 


\section{HEADLEE PROPERTY FINDINGS}

The Headlee property excavation was conducted to salvage archaeological information in the face of pending apartment construction there. As the excavation crew worked, bulldozers removed the trees and brush, scraped the surface bare and dug to a depth of several feet in some areas of the property. The Headlee portion of the site was not originally intended for inclusion in this thesis and only preliminary analysis of the artifacts recovered has been possible. Artifacts were counted by level and their distribution plotted as shown in Figure 29. (Note: This unit measured $1 \times 2$ meters from surface to 40 centimeters, but $1 \times 1$ meters from 40 centimeters to the cobble layer.)

The artifact distribution deviates significantly from that in all units at 250 Furnace St. in the adjacent block. In the unit on the Headlee property, one high peak of artifact concentration is found in the 30 to 40 centimeter level. The count then diminishes rather evenly with depth to sterility at 140 centimeters. This unimodal distribution is in sharp contrast to the bimodal pattern evident in all four units at 250 Furnace St. The initial high peak is apparent at approximately the same 30-40 centimeter depth at both locations, however. The reduction in the size of the unit from $1 \times 2$ meters to $1 \times 1$ meters at the 40 centimeter level may account in part for the gross reduction in artifacts recovered. Even considering the reduction of unit size, there is still no hint of the artifact concentration at 50-70 centimeters seen in the units at 250 Furnace St. 
FEATURES, SOIL DISTURBANCE

\section{Features}

No unequivocal features such as hearths or rock structures were found. An area of soil disturbance on the east wall of Unit C was noted and recorded as a feature but it may well have a different origin. This basin or pit-shaped area was encountered just below the plow zone at an elevation of 32 centimeters below datum. It had a vertical measurement of about 55 centimeters and a width of 56 centimeters. Lithics and charcoal were found within the boundaries. The area is pit shaped but has no other qualifications to identify it as a feature. A small tree, removed in the 1970s, is known to have been located in the general area of the front yard where this disturbed soil is found and the filled pit may have been the space occupied by the root ball. The tree is known to have been transplanted to nearby George Rogers Park so some care was taken in removing it from the yard. Careful analysis of the soil sample taken from this possible feature could establish or refute its authenticity.

\section{Soil Disturbance}

The difference in the vertical distribution pattern between 250 Furnace St. and the Headlee property suggests that the site has considerable internal complexity caused by some unidentified variation in natural or cultural deposition processes. Do the areas of artifact concentration reflect intensified activities by the aboriginal occupants or are they the result of natural processes acting upon artifacts deposited in some other pattern over thousands of years? 
The excavations at 250 Furnace St. presented no evidence of modern disturbance, except for a plow or lawn zone near the surface, and no stratigraphy or other indications of disturbance between the Bretz flood cobbles and the lawn zone. This could be seen as evidence that concentrations of artifacts are the result of occupation of the site at the time the levels were at or near the surface. However, it also could also have resulted from displacement of the artifacts from their original level of deposition.

Numerous theories have been advanced to account for artifact movement through soil. As Villa (1982) points out, considerable vertical displacement of artifacts may occur even when the matrix itself has not been visibly disturbed or displaced. Surface displacement, selective removal, transport and redeposition, frost heave, water and fauna are forces which can cause vertical displacement. Other processes can account for the movement of artifacts through soil. Among these are plowing, collection, construction, gravity, soil creep, earthworms, clay expansion and roots and other vegetation activity (Butzer 1985).

In addition, trampling can leave larger pieces on or close to the surface while small objects may be pushed down about 10 centimeters. Butzer(1985) believes trampling is capable of moving artifacts as much as 50 centimeters and possibly simulate multiple levels, while repeated freeze and thaw cycles also can create apparent multiple occupation levels from a single initial layer (Butzer 1985). Pettigrew (1980) agrees with Butzer and Villa that an apparently random process, such as movement of artifacts by disturbance, can create a nonrandom pattern that can easily be misinterpreted as cultural in origin, as may be the case here. 
Tree falls are one of the major potential factors in artifact movement at the site. The few large Douglas firs and other conifers remaining in the Old Town neighborhood indicate that the site must have been heavily forested in the past. These trees must have grown to maturity and have been toppled by wind and age numerous times during the thousands of years the artifacts have been in the ground here. The soil disturbance caused by the upheaval of roots of large trees can be extensive and this could have had a significant impact on artifact distribution.

Excavators found many of the flakes and tools on edge rather than lying on a flat side and this orientation suggests that the soil has been disturbed since the items were dropped. In his report on the Ripple site (Lebow 1985), notes that the large number of artifacts found on edge is believed to indicate mixing of cultural material and the resulting destruction of all evidence of primary deposition. The thousands of years of disturbance at the Ripple site may have mixed the deposits to the point that any patterning or clustering may be the result of these natural forces, rather than evidence of cultural activity (Lebow 1985).

The amount and variety of artifacts indicate that the prehistoric inhabitants carried on a wide variety of of activities at 35CL96, probably over a long period of time. The collection of projectile points and cutting and scraping tools and the absence of grinding implements suggests a huntingoriented culture. The site's location on the banks of the Willamette River near a substantial creek points to possible utilization of salmon and other fish.

Distribution of the points and other artifacts from the level of the Bretz flood cobbles to the present ground surface suggests a lengthy occupation, 
perhaps beginning soon after the last major flood about 13,000 years ago. At the 250 Furnace St. locale, artifacts are distributed in a bimodal pattern that could be the result of two periods of intense occupation or, alternatively, of artifact movement by natural forces. The unimodal distribution pattern at the Headlee locale may represent one period of occupation there. As only one unit was excavated on the Headlee property, the significance of the unimodal pattern there and its relation to the bimodal pattern at 250 Furnace have not been established. 
TABLE I

TOTAL STONE ARTIFACTS INCLUDING MANUFACTURING DEBITAGE

IN UNITS A, B, C, D

Basalt CCS Obsidian Total

Unit A 738 $989 \quad 43$

$1770 \quad 26.61 \%$ of total

Unit B 775

101346

$183427.57 \%$ of total

Unit C 555

$861 \quad 31$

$144721.76 \%$ of total

Unit D 672

$896 \quad 32$

$160024.06 \%$ of total

$\begin{array}{lllll}\text { Totals } & 2740 & 3759 & 152 & 6651\end{array}$ 
TABLE II

PERCENTAGES OF BASALT, CCS AND OBSIDIAN ARTIFACTS IN UNITS A, B, C, D

\begin{tabular}{|c|c|c|c|c|}
\hline & \%Basalt & \%CCS & \%Obsidian & Total \\
\hline Unit A & 41.69 & 55.88 & 2.43 & $100 \%$ \\
\hline Unit B & 42.26 & 55.23 & 2.51 & $100 \%$ \\
\hline Unit C & 38.36 & 59.50 & 2.14 & $100 \%$ \\
\hline Unit D & 42.00 & 56.00 & 2.00 & $100 \%$ \\
\hline
\end{tabular}

$\begin{array}{llll}\text { Average } & 41.20 \% & 56.52 \% & 2.29 \%\end{array}$ 
TABLE III

NUMBERS OF BASALT, CCS AND OBSIDIAN ARTIFACTS

RECOVERED FROM EACH LEVEL IN UNITS A, B, C, D

UNIT A

LEVEL $9-20 \mathrm{~cm}$

20-30

$30-40$

$40-50$

$50-60$

$60-70$

$70-80$

$80-90$

$90-100$

100-110

$110-120$

120-130

TOTAL
BASALT CCSOBSIDIAN TOTAL

$\begin{array}{rrrr}22 & 37 & 2 & 61 \\ 131 & 138 & 10 & 279 \\ 161 & 170 & 4 & 335 \\ 64 & 90 & 4 & 158 \\ 75 & 93 & 6 & 174 \\ 102 & 137 & 8 & 247 \\ 75 & 118 & 3 & 196 \\ 40 & 73 & 1 & 114 \\ 24 & 67 & 2 & 93 \\ 29 & 52 & 3 & 84 \\ 15 & 14 & 0 & 29 \\ 0 & 0 & 0 & 0 \\ 738 & 989 & 43 & 1770\end{array}$

Unit C

LEVEL BASALT CCS OBSIDIAN TOTAL

13-30 $\mathrm{cm} \quad 114 \quad 181$

$30-40$

$40-50$

$50-60$

$60-70$

$70-80$

$80-90$

$90-100$

$100-110$

$110-120$

120-130

TOTAL
$95 \quad 185$

$50 \quad 65$

$\begin{array}{ll}79 & 101\end{array}$

$\begin{array}{ll}75 & 140\end{array}$

$59 \quad 73$

2430

$23 \quad 35$

$14 \quad 25$

$10 \quad 16$

1210

$555 \quad 861$
8303

$2 \quad 282$

$4 \quad 119$

$3 \quad 183$

$5 \quad 220$

$5 \quad 137$

256

$1 \quad 59$

39

26

123

$31 \quad 1447$
UNIT B

LEVEL BASALT COS OBSIDIAN TOTAL - -

$\begin{array}{lrrrr}15-34 \mathrm{~cm} & 203 & 241 & 10 & 454 \\ 34-40 & 54 & 103 & 1 & 158 \\ 40-50 & 63 & 61 & 3 & 127 \\ 50-60 & 107 & 123 & 9 & 239 \\ 60-70 & 102 & 122 & 3 & 227 \\ 70-80 & 91 & 138 & 6 & 235 \\ 80-90 & 65 & 91 & 4 & 160 \\ 90-100 & 53 & 61 & 5 & 119 \\ 100-110 & 25 & 54 & 4 & 83 \\ 110--120 & 12 & 19 & 1 & 32 \\ 120-130 & 0 & 0 & 0 & 0 \\ \text { TOTAL } & 775 & 1013 & 46 & 1834\end{array}$

\section{UNIT D}

LEVEL BASALT CCS OBSIDIAN TOTAL $\begin{array}{lllll}13-30 \mathrm{~cm} & 172 & 164 & 9 & 345\end{array}$

$30-40$

$\begin{array}{ll}108 & 187\end{array}$

$4 \quad 299$

$40-50$

$\begin{array}{ll}55 & 79\end{array}$

$\begin{array}{ll}3 & 137\end{array}$

$50-60$

$81 \quad 117$

4202

$60-70$

$89 \quad 106$

$\begin{array}{ll}2 & 197\end{array}$

$70-80$

$\begin{array}{ll}60 & 100\end{array}$

$5 \quad 165$

$80-90$

$37 \quad 55$

294

$90-100$

$32 \quad 40$

72

100-110

$\begin{array}{ll}19 & 24\end{array}$

144

$\begin{array}{ll}13 & 17\end{array}$

30

$110-120$
$120-130$

58

TOTAL

$671 \quad 897$

215

321600 


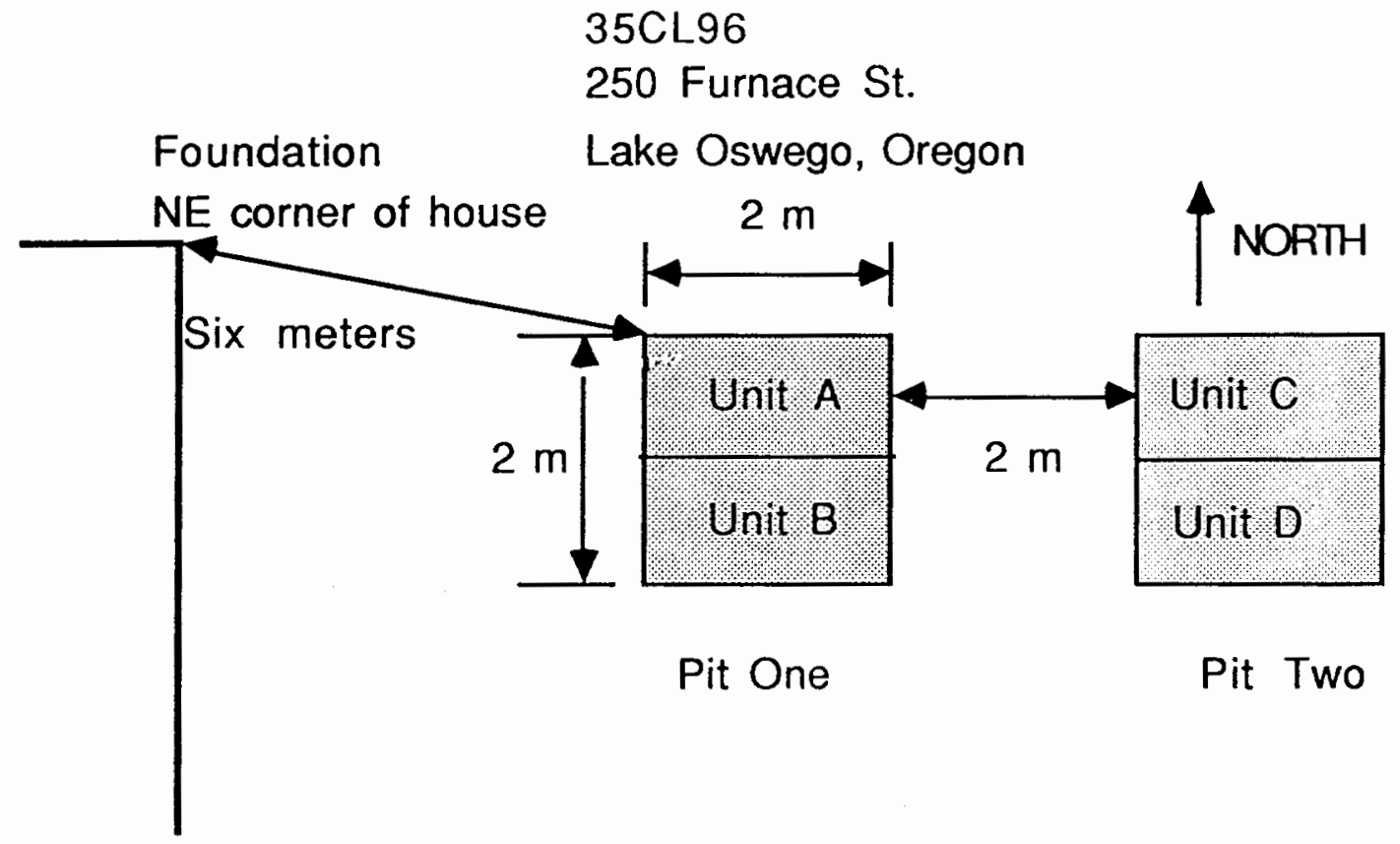

Figure 1. Relationship of excavation units to house and to each other. 


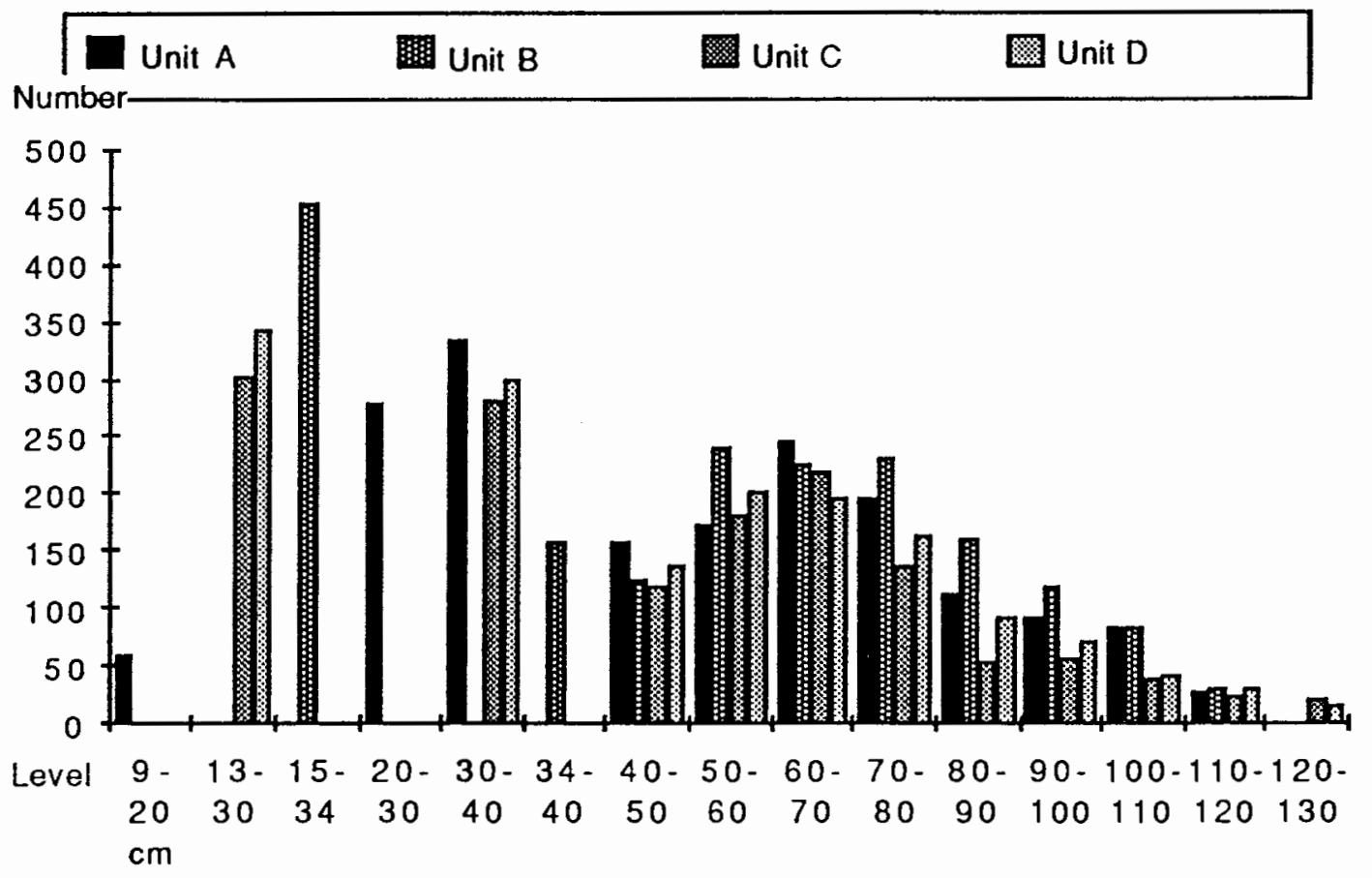

Figure 2. Vertical distribution of artifacts in Units A, B, C, D. 

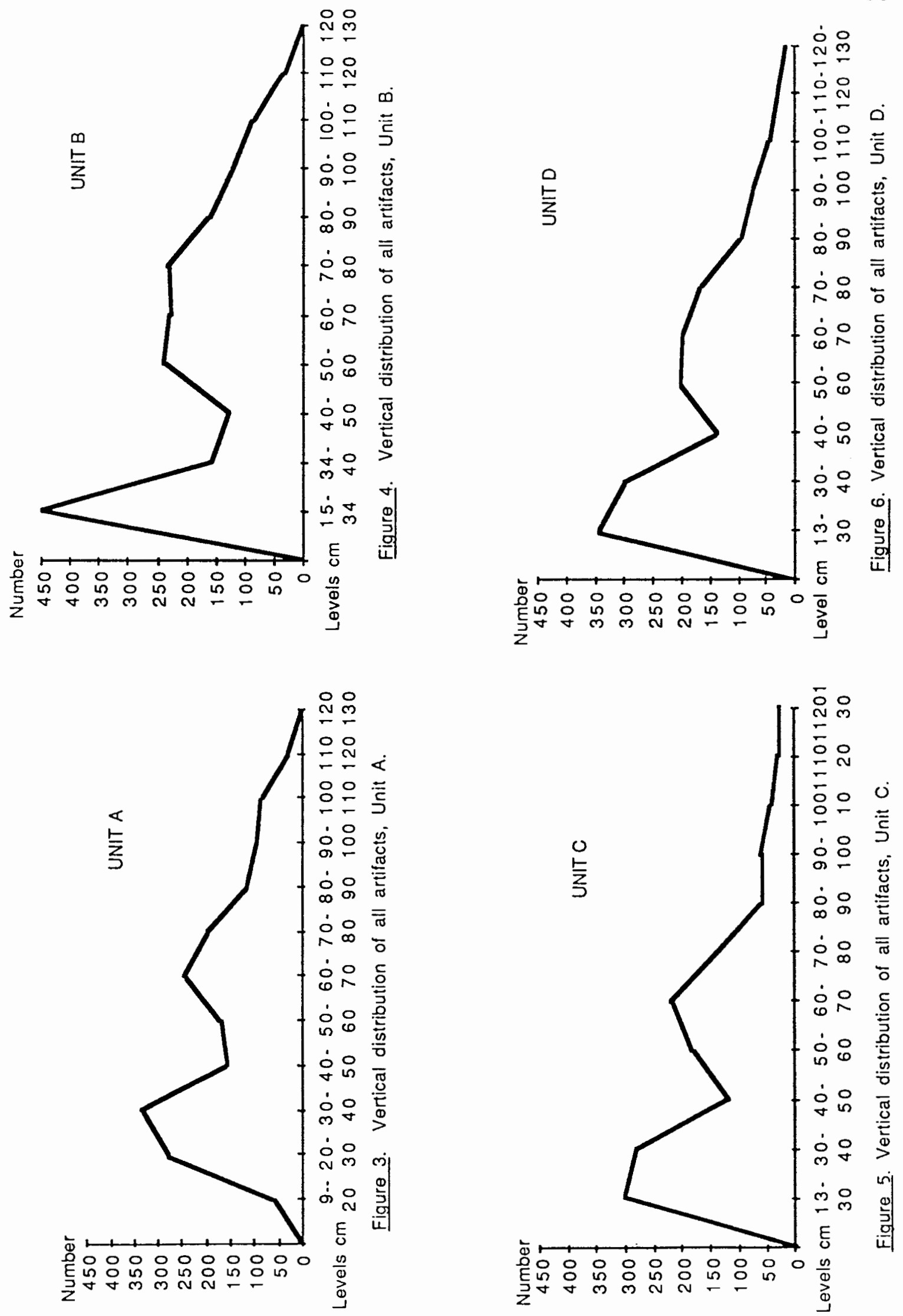


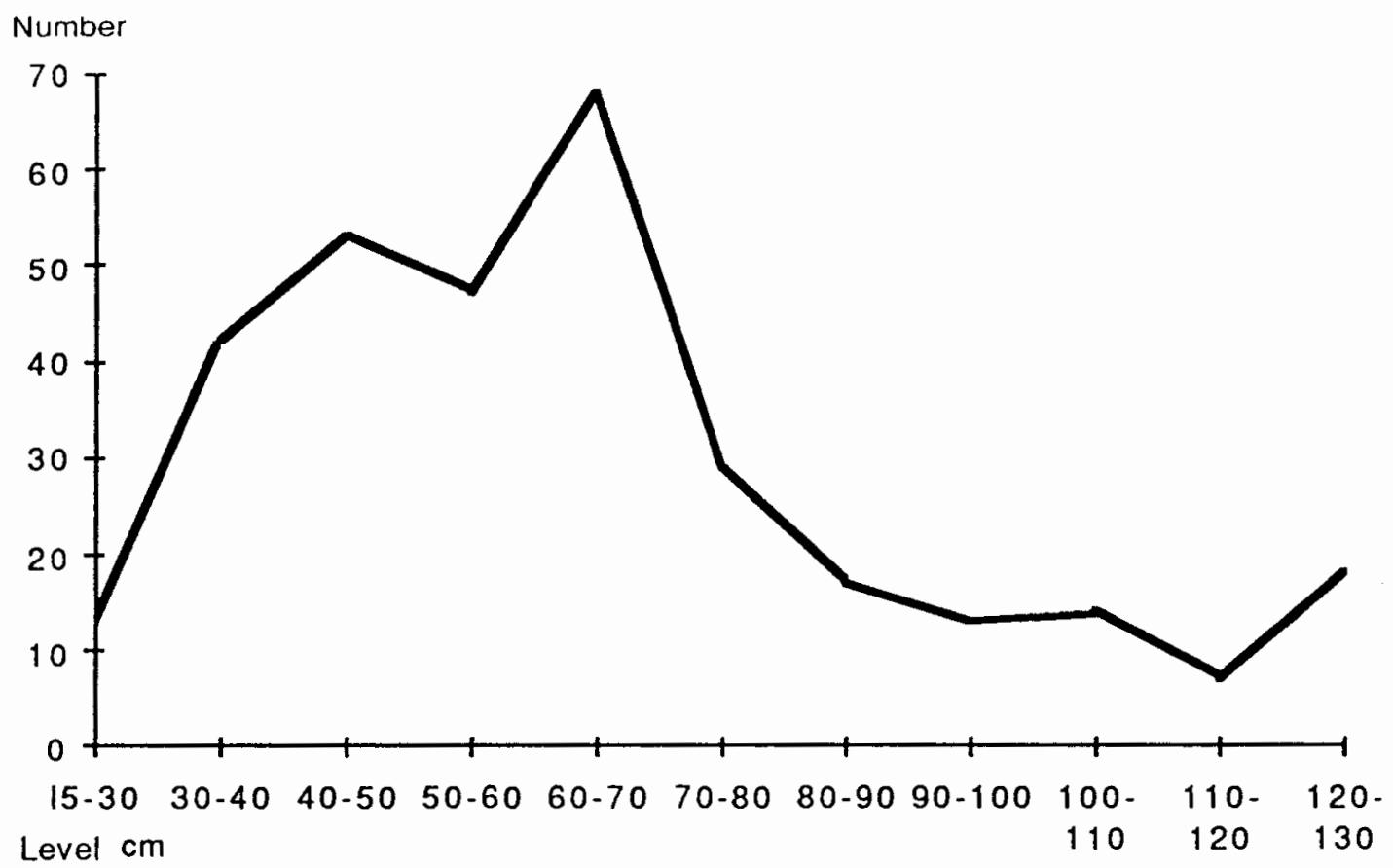

Figure 7. Distribution pattern of Unit $\mathrm{C}$ fine screened flakes. 
Number

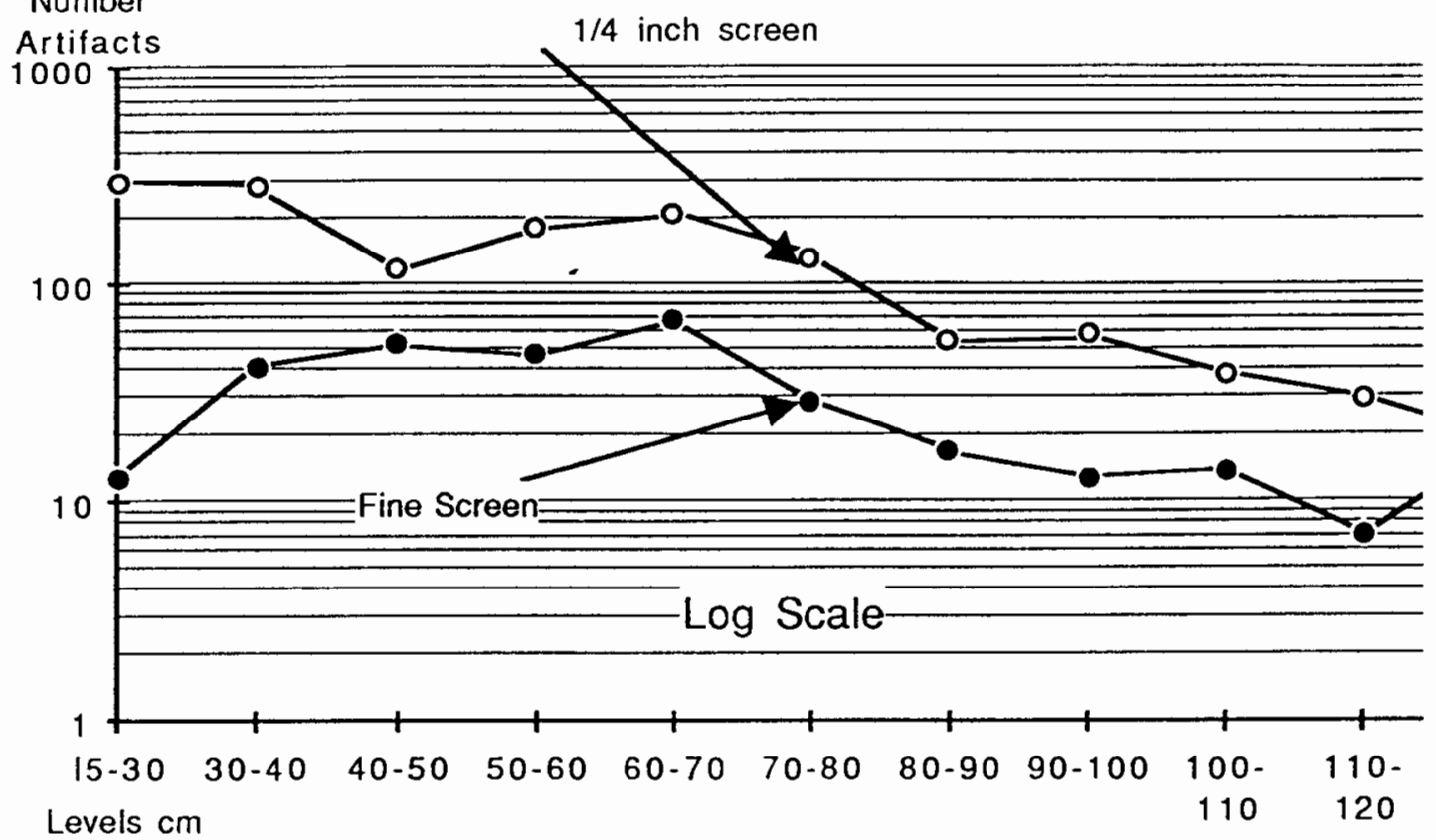

Figure 8. Unit $\mathrm{C}$ artifacts from $1 / 4$ inch and fine screen.

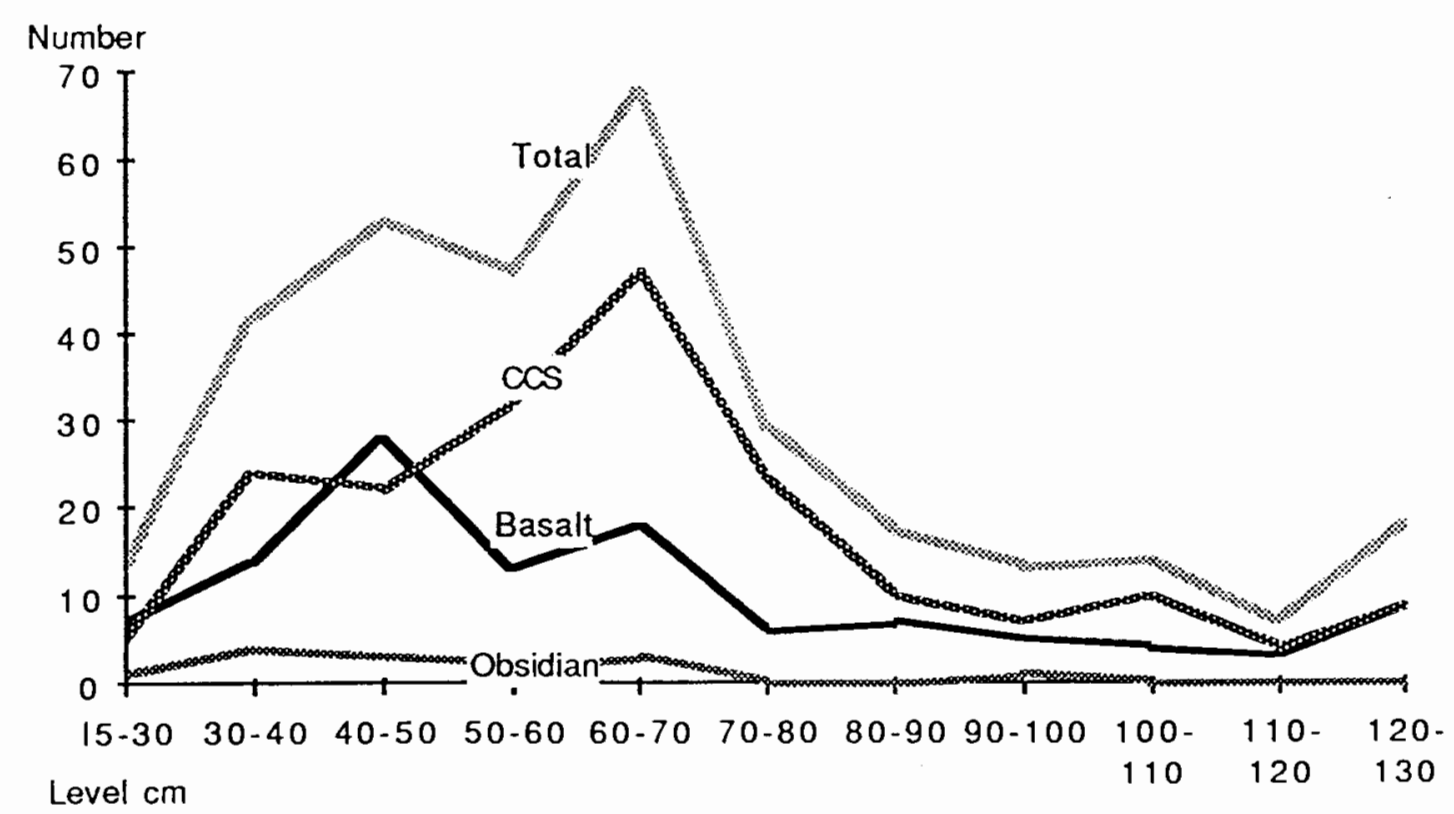

Figure 9. Material distribution, fine screened soil sample. 


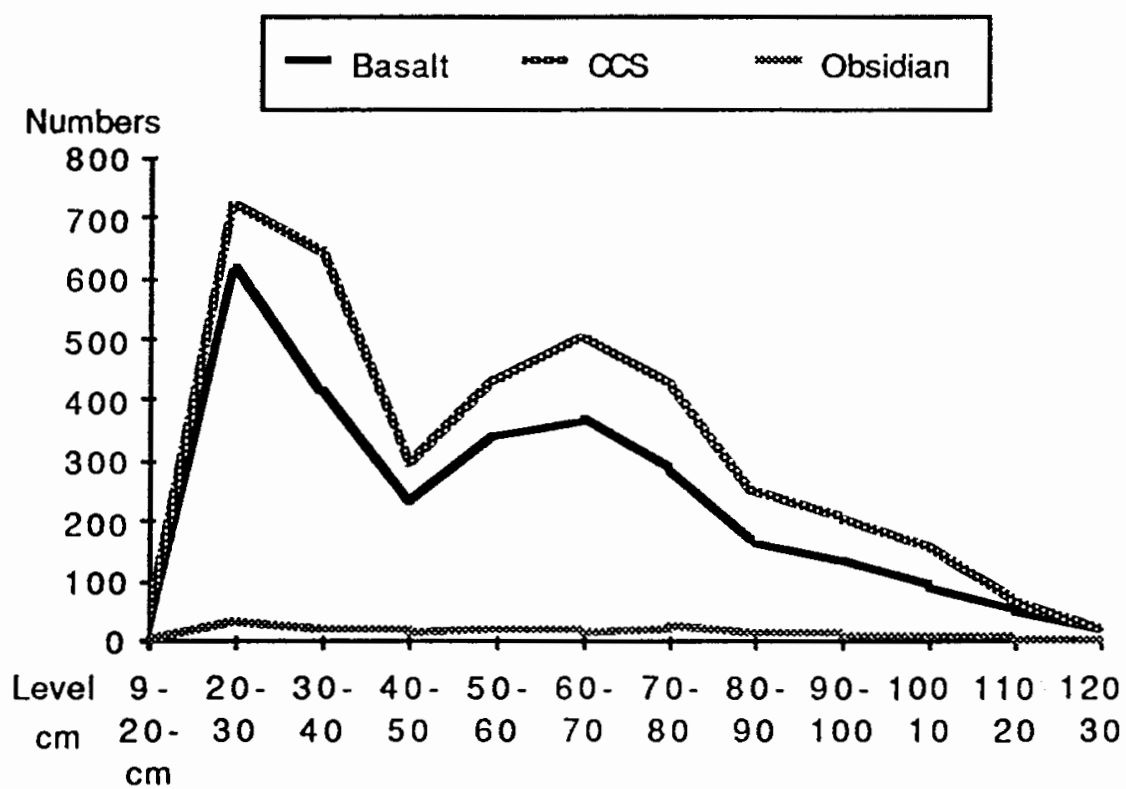

Figure 10. Distribution of material, Units A, B, C, D combined. 

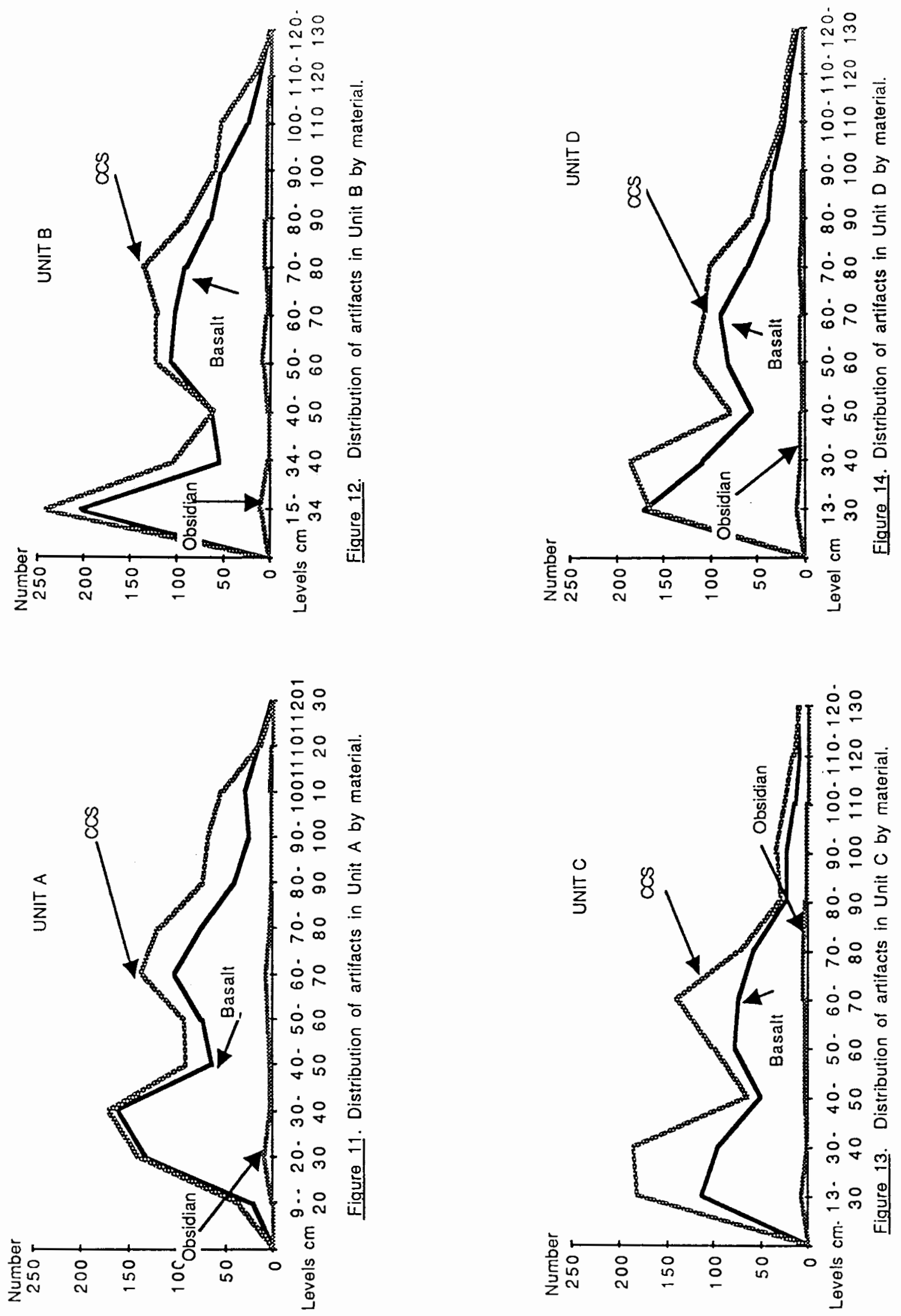


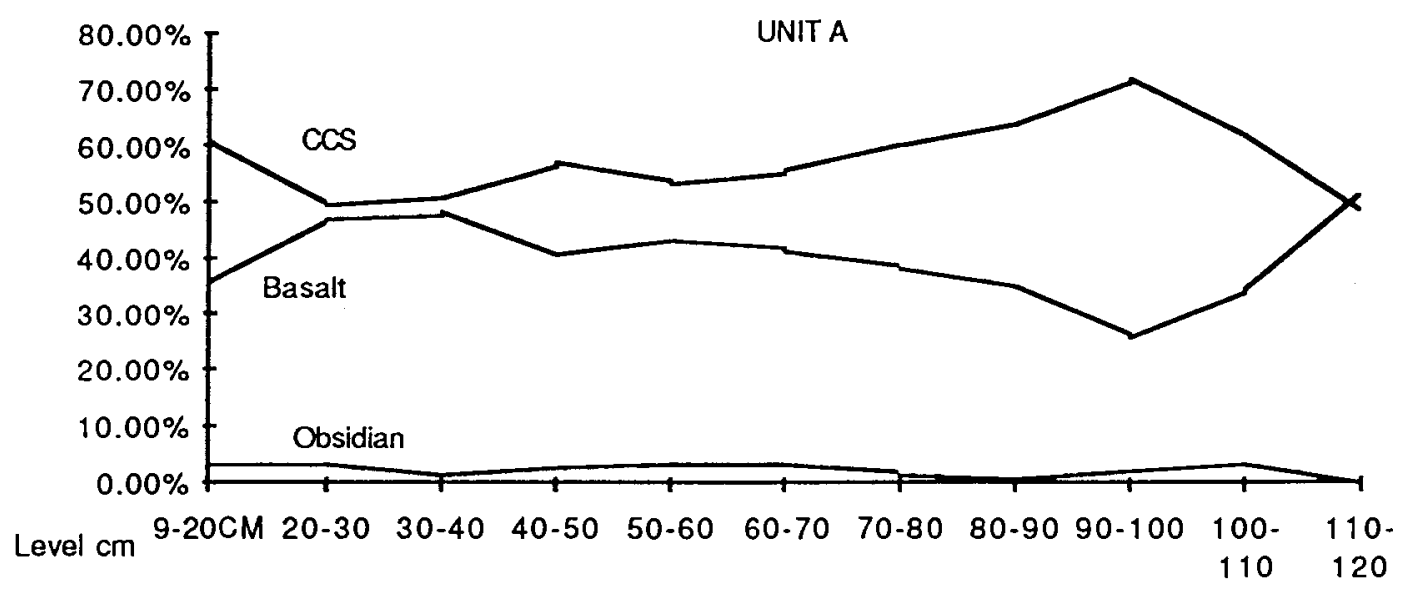

Figure 15. Percentages of basalt, CCS and obsidian in Unit A levels.

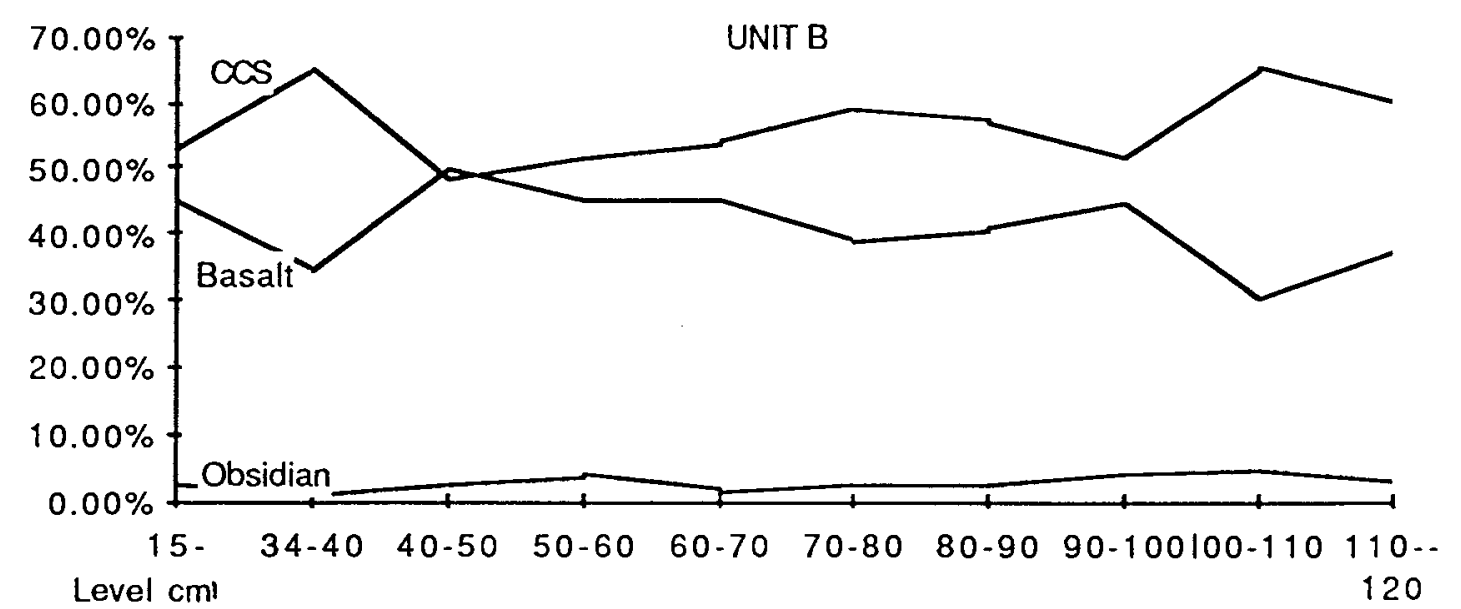

Figure 16. Percentage of basalt, CCS and obsidian in Unit B levels. 


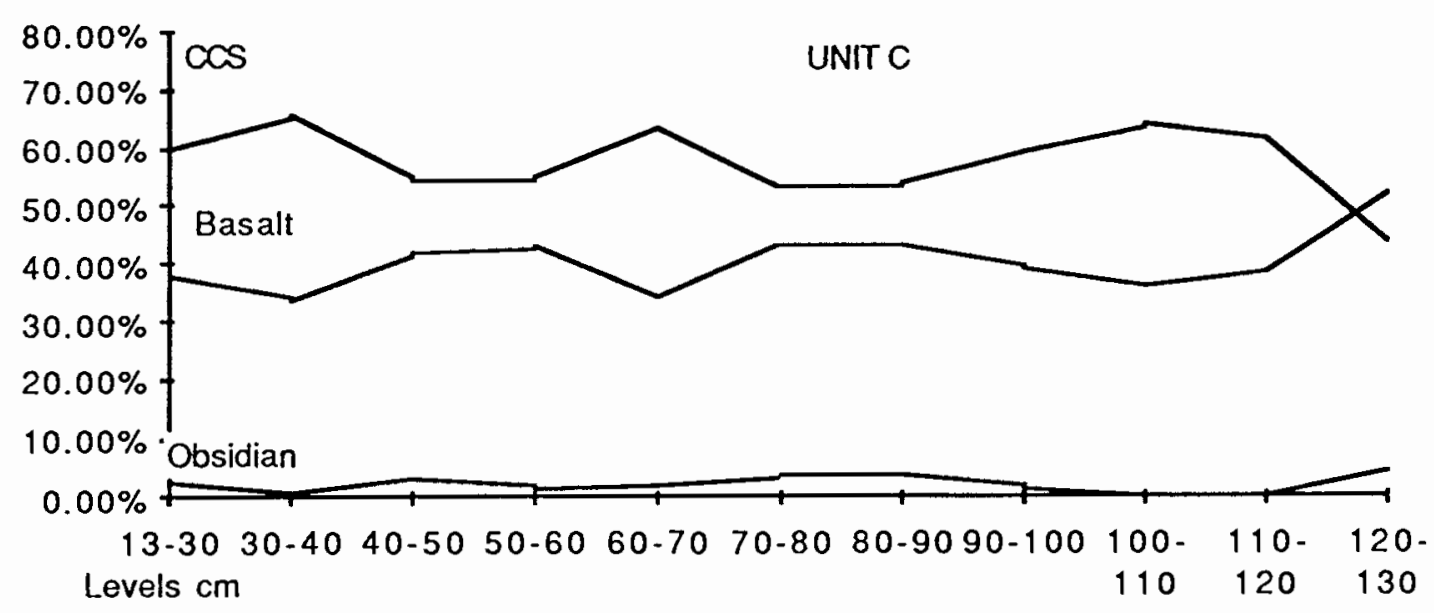

Figure 17. Percentage of basalt, CCS and obsidian in Unit C levels.

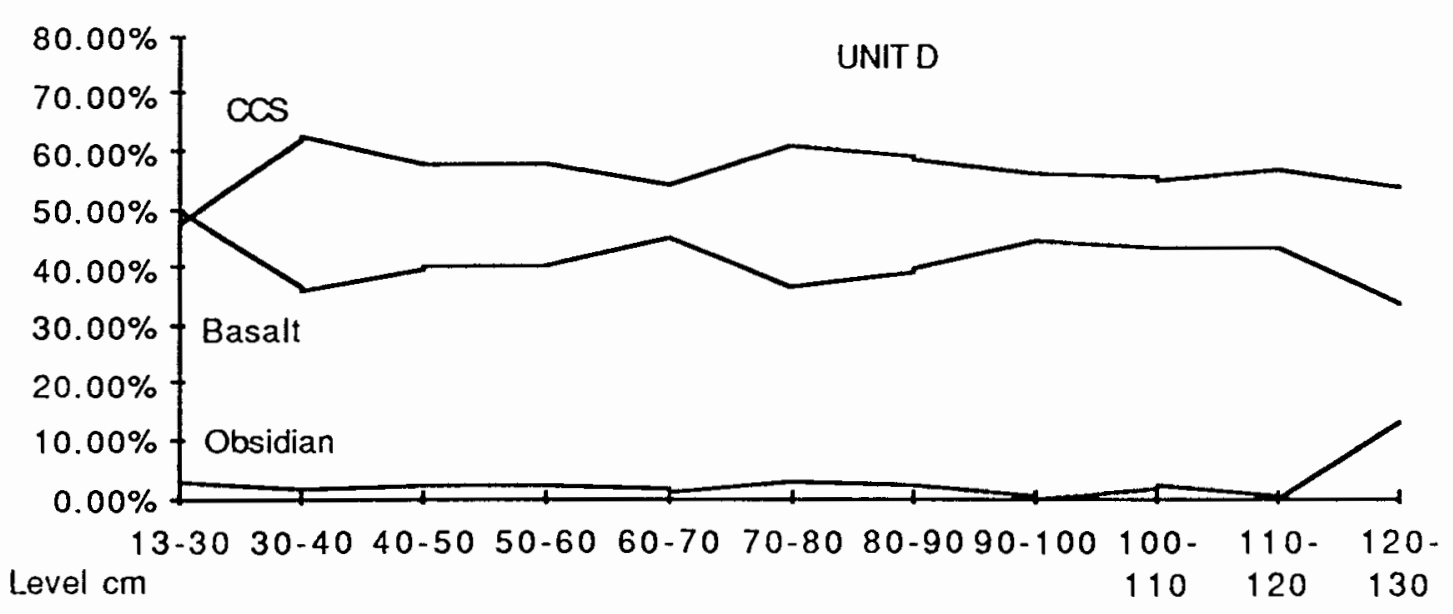

Figure 18. Percentage of basalt, CCS and obsidian in Unit D. 

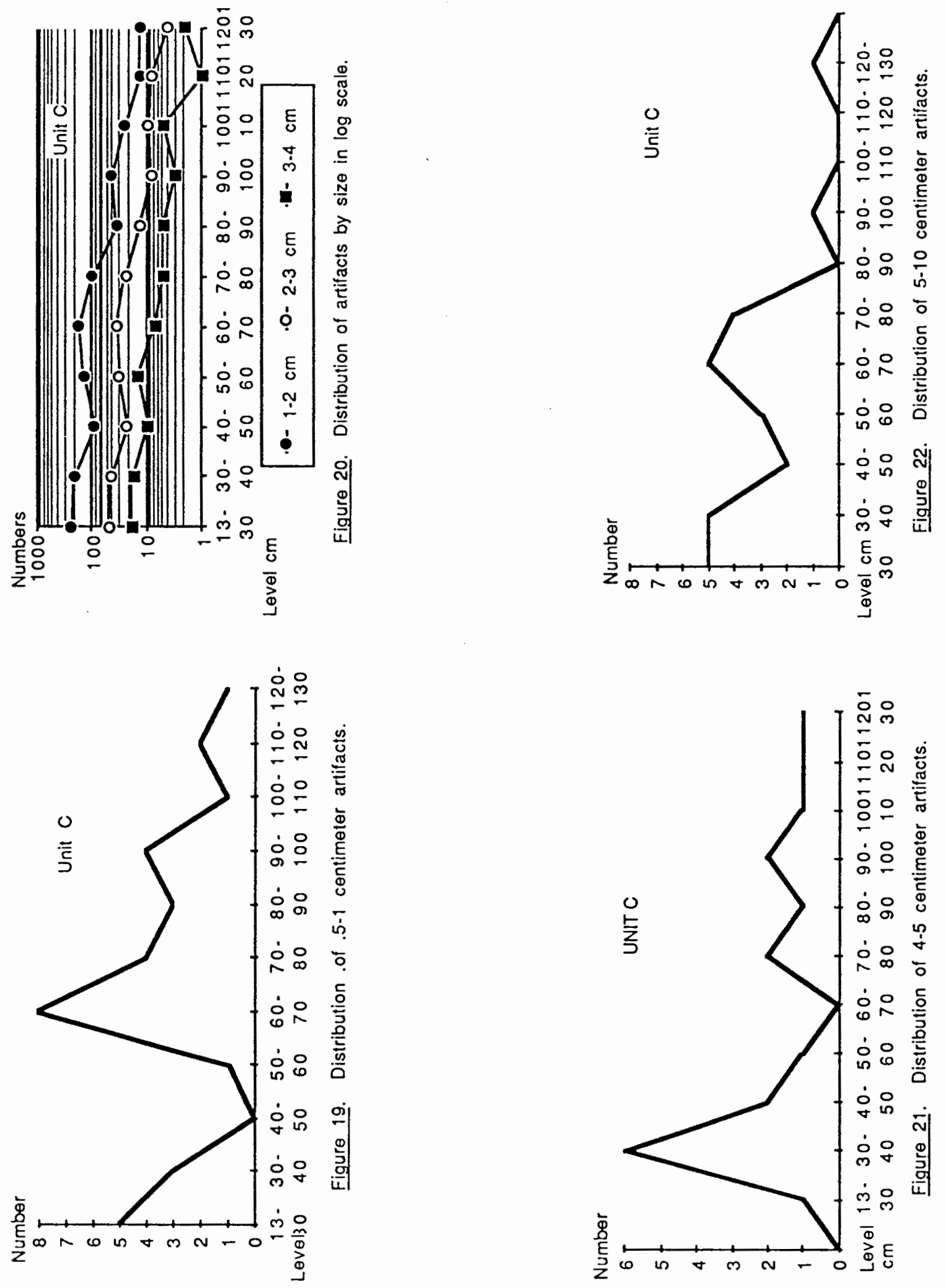


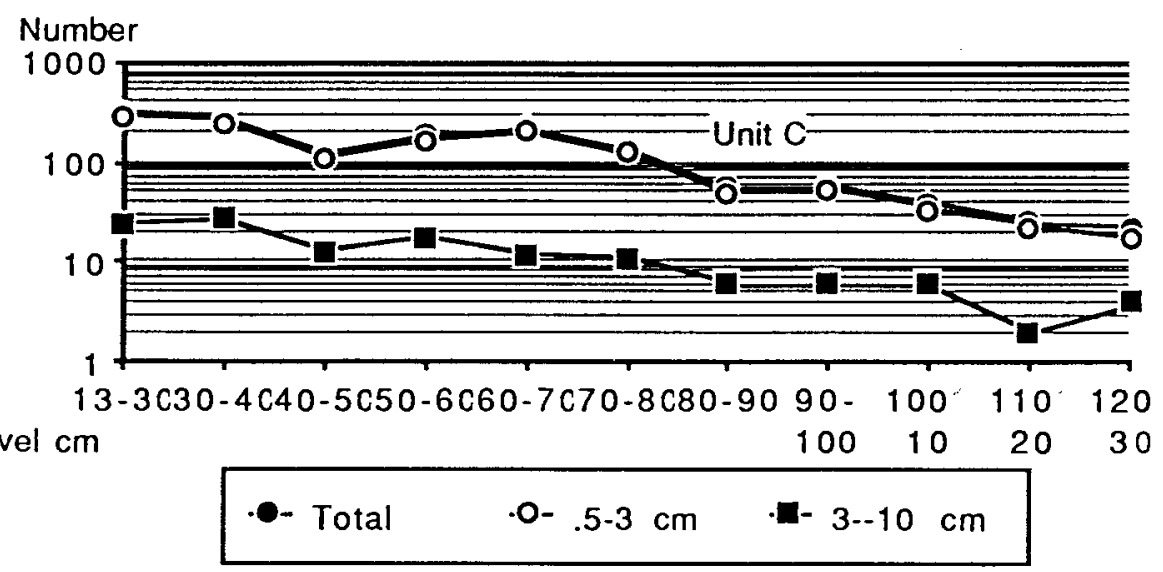

Figure 23. Log scale distribution of large, small artifacts.

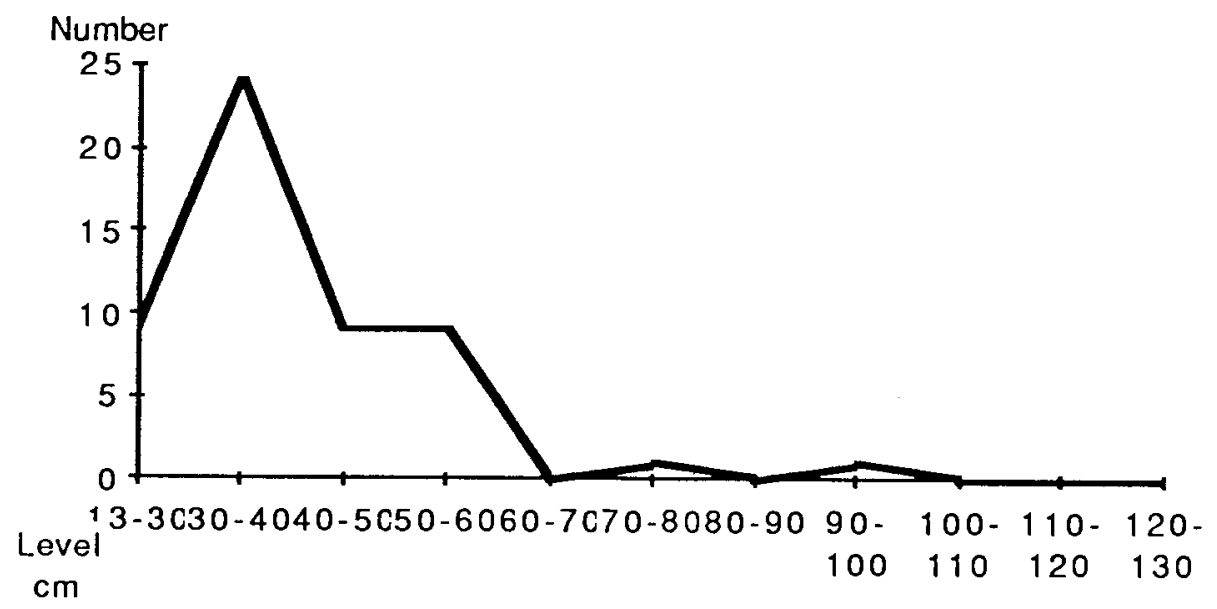

Figure 24. Distribution of heated flakes, Unit C. 


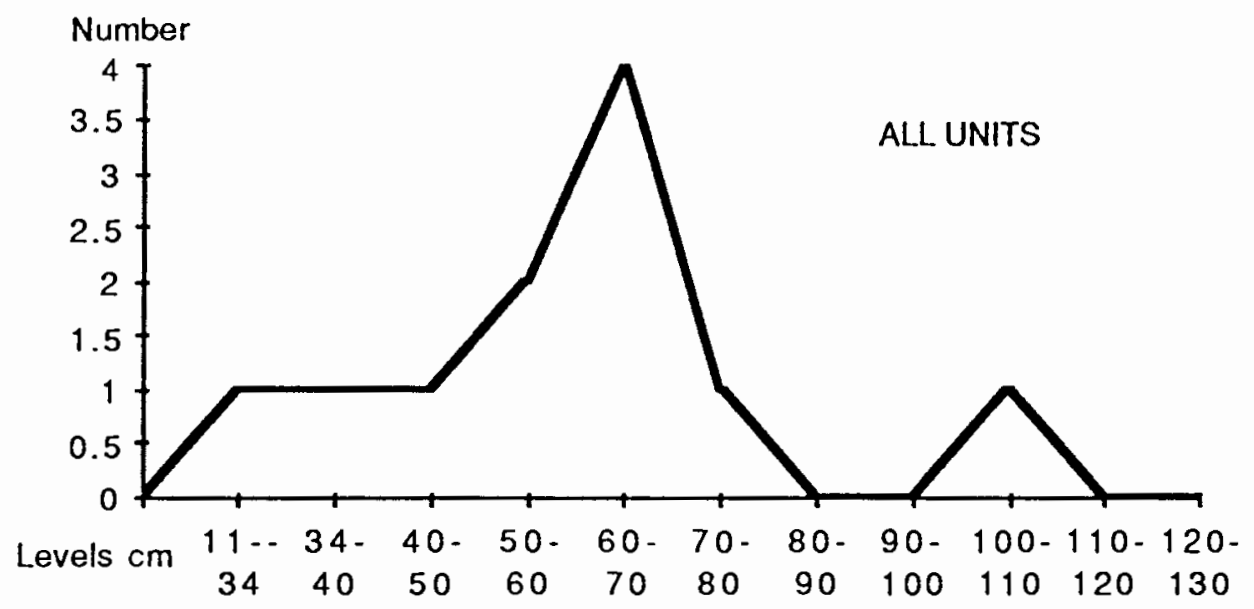

Figure 25. Bipolar flake and core distribution, all units.

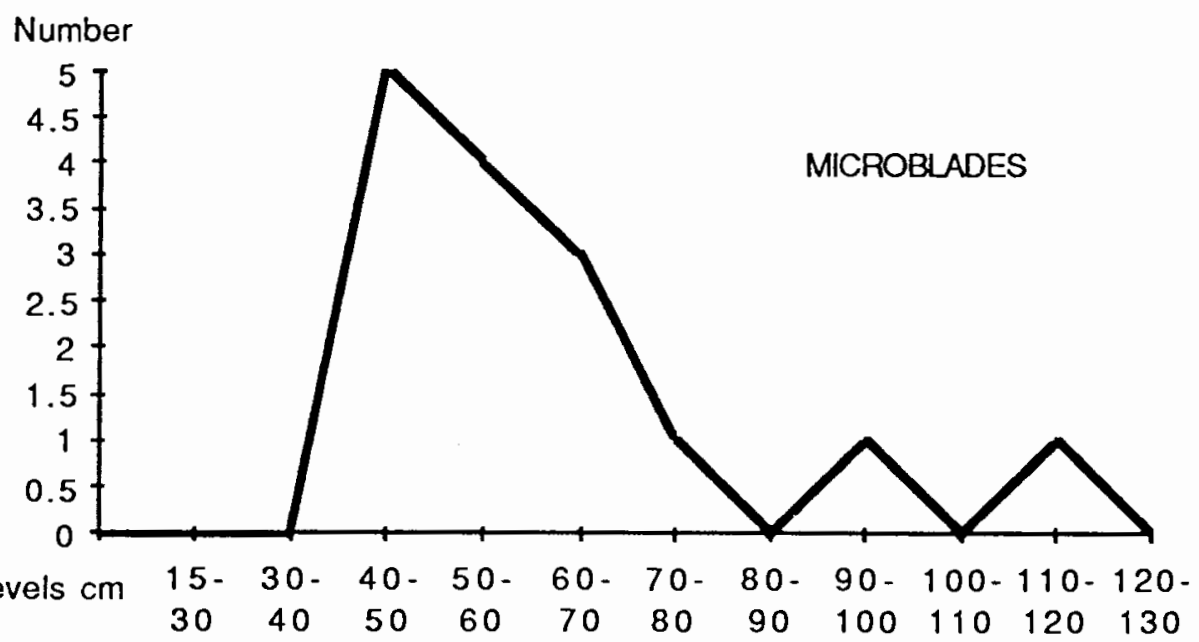

Figure 26. Microblade distribution, all units. 


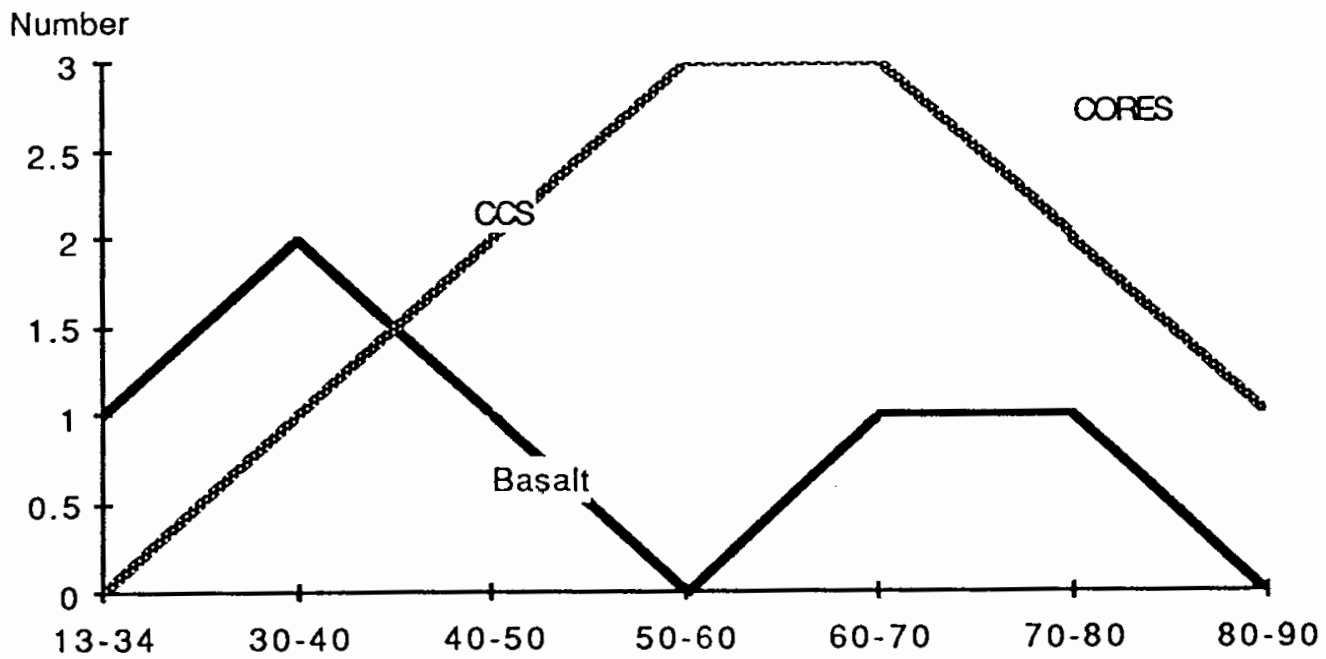

Level $\mathrm{cm}$

Figure 27. Basalt, CCS core distribution.

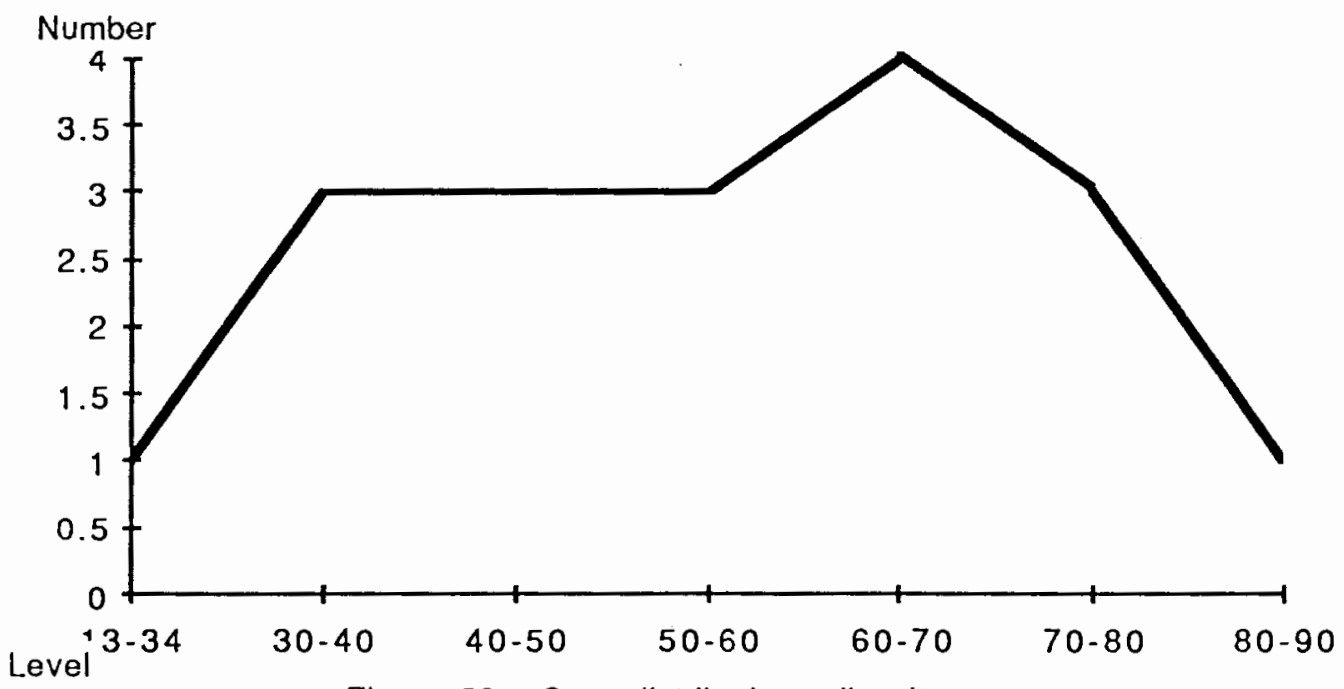

Figure 28. Core distribution, all units. 


\section{Number}

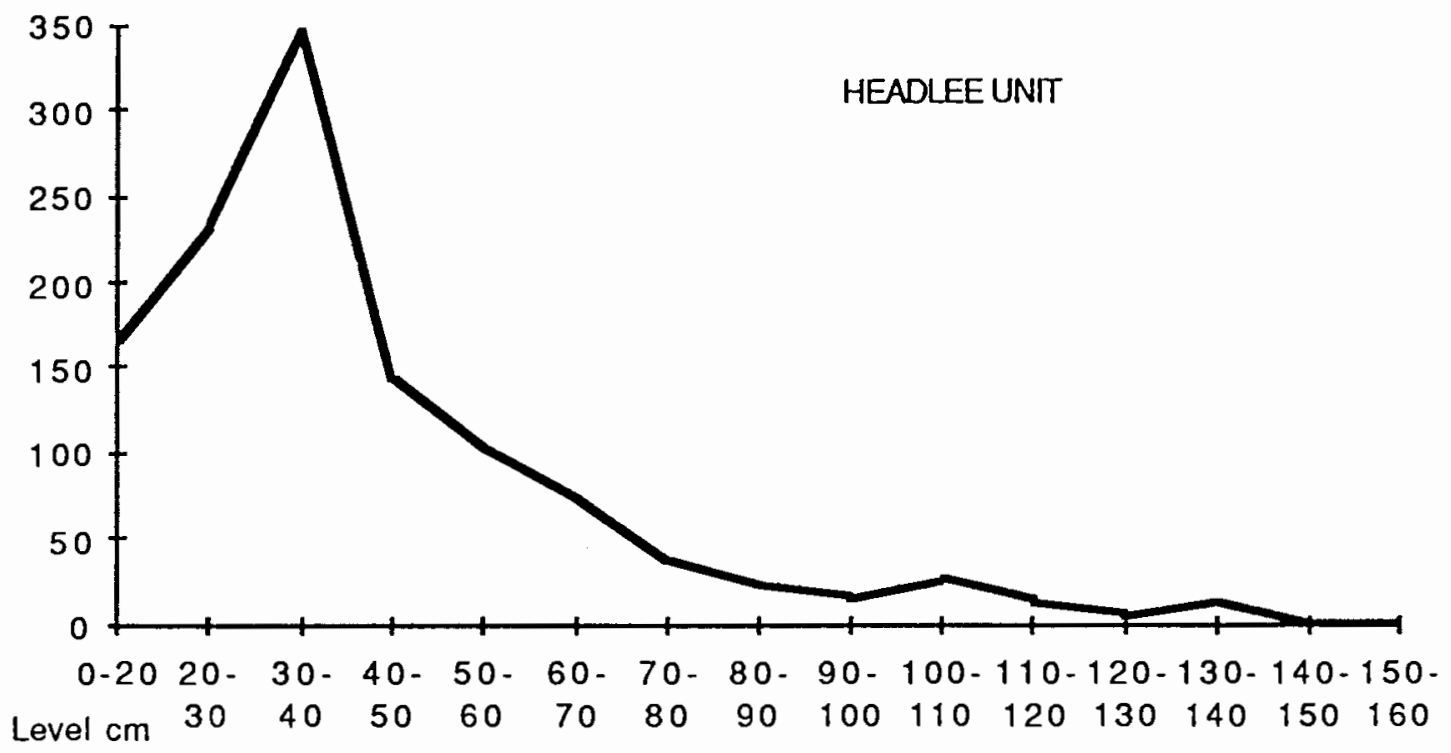

Figure 29. Unimodal distribution of artifacts in Headlee unit. 


\section{CHAPTER III}

\section{ARTIFACT DESCRIPTIONS}

This section describes bifacially flaked artifacts that appear to have been designed for use as either projectile points, thrusting implements or cutting tools. Also described briefly are other artifact types such as flake tools, cobble tools and scrapers.

The Burnett site assemblage of complete projectile points, point fragments and point-like bifaces through 1990 totals 137 flaked stone artifacts ranging from rough, uncompleted pieces to finely finished items. Of these, 46 were recovered from the surface at or near 250 Furnace St. from 1985 through early 1987 before organized excavations began. Another 80 were found in the four units excavated systematically in 1987 and 1988. Eleven (including three surface finds) are from the work at the Headlee property in 1990.

The excavated and surface collections are combined here for descriptive purposes. Although most of the points in the surface collection were found on the surface or in the upper 30 centimeters of the site while preparing garden areas, their exact provenience is lacking and they are not included in discussion of the vertical distribution of artifacts.

The numbers of excavated projectile points and bifaces and their types of material are similar in the five excavated units as shown in the following tables. The four units at 250 Furnace St. produced about 2.6 cubic meters of 
excavated fill each, while the one Headlee unit produced about two cubic meters. Projectile point distribution in the excavation units is shown in Tables IV and V.

Projectile points and bifaces have been assigned to 12 provisional groups and are described here on the basis of material, form, condition, technology and metrics. Groups I, II, III, and IV include complete or near complete points. The remainder of the specimens are fragments apparently intended for use as projectile points or knives, or unfinished pieces intended to serve as projectile points or knives.

The groups are:

I. Large points-bifaces, complete, near complete (7)

II. Small, lanceolate, complete (11)

III. Square base, round tip, hafted, complete (4)

IV. One-shouldered points, complete (1) (Fragments)

V. Long narrow blade tips (4)

VI. Long medial sections (7)

VII. Large biface tips and fragments (26)

VIII. Point tips, medium, small (23)

IX. Short, rounded projectile point tips (8)

$X$. Point stems (2)

XI. Medial blade-point fragments (37)

XII. Large rough bifaces (7)

The system used here is based on the descriptive system utilized by David G. Rice in his analysis of the Windust phase in the lower Snake River Region of Washington and Idaho (Rice 1972). Length, width and thickness are in centimeters, weight in grams. 
Group I contains seven large complete or near complete bifacesprojectile points of distinctive and separate shapes. Five are basalt, two are of CCS (Figure 30).

Catalog No. 178: Large, slender lanceolate projectile point

Description: Bipointed; convex sides; acute tip; no shoulders; distal third thinned and smoothed to knife blade shape; proximal end has large irregular piece removed, gives appearance of stem, but probably a break; distinctively thin lenticular cross section; rough percussion and pressure flaking with step fractures; some edge retouch; shovel damage. Longest flaked tool in the collection. Deep and irregular flaking scars cover more than half the surface on both sides. Remainder shows additional finer flaking and thinning, either in preparation of a hafting area or for use as a cutting tool. Area of additional thinning is asymmetrical and can be envisioned as knife shaped. Found on surface in flower bed north side of Unit A, led to discovery of the site. "Cascade" type.

Material: Basalt

Dimensions: $\mathrm{L} \quad 11.4 \mathrm{~cm}$.

W $\quad 3.0 \mathrm{~cm}$.

Th $\quad 1.0 \mathrm{~cm}$.

Wt 30.0 grams

Found Surface

Catalog No. 17 and 276: Large, narrow lanceolate projectile point Description: Slightly convex to straight sides; tips missing; no shoulders; eroded nearly smooth, flaking indistinct; cross section biconvex; edges serrated; mineral encrustations; is in two parts--Cat. No. 17 and Cat. No. 276. Fitted together form a long, narrow point or knife blade fragment with tip missing. No. 276, which appears to be the base, was found in Unit C during the 1988 excavation while No. 17 was found during the 1987 excavation of Unit A. Surface is smooth. Faint serration. No. 276 is 4.9 centimeters in length, 2.8 wide and .95 thick. No. 17 is 3.4 centimeters in length, 2.67 in width and .9 thick. "Cascade" type.

Material: Basalt

$\begin{array}{lcc}\text { Dimensions: } & \mathrm{L} & 8.1 \mathrm{~cm} \text { (combined) } \\ & \mathrm{W} & 2.8 \mathrm{~cm} \\ & \mathrm{Th} & .95 \mathrm{~cm}\end{array}$


Weight No. 17--10 g; No. 276--18.1 g.

(comb. $18.1 \mathrm{~g}$ )

Found: $\quad$ No. 17, Unit A, 20-25 cm; No. 276, Unit C $13-30 \mathrm{~cm}$.

Catalog No. 176: Shouldered lanceolate projectile point

Description: Straight-convex sides; very slight shoulders; acute tip;

proximal tip possibly missing or may be square base; distal

end thinned and shaped to knife form; proximal end thinned,

possibly for hafting; lenticular cross section; rough; has a

square base, is asymmetricaly flaked into shape resembling a knife blade. Irregular flaking; widest part near middle; little erosion. Cascade" type.

Material: Basalt

Dimensions L $7.6 \mathrm{~cm}$

W $\quad 2.5 \mathrm{~cm}$

Th $1.0 \mathrm{~cm}$

Wt. 17.8 grams

Found: $\quad$ Surface

Catalog No. 363 Crude biface

Description: Crude, elongated oval outline; acute tips; sinusoid sharp edges; tips possibly missing; cross section very

planoconvex; rough bifacial percussion flaking; similar to Category 3 of Rice Windust assemblage. Heavy blocky biface, probably a preform or blank.

Material: Basalt

Dimensions

$$
\begin{array}{cc}
\text { L } & 7.7 \mathrm{~cm} \\
\text { W } & 3.3 \mathrm{~cm} \\
\text { Th } & 1.1 \mathrm{~cm} \\
\text { Wt. } & 28.7 \text { grams }
\end{array}
$$

Found: Unit D, 105-l10 centimeters

Catalog No. 177 Straight lanceolate projectile point

Description: Sides straight-convex, asymmetrical; tip acute (missing);

straight base; lenticular cross section; rough broad flaking;

edges retouched distal third; very slight shoulders; distal two

thirds slightly thinner; similar to Category l-15 Rice Windust.

Flaked to distinctive thinness for size. Surface eroded, but shows large flat flake scars, retouched edges.

Material: Basalt

Dimensions: L $\quad 5.9 \mathrm{~cm}$

W $\quad 3.1 \mathrm{~cm}$

Th $\quad .7 \mathrm{~cm}$

Wt 15.1 grams

Found: Surface. 
Catalog No. 277 Lanceolate projectile point, wide straight base

Description: Sides slightly convex; wide straight base; cross section plano convex; rough irregular flaking; edges have large, wide serrations; possibly unfinished; possible negative bulb at ventral base; ovate. Distal tip irregular. Notches on opposite sides about two centimeters from proximal end, probably not hafting notches.

Material: CCS

Dimensions:

$$
\begin{array}{lc}
\text { L } & 6.2 \mathrm{~cm} \\
\text { W } & 3.8 \mathrm{~cm} \\
\text { Th } & .8 \mathrm{~cm} \\
\text { Wt } & 20.4 \text { grams }
\end{array}
$$

Found: Unit C 14-27 centimeters

Catalog No. 206

Description: Wide, ovate outline; sides convex, asymmetrical; tip acute; slight shoulders; base flaked slightly thinner, pointed; thin lenticular cross section; rough percussion and pressure flaking; edge retouch distal two thirds; edges sinusoid; widest part near middle. Proximal end appears to have been narrowed slightly, possibly for hafting. Point broken in collection, pieces have been glued together. "Cascade" type.

Material: CCS

Dimensions:

$$
\begin{array}{ll}
\text { L } & 10.1 \mathrm{~cm} \\
\text { W } & 4.2 \mathrm{~cm} \\
\text { Th } & 1.0 \mathrm{~cm} \\
\text { Wt. } & 37.2 \text { grams }
\end{array}
$$

Found: $\quad$ Surface, Headlee site

This category of large projectile points is noteworthy for the diversity of styles and shapes, and that fact that only one was recovered below 40 centimeters. As larger points are usually considered to be older than smaller points, recovery of larger points from the upper levels is at variance with that hypothesis. A possible explanation is that the larger points have been moved less by rodent and other disturbance as Pettigrew (Mill Creek n.d.) believes or that larger points were in use in more recent times, if in fact, the upper layers of this site reflect a more recent occupancy. Smaller points are found from surface to the bottom levels. 
Group II

This group contains small, complete or near-complete projectile points. Ten are lanceolate, one is stemmed (Figure 31).

No. of specimens 11

Catalog No. 334 Slender, lanceolate projectile points

Description: Convex sides; acute tips; slight shouldering one side; base pointed slightly thinned and narrowed; cross section planoconvex; flaking irregular. "Cascade" type.

Material: Basalt

Dimensions

$$
\begin{array}{ll}
\text { L } & 5.4 \mathrm{~cm} \\
\text { W } & 1.4 \mathrm{~cm} \\
\text { Th } & 6 \mathrm{~cm} \\
\text { Wt. } & 3.9 \text { grams }
\end{array}
$$

Found: $\quad$ Unit D, 50-55 cm

Catalog No. 220 Very small lanceolate projectile point

Description: Very small tear drop shaped; convex sides; acute tip; rounded convex base; cross section lenticular; badly eroded, no flaking visible. "Cascade type."

Material: Basalt

Dimensions:

$$
\begin{aligned}
& \text { L } \quad 2.7 \mathrm{~cm} \\
& \text { W } \quad .9 \mathrm{~cm} \\
& \text { Th } .4 \mathrm{~cm} \\
& \text { Wt. } 1.1 \mathrm{grams} \\
& \text { Unit B } 0-34 \mathrm{~cm} \text {. }
\end{aligned}
$$

Found

Catalog No. 353 Small shouldered lanceolate projectile point

Description: Convex sides; sharp acute tips; weak shoulders, more pronounced on one side; weakly contracting stem;

planoconvex cross section; flaking controlled but surface worn; proximal end thinned and narrowed, possibly for hafting. "Cascade" type.

Material: Basalt

Dimensions:

$$
\begin{array}{ll}
\text { L } & 3.3 \mathrm{~cm} \\
\text { W } & 1.2 \mathrm{~cm} \\
\text { Th } & .6 \mathrm{~cm} \\
\text { Wt. } & 1.8 \text { grams }
\end{array}
$$

Found:

$$
\text { Unit B, 70-75 cm }
$$


Catalog No. 285 Small, slender lanceolate projectile point

Description: Sides convex; tips acute; slight shoulder one side;

lenticular cross section; controlled flaking; proximal one third thinned and narrowed, possibly for hafting. "Cascade" type.

Material: Obsidian

Dimensions:

$$
\begin{array}{ll}
\mathrm{L} & 3.5 \mathrm{~cm} \\
\mathrm{~W} & 1.0 \mathrm{~cm} \\
\text { Th. } & 0.5 \mathrm{~cm} \\
\text { Wt } & 1.4 \mathrm{grams}
\end{array}
$$

Found:

$$
\text { Unit C, 55-60 cm. }
$$

Catalog No. 208 Slender lanceolate projectile point

Description: Convex sides; acute tip; lenticular cross section; well controlled pressure flaking; slight shoulder one side; base

Material: CCS slightly thinned by flaking. "Cascade" type.

Dimensions:

Found:

$$
\begin{aligned}
& \text { L } \quad 4.6 \mathrm{~cm} \\
& \text { W } \\
& \text { Th } \quad 1.3 \mathrm{~cm} \\
& \text { Wt. } \quad .6 \mathrm{~cm} \\
& \text { Surface }
\end{aligned}
$$

Catalog No. 381 Lanceolate projectile point

Description: Badly eroded, base narrowed, perhaps for hafting.

Encrusted with minerals. "Cascade" type.

Material: Basalt

Dimensions:

Found:

L $\quad 5.9 \mathrm{~cm}$

W $\quad 1.8 \mathrm{~cm}$

Th $\quad .8 \mathrm{~cm}$

Wt. 7.8 grams

Surface

Catalog No. 485 Lanceolate projectile point

Description: Slender, very badly eroded. Tip acute, base slightly rounded, possible slight shoulder, base area possibly thinned. Heavy soil-mineral encrustation covers details if any remain from erosion. "Cascade" type.

Material: Probably basalt.

$\begin{array}{lll}\text { Dimensions: } & \text { L } & 4.1 \mathrm{~cm} \\ & \text { W } & 1.0 \mathrm{~cm} \\ & \text { Th } & 0.5 \mathrm{~cm} \\ & \text { Wt } & 1.8 \text { grams }\end{array}$

Found: Headlee unit, $30-40 \mathrm{cms}$ below surface 
Catalog No. 486 Lanceolate projectile point

Description: Slender, irregular pressure flaking, sides straight, tip sharp, base slightly rounded. Very similar to No. 485 , but not eroded or encrusted. Possible slight basal thinning.

Slight shovel damage. "Cascade" type.

Material: Basalt

Dimensions:

$$
\begin{array}{ll}
\mathrm{L} & 4.3 \mathrm{~cm} \\
\mathrm{~W} & 1.0 \mathrm{~cm} \\
\mathrm{Th} & 0.4 \mathrm{~cm} \\
\mathrm{Wt} & 1.5 \text { grams }
\end{array}
$$

Found: $\quad$ Headlee unit, $60-70 \mathrm{cms}$ below surface

Catalog No. 487 Lanceolate projectile point

Description: Ovate shape, convex sides, tip sharp, base thinned and narrowed with small square break. Planoconvex in cross section. flaking irregular, fine edge flaking. "Cascade" type.

Material: Chert

Dimensions:

$$
\begin{array}{cl}
\mathrm{L} & 3.9 \mathrm{~cm} \\
\mathrm{~W} & 1.2 \mathrm{~cm} \\
\mathrm{Th} & 0.6 \mathrm{~cm} \\
\mathrm{Wt} & 2.2 \text { grams }
\end{array}
$$

Found: Headlee unit, 60-70 centimeters below surface.

Catalog No. 488 Stemmed projectile point

Description: Only complete stemmed point found at Burnett site.

Similar to Rice category 11 Windust points labeled shouldered lanceolate projectile points with elongated stems. straight and convex sides, acute tip, well-defined shoulders, one shoulder more pronounced than other, convex base, lenticular cross section.

Material: Obsidian

Dimensions

$$
\begin{array}{ll}
\text { L } & 3.2 \mathrm{~cm} \\
\text { W } & 1.2 \mathrm{~cm} \\
\text { Th } & 0.4 \mathrm{~cm}
\end{array}
$$

Stem Length $1.2 \mathrm{~cm}$

Stem Width $0.9 \mathrm{~cm}$

Wt 1.2 grams

Found: Headlee unit, 100-110 centimeters 
Catalog No. 338 Small lanceolate point with irregular base

Description: Convex asymmetrical base; acute tip; base irregular with four pronglike projections; planoconvex cross section;

flaking rough, distal end slightly thinned; tip missing."Cascade" type.

Material: Basalt

Dimensions:

$$
\begin{array}{ll}
\text { L } & 4.6 \mathrm{~cm} \\
\text { W } & 1.3 \mathrm{~cm} \\
\text { Th } & .6 \mathrm{~cm} \\
\text { Wt. } & 3.1 \text { grams }
\end{array}
$$

Found:

Surface

\section{GROUP III}

This group contains small, square based, round tip projectile points and fragmentsFigure 32).

No. of specimens: 4

Description: Slightly convex to straight sides; rounded tips; very slight shoulders; base straight; cross section lenticular to biconvex; flaking very rough to indistinct, one specimen very smooth; all show slight basal thinning and narrowing, possibly for hafting. "Cascade" type.

Material: All basalt

Dimensions:

Cat. No.

226

232

316

367
L W

$4.5 \quad 1.5$

$3.8 \quad 1.5$

$3.7 \quad 1.6$

$3.5 \quad 1.5$
$\mathrm{Th}$

.7

.7

.7

.6

.5
Wt.

4.6

3.5

4.3

2.9
Found

Unit B 30-40 cm

Unit B 50-60

Unit C 60

Unit D 115-120

\section{GROUP IV}

A single one-shouldered point is in this group (Figure 33).

No. of specimens: 1

Description: Sides straight to convex; tip acute; one pronounced shoulder, short concave base narrowed on one side only. Base 
straight. Similar to Rice's Windust category 1-2, shouldered lanceolate projectile point with straight or convex base.

Dimensions:

$\begin{array}{lllllll}\text { Cat. No. } & \text { L } & \text { W } & \text { Th } & \text { Wt. } & \text { Material } & \text { Found } \\ 106 & 3.8 & 2.2 & .9 & 7.4 & \text { Basalt } & \text { Unit A 50-60 }\end{array}$

\section{GROUP V}

This group contains long, narrow blade tips (Figure 34).

No. of specimens 4

Description: Sides straight to slightly convex; tips rounded, pointed; cross section biconvex; flaking rough to well controlled; two appear to be knife blades, other possibly a drill. Nos. 235 and 237 broken by shovel, form one point fragment when placed together.

Dimensions:

$\begin{array}{lllllll}\text { Cat. No. } & \text { L } & \text { W } & \text { Th } & \text { Wt. } & \text { Material } & \text { Found } \\ 382 & 5.6 & 2.3 & .6 & 8.6 & \text { CCS } & \text { Surface } \\ 301 & 4.7 & 1.7 & .5 & 4.95 & \text { CCS } & \text { Unit C 70-75 } \\ 207 & 4.0 & 1.4 & .5 & 3.1 & \text { Basalt } & \text { Surface } \\ 235-237 & 4.0 & 1.5 & .5 & 3.4 & \text { Basalt } & \text { Unit B 50-60 }\end{array}$

\section{GROUP VI}

This group contains long, narrow medial sections (Figure 35).

No. of specimens: 7

Description: Convex to nearly straight sides; tips missing; cross section biconvex, lenticular, planoconvex; flaking well controlled to indistinct: one specimen shows serrated edges;

Numbers 374 and 307 show narrowing and thinning for possible hafting; No. 224 very slight shoulder and basal thinning; appear to be sections of knife blades or spear points.

Dimensions:

$\begin{array}{lllllll}\text { Cat. No. } & \text { L } & \text { W } & \text { Th } & \text { Wt. } & \text { Material } & \text { Found } \\ 306 & 4.7 & 2.0 & .5 & 4.8 & \text { Basalt } & \text { Unit C 95 cm } \\ 307 & 2.9 & 1.8 & .6 & 3.4 & \text { CCS } & \text { Unit C 80-85 } \\ 224 & 2.4 & 1.1 & .4 & 1.7 & \text { Basalt } & \text { Unit B 30-40 }\end{array}$


359

329

383

384

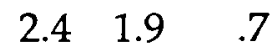

$\begin{array}{lll}2.3 & 1.8 & .5\end{array}$

$\begin{array}{lll}3.8 & 1.7 & .6\end{array}$

$\begin{array}{lll}2.8 & 1.4 & .5\end{array}$
4.2 CCS

2.9 CCS

5.0 Basalt

2.2 Basalt
Unit D 85-90

Unit D40-45

Surface

Surface

\section{GROUP VII}

This group contains large biface tips and fragments (Figure 36).

No. of specimens: 25

Description: Convex to straight sides; acute tips; cross section planoconvex, biconvex, lenticular; flaking well controlled to rough; some base thinning, possibly for hafting. No. 287-288 in two pieces, shovel broken, combine to form one point.

Dimensions:

$\begin{array}{lllccll}\text { Cat. No. } & \text { L } & \text { W } & \text { Th } & \text { Wt. } & \text { Material } & \text { Found } \\ 281 & 5.8 & 2.6 & 1.1 & 15.5 & \text { CCS } & \text { Unit C 40 cm } \\ 293 & 2.9 & 2.6 & .8 & 5.0 & \text { Basalt } & \text { Unit C 60-65 } \\ 179 & 5.8 & 2.9 & .6 & 11.5 . & \text { CCS } & \text { Surface } \\ 336 & 4.8 & 3.8 & .9 & 14.1 & \text { Basalt } & \text { Unit D 55 cm } \\ 183 & 4.0 & 3.3 & 1.2 & 13.8 & \text { CCS } & \text { Surface } \\ 217 & 4.4 & 2.7 & .8 & 12.1 & \text { Basalt } & \text { Unit B 0-34 } \\ 190 & 4.0 & 3.0 & .9 & 10.0 & \text { CSS } & \text { Surface } \\ 184 & 4.2 & 3.1 & .9 & 13.5 & \text { CCS } & \text { Surface } \\ 180 & 4.5 & 3.4 & 1.1 & 18.4 & \text { CCS } & \text { Surface } \\ 326 & 5.0 & 3.1 & 1.0 & 13.4 & \text { CCS } & \text { Unit D 13-27 } \\ 189 & 3.3 & 2.0 & 0.7 & 5.9 & \text { Basalt } & \text { Surface } \\ 192 & 3.2 & 2.0 & 0.7 & 4.9 & \text { Basalt } & \text { Surface } \\ 197 & 3.1 & 1.8 & 0.7 & 3.7 & \text { Basalt } & \text { Surface } \\ 221 & 2.9 & 1.8 & 0.7 & 3.6 & \text { CCS } & \text { Unit B 0-34 } \\ 294 & 2.8 & 1.7 & 0.5 & 2.9 & \text { Basalt } & \text { Unit C 75-80 } \\ 188 & 2.7 & 1.6 & 0.6 & 3.6 & \text { Basalt } & \text { Surface } \\ 98 & 5.8 & 4.8 & 2.2 & 36.6 & \text { Basalt } & \text { Unit A 45-50 } \\ 304 & 6.0 & 3.5 & 1.7 & 36.2 & \text { Basalt } & \text { Unit C 35-40 } \\ 397 & 5.6 & 3.3 & 1.0 & 18.1 & \text { Basalt } & \text { Surface } \\ 398 & 5.9 & 4.0 & 1.3 & 30.6 & \text { Basalt } & \text { Surface } \\ 126 & 3.9 & 3.3 & 1.0 & 10.4 & \text { Basalt } & \text { Surface } \\ 169 & 5.3 & 4.2 & 1.7 & 33.0 & \text { Basalt } & \text { Surface } \\ 120 & 3.5 & 3.8 & 1.2 & 5.1 & \text { CCS } & \text { Surface } \\ 483 & 2.5 & 3.8 & 0.7 & 5.2 & \text { Basalt } & \text { Surface } \\ 490 & 4.3 & 2.5 & 0.8 & 9.2 & \text { Basalt } & \text { Surface } \\ 287-288 & 4.3 & 2.5 & 0.7 & 5.5 & \text { Basalt } & \text { Unit C 56, 57 }\end{array}$


This group contains medium-small projectile point tips (Figure 37).

No. of specimens: 23

Description: Sides straight to convex; tips acute; cross section lenticular, biconvex; flaking well controlled to indistinct; edges serrated to smooth. Sorted by length, the tips fall into four size categories:

1.2-1.4 centimeters(7); $1.7-1.9 \mathrm{~cm}(4) ; 2.1-2.3 \mathrm{~cm}(4)$ and $2.4-3.2 \mathrm{~cm}(7)$.

Dimensions:

$\begin{array}{lrrrrll}\text { Cat. No. } & \text { L } & \text { W } & \text { Th } & \text { Wt } & \text { Material } & \text { Found } \\ 201 & 1.4 & 1.0 & .3 & .3 & \text { CCS } & \text { Surface } \\ 349 & 1.4 & .9 & .3 & .4 & \text { CCS } & \text { Unit D 65-70 } \\ 369 & 1.2 & 1.4 & .4 & .5 & \text { CCS } & \text { Unit A 35-40 } \\ 267 & 1.3 & 1.0 & .4 & .5 & \text { Basalt } & \text { Unit A 70-80 } \\ 223 & 1.2 & 1.1 & .4 & .2 & \text { CCS } & \text { Unit B 30-40 } \\ & & & & & & \\ 296 & 1.7 & 1.4 & .4 & .8 & \text { Basalt } & \text { Unit C 65-70 } \\ 215 & 1.8 & 1.4 & .5 & 1.1 & \text { Basalt } & \text { Unit B 0-34 } \\ 302 & 1.7 & 1.3 & .3 & .7 & \text { Basalt } & \text { Unit C 65-70 } \\ 219 & 1.7 & 1.7 & .5 & 1.1 & \text { CCS } & \text { Unit B 0-34 } \\ 444 & 1.9 & 1.1 & .3 & .3 & \text { Basalt } & \text { Unit A 60-70 } \\ & & & & & & \\ 305 & 2.1 & 1.8 & .4 & 1.2 & \text { Basalt } & \text { Unit C 95-.100 } \\ 308 & 2.2 & 1.3 & .6 & 1.4 & \text { Basalt } & \text { Unit C 80-85 } \\ 100 & 2.3 & 1.5 & .6 & 2.1 & \text { Basalt } & \text { Unit A 45-50 } \\ 95 & 2.2 & 1.5 & .4 & 1.7 & \text { Jasper } & \text { Unit A 40-45 } \\ & & & & & & \\ 198 & 3.2 & 1.4 & .5 & 2.3 & \text { Basalt } & \text { Surface } \\ 199 & 2.6 & 1.4 & .5 & 2.1 & \text { CCS } & \text { Surface } \\ 196 & 2.9 & 1.5 & .4 & 2.2 & \text { Basalt } & \text { Surface } \\ 344 & 2.8 & 1.2 & .5 & 1.3 & \text { CCS } & \text { Unit D 60-65 } \\ 191 & 2.4 & 1.2 & .6 & 1.5 & \text { Basalt } & \text { Surface } \\ 368 & 2.4 & 1.6 & .5 & 1.9 & \text { CCS } & \text { Unit D120-125 } \\ 354 & 2.6 & 1.7 & .6 & 2.7 & \text { CCS } & \text { Unit D 73 } \\ 253 & .7 & .7 & .3 & .05 & \text { Basalt } & \text { Unit B 80-90 } \\ 402 & 1.1 & 1.1 & .3 & .6 & \text { Basalt } & \text { Unit C 80-85 }\end{array}$


This group contains short, rounded projectile point tips (Figure 38).

No. of specimens: 8

Description: Sides straight to convex; tips rounded; flaking rough; cross section plano convex; may be knife tips.

Dimensions:

\begin{tabular}{|c|c|c|c|c|c|c|}
\hline Cat. No. & $\mathrm{L}$ & W & Th & Wt. & Material & Found \\
\hline 255 & 2.0 & 1.5 & .4 & .7 & CCS & Unit B 90-100 \\
\hline 240 & 2.1 & 1.3 & .4 & 1.35 & Basalt & Unit B 50-60 \\
\hline 340 & 1.8 & 1.4 & .5 & 1.2 & Basalt & Unit D 55-60 \\
\hline 214 & 1.8 & 1.3 & .5 & 1.3 & Basalt & Unit B 0-34 \\
\hline 236 & 2.0 & 1.6 & .5 & 1.5 & $\mathrm{CCS}$ & Unit B $50-60$ \\
\hline 391 & 2.7 & 1.6 & .6 & 2.5 & CCS & Surface \\
\hline 494 & 2.2 & 1.2 & .4 & 0.6 & $\mathrm{CCS}$ & Headlee $20-30$ \\
\hline 278 & 2.3 & 1.2 & .4 & 1.0 & CCS & Unit C 35-40 \\
\hline
\end{tabular}

\section{GROUP X}

This group contains Windust-type point stems. (Figure 39)

No. of specimens: 2

Description: Square base fragments with flaked concave distal end. Appear to be similar to stems of Windust points.

Dimensions

$\begin{array}{lllllll}\text { Cat. No. } & \text { L. } & \text { W. } & \text { Th. } & \text { Wt. } & \text { Material } & \text { Found } \\ 447 & 1.1 & 2.0 & .5 & 1.0 & \text { CCS } & \text { Unit A 45-50 } \\ 390 & 1.8 & 2.2 & .5 & 2.7 & \text { CCS } & \text { Surface }\end{array}$




\section{GROUP XI}

This group contains medial fragments of biface blades or points(Figure 40)..

No. of specimens: 37

Description: Sides straight to convex; flaking varied; cross section planoconvex to biconvex.

Dimensions:

$\begin{array}{rrrrrll}\text { Cat. No. } & \text { L } & \text { W } & \text { Th } & \text { W t } & \text { Material } & \text { Found } \\ 111 & 4.1 & 1.6 & 0.5 & 4.5 & \text { Basalt } & \text { Unit A 60-70 } \\ 216 & 2.9 & 2.5 & 0.8 & 7.5 & \text { Basalt } & \text { Unit B 0-34 } \\ 127 & 2.8 & 3.0 & 0.9 & 9.8 & \text { Basalt } & \text { Surface } \\ 230 & 2.4 & 2.4 & 0.8 & 6.3 & \text { Obsidian } & \text { Unit B 50-60 } \\ 272 & 2.8 & 2.0 & 0.7 & 4.7 & \text { CCS } & \text { Unit A 107 } \\ 222 & 2.2 & 2.4 & 0.9 & 4.5 & \text { CCS } & \text { Unit B 30-40 } \\ 200 & 2.4 & 1.7 & 0.6 & 3.1 & \text { CCS } & \text { Surface } \\ 443 & 2.0 & 1.7 & 0.4 & 1.6 & \text { CCS } & \text { Unit A 80-90 } \\ 264 & 1.5 & 1.5 & 0.6 & 1.2 & \text { Basalt } & \text { Unit A 50-60 } \\ 195 & 2.0 & 1.7 & 0.6 & 1.8 & \text { Basalt } & \text { Surface } \\ 194 & 1.5 & 2.0 & 0.5 & 1.5 & \text { Obsidian } & \text { Surface } \\ 283 & 1.3 & 1.7 & 0.5 & 1.3 & \text { Basalt } & \text { Unit C 50-55 } \\ 275 & 2.3 & 1.3 & 0.5 & 1.6 & \text { Basalt } & \text { Unit C13-30 } \\ 1 & 2.1 & 1.4 & 0.5 & 1.4 & \text { Basalt } & \text { Unit A 9-20 } \\ 104 & 1.7 & 1.4 & 0.6 & 1.7 & \text { CCS } & \text { Unit A 50-60 } \\ 310 & 1.7 & 1.4 & 0.5 & 1.8 & \text { Basalt } & \text { Unit C 35 } \\ 218 & 1.5 & 1.5 & 0.6 & 2.1 & \text { Basalt } & \text { Unit B 10-34 } \\ 335 & 1.9 & 1.5 & 0.4 & 1.3 & \text { Basalt } & \text { Unit D 50-55 } \\ 318 & 1.4 & 1.3 & 0.4 & .7 & \text { CCS } & \text { Unit D 13-27 } \\ 321 & 1.1 & 1.1 & 0.4 & .7 & \text { Basalt } & \text { Unit D 13-27 } \\ 266 & 1.0 & .8 & 0.4 & .4 & \text { CCS } & \text { Unit A 70-80 } \\ 213 & 1.0 & .4 & 0.3 & .2 & \text { Basalt } & \text { Unit B 10-34 } \\ 370 & .7 & 1.2 & 0.4 & .3 & \text { Obsidian } & \text { Unit A 40-45 } \\ 311 & 2.0 & 2.0 & 0.5 & 2.0 & \text { Basalt } & \text { Unit C 35-40 } \\ 339 & 3.5 & 2.7 & 0.7 & 7.4 & \text { Basalt } & \text { Unit D 55-60 } \\ 386 & 2.0 & 1.4 & 0.4 & 1.1 & \text { CCS } & \text { Unit D 90-95 } \\ 140 & 2.3 & 1.5 & 0.5 & 1.5 & \text { CCS } & \text { Surface } \\ 389 & 1.6 & 1.3 & 0.4 & .7 & \text { Obsidian } & \text { Surface } \\ 419 & 3.8 & 2.3 & 0.4 & 3.5 & \text { CCS } & \text { Surface } \\ 445 & 3.2 & 2.8 & 0.8 & 11.5 & \text { Basalt } & \text { Surface } \\ 489 & 3.0 & 3.6 & 1.0 & 12.7 & \text { Basalt } & \text { Headlee 50-60 } \\ 491 & 4.6 & 3.1 & 1.0 & 14.2 & \text { Basalt } & \text { Headlee 5urface } \\ & & & & & & \end{array}$


61

484

492

387

493

327 $\begin{array}{ll}2.8 & 1.7\end{array}$

$1.4 \quad 1.6$

$2.5 \quad 3.2$

$\begin{array}{ll}1.6 & 1.1\end{array}$

$3.5 \quad 1.5$
$0.5 \quad 0.9$

$0.4 \quad 1.0$

$1.3 \quad 2.7$

0.4

$\begin{array}{ll}0.5 & 14.9\end{array}$
CCS

CCS

CCS

Basalt

Basalt
Headlee Surface

Headlee 0-20

Surface

Headlee 0-20

Unit D115-120

\section{GROUP XII}

This group contains large, roughly flaked bifaces(Figure 41).

No. of specimens: 7

Description: Large, rough, vaguely point-shaped bifaces. Massive, thick in cross section, large percussion flake scars, all but one of basalt. No. 263 is of green jasper, shows a large percussion cone below remnant of striking platform. These artifacts appear to be unfinished.

Dimensions:

Cat. No. L $\mathrm{W} \quad \mathrm{Th}$ Wt Material Found

$\begin{array}{rrrrrll}263 & 7.1 & 4.8 & 2.1 & 63.4 & \text { CCS } & \text { Unit A 52 cm } \\ 280 & 6.2 & 3.1 & 1.8 & 24.2 & \text { Basalt } & \text { Unit C 35-40 } \\ 185 & 5.3 & 3.1 & 1.0 & 15.5 & \text { Basalt } & \text { Surface } \\ 356 & 4.9 & 3.1 & .9 & 14.5 & \text { Basalt } & \text { Unit D 78 } \\ 395 & 5.4 & 3.3 & 1.5 & 21.9 & \text { Basalt } & \text { Surface } \\ 116 & 6.8 & 4.5 & 2.6 & 68.1 & \text { Basalt } & \text { Surface } \\ 136 & 6.4 & 3.6 & 2.6 & 59.6 & \text { Basalt } & \text { Surface }\end{array}$




\section{OTHER ARTIFACT CLASSES}

In addition to projectile points, other artifact classes in the assemblage include flake blanks, scrapers, edge-modified cobbles, hammerstones, bifaces, utilized flakes and cores.

\section{Flake Blanks}

Conspicuous for their size and shape are eight large flake blanks that could also have been utilized as flake tools. These artifacts range in length from 6.7 to 9.6 centimeters and do not appear to have had unifacial or bifacial edge alteration. They are distinctive for their curvate shape, smooth ventral surface and ridged dorsal surface. Three are of CCS and five of basalt. Edges are typically sharp, but use-wear analysis has not been conducted on any of the Burnett site artifacts. These flakes are similar to those found in Rice's Category 9 (utilized flakes) of Windust Phase artifacts (Rice 1972) (Figure 42).

\section{Scrapers}

Ten artifacts identified as scrapers were recovered. They are generally of broad, oval outline, of thick triangular cross section, with the ventral side a smooth, single fracture surface. Most edges are unifacially flaked and have evidence of use. Edge angles range from 30 to 80 degrees. One is basalt, nine are CCS (Figure 43). 


\section{Hammerstones}

One large hammerstone measuring $12.5 \times 8.6$ centimeters was found on the surface beside the house foundation. This artifact has minor end battering, but has pronounced areas of damage on alternate sides near the ends. It is similar to hammerstones used in bipolar flake manufacture (Figure 44).

\section{Edge-Modified Cobbles}

Included in this category are 10 edge-flaked cobbles or cobble flakes. Eight are unifacially flaked and two are bifacially flaked. Nine are of basalt and one is of a chert-like material. No edge ground cobbles were noted Figures 44, 45).

\section{Utilized Flakes}

The collection includes numerous flakes which probably were utilized opportunistically. These flakes have not been classified or analyzed.

\section{Blade Knife}

A thin narrow flake of a material resembling agate is distinctive for its sharp edges. This unusual piece has a smooth ventral surface with a pronounced percussion bulb and a platform remnant. It does not appear to have been modified after removal from its core. The dorsal surface bears flake scars from previous flaking. Dimensions: 9X2.6X.9 centimeters(Figure 46). 
Net Weight

One grooved cobble, similar to artifacts known as net weights along the Columbia River, was found on the surface at the Headlee site after the property had been cleared and scraped. The apparent incongruity of this specimen, in relation to the total assemblage, leads to the conjecture that it may have been collected elsewhere and brought to the site, either in historic or prehistoric times.

$\underline{\text { Cores }}$

Of the 26 cores or fragments recovered, seven are of basalt, two are of andesite and 17 are of materials such as jasper, quartzite and chalcedony. Recovered cores had been used for the production of flakes(Figure 47). 
TABLE IV

NUMBER OF EXCAVATED PROJECTILE POINTS AND BIFACES BY MATERIAL

250 Furnace Basalt

Unit A

8.5

Unit B

Unit C

14.0

14.5

Unit D

10.0

Diff

(Different halves of same point found in Units A and C.)

Total

47

30

5

5
Obsidian Total 1

$1 \quad 21.0$

$1 \quad 22.5$

$0 \quad 19.0$

Headlee Unit

3

80

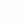


TABLE $V$

PERCENTAGE OF PROJECTILE POINTS AND BIFACES BY MATERIAL IN UNITS A, B, C, D

$\begin{array}{llll}\text { 250 Furnace } & \text { Basalt } & \text { CCS } & \text { Obsidian } \\ \text { Unit A } & 48.57 \% & 45.71 \% & 5.71 \% \\ \text { Unit B } & 66.67 & 28.57 & 4.76 \\ \text { Unit C } & 64.44 & 31.11 & 4.44 \\ \text { Unit D } & 52.63 & 47.36 & 0 \\ \text { Average } & 58.08 \% & 38.14 \% & 3.73 \% \\ \text { Headlee Unit } & 45.45 \% & 45.45 \% & 9.1 \%\end{array}$

(Above percentages computed by dividing number of points of each material by total number of points in each unit.) 

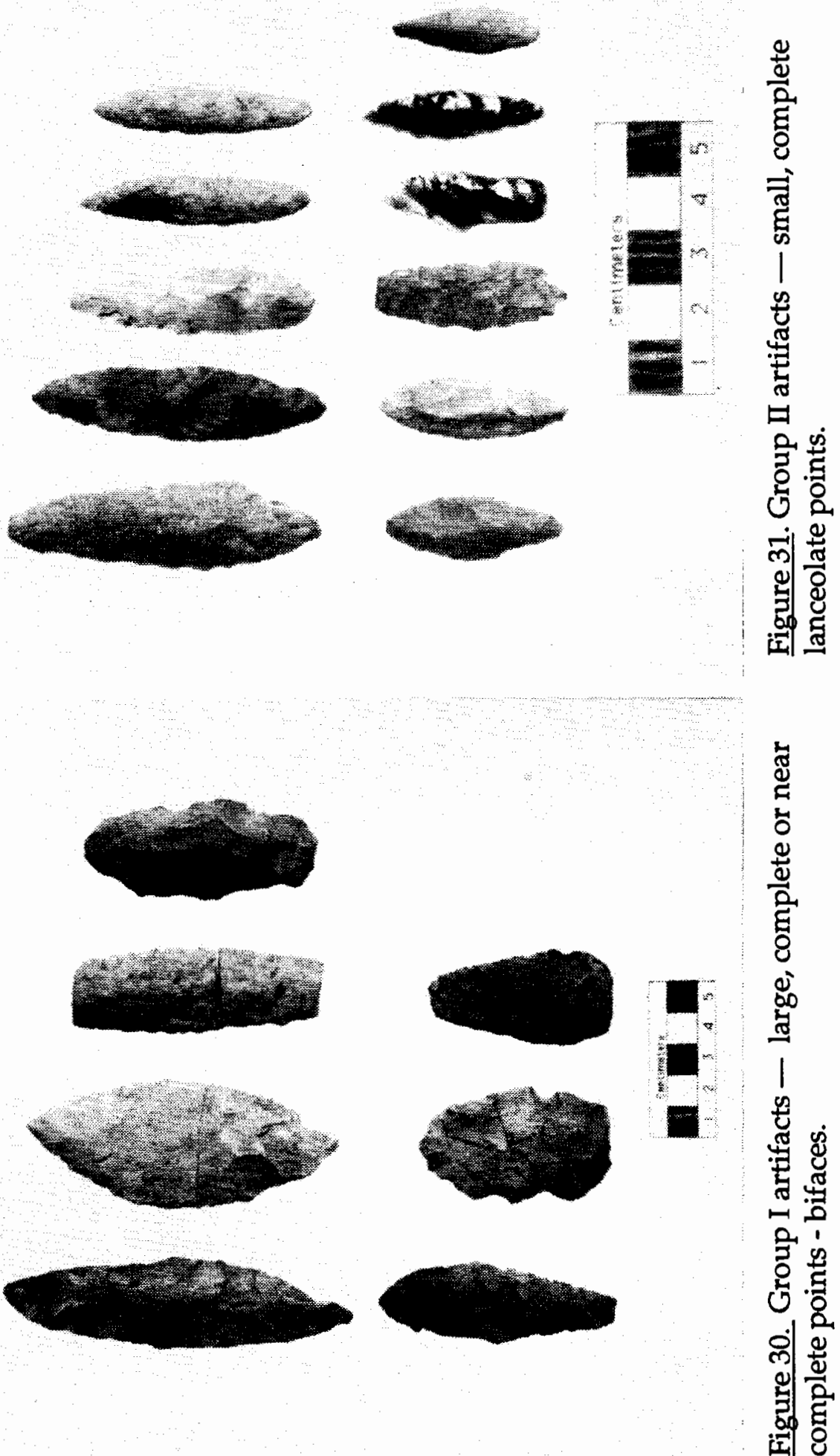

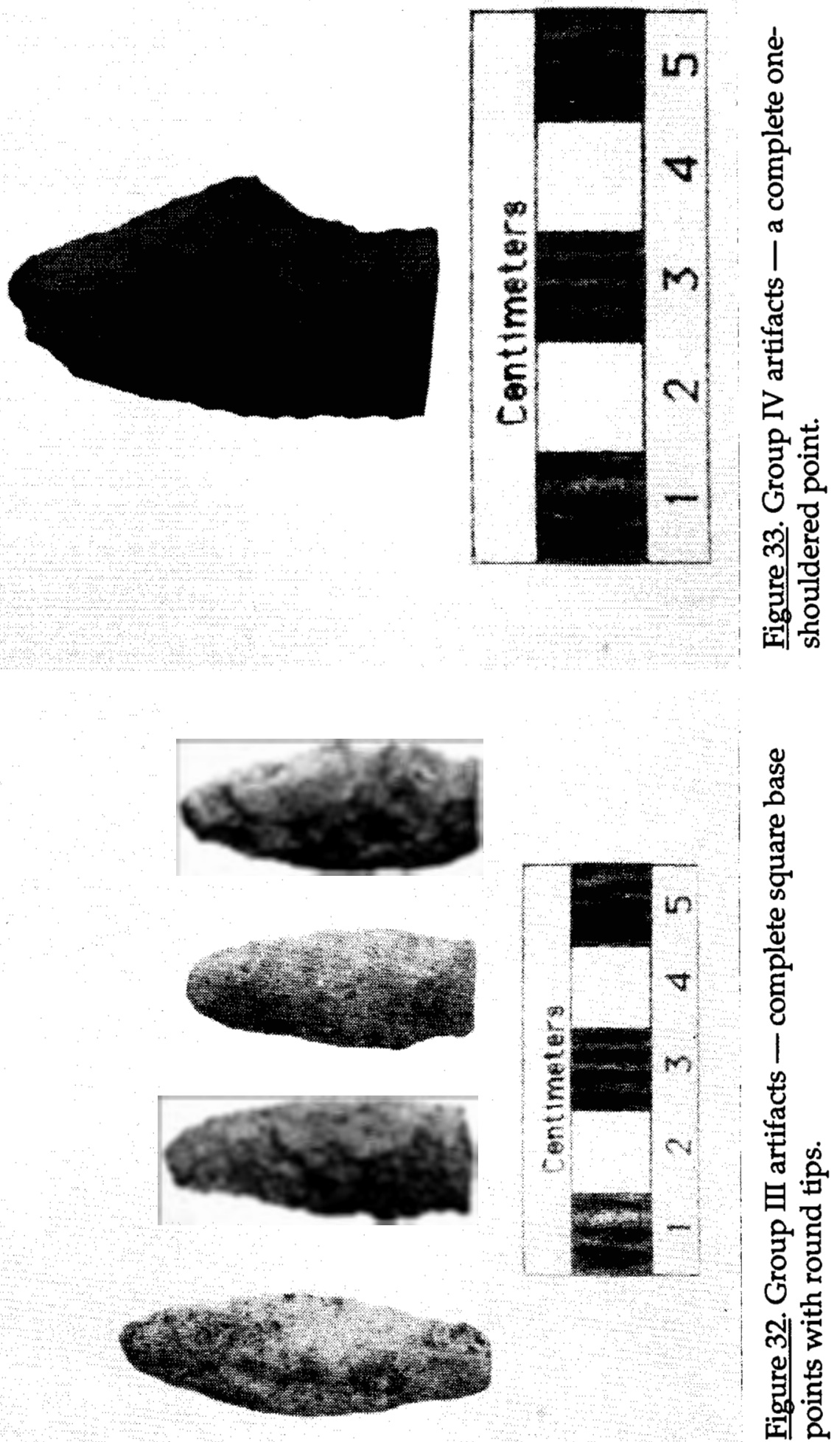

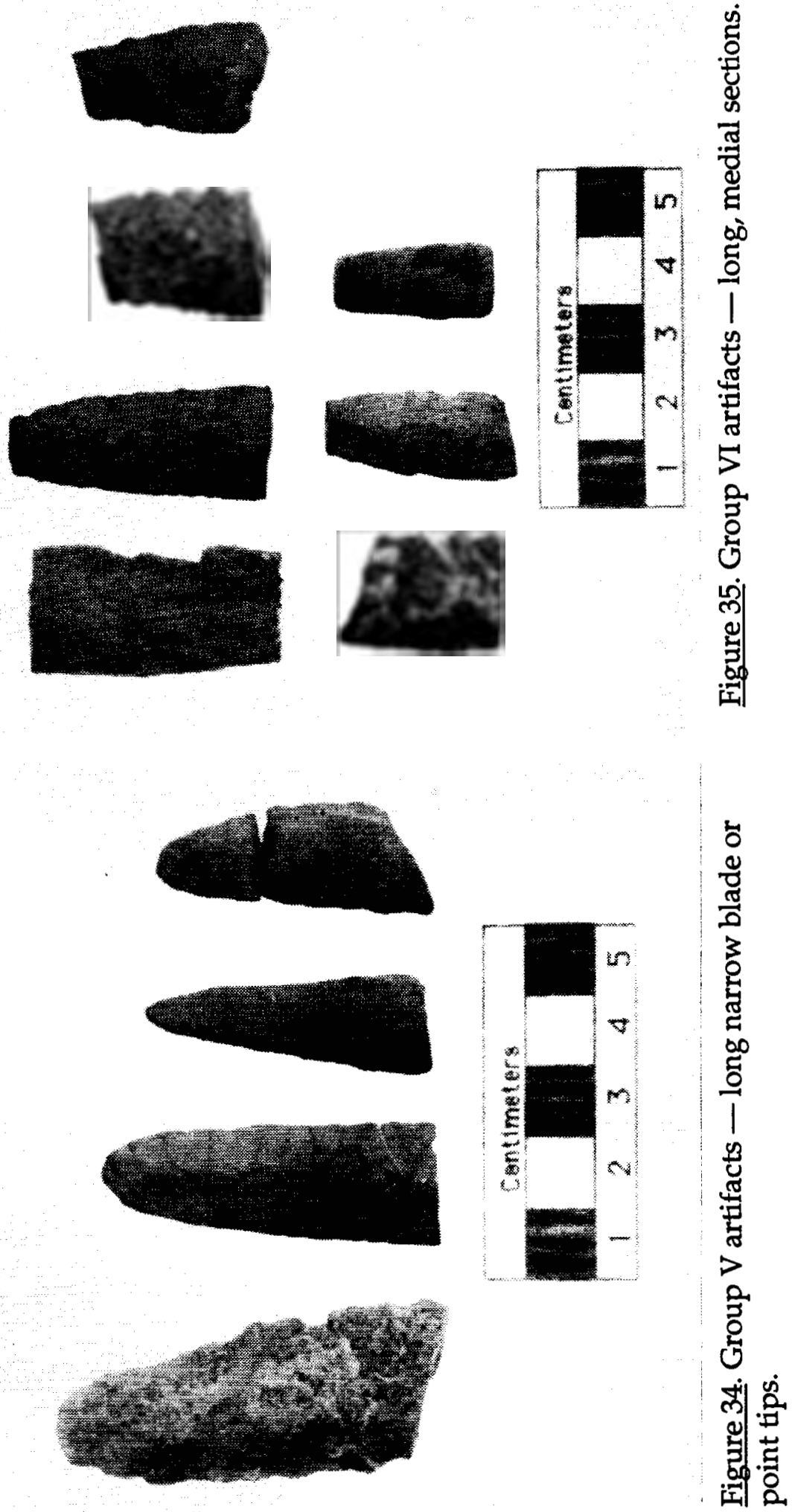

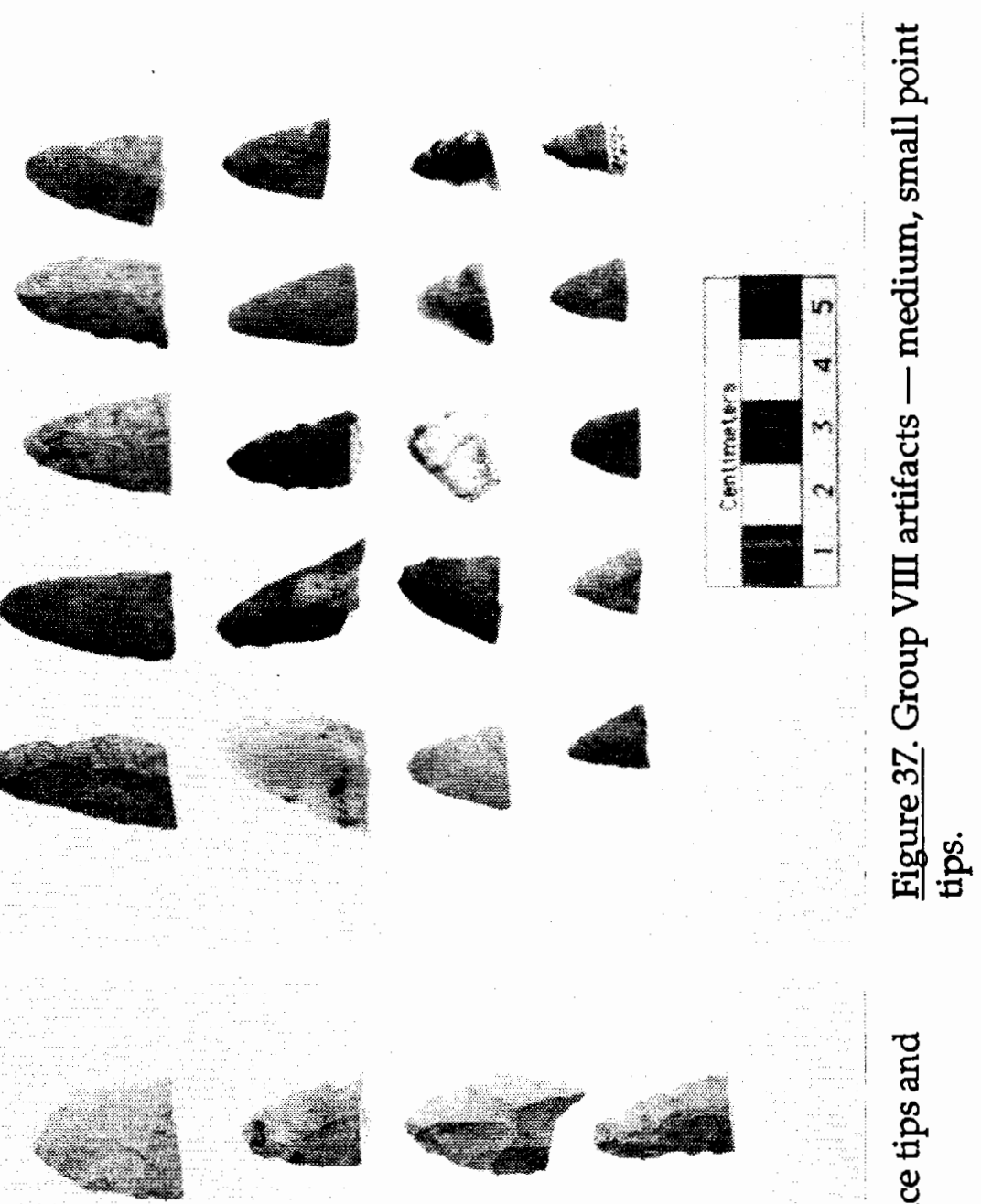

옹
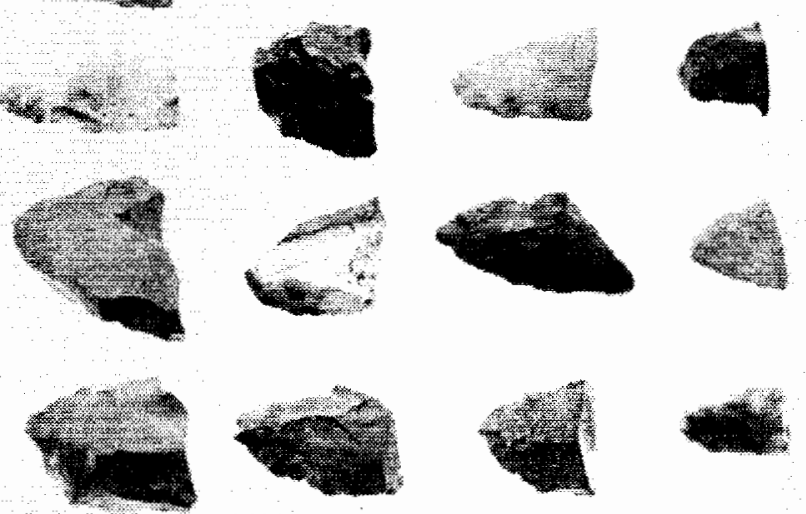

$\stackrel{8}{7}$

苋

E.

8

픈

I
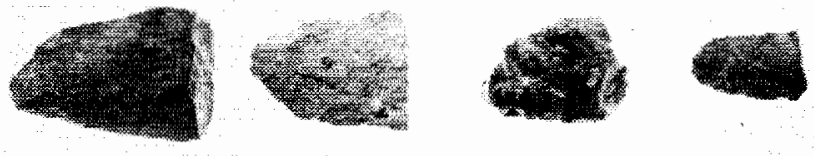

幽峦 

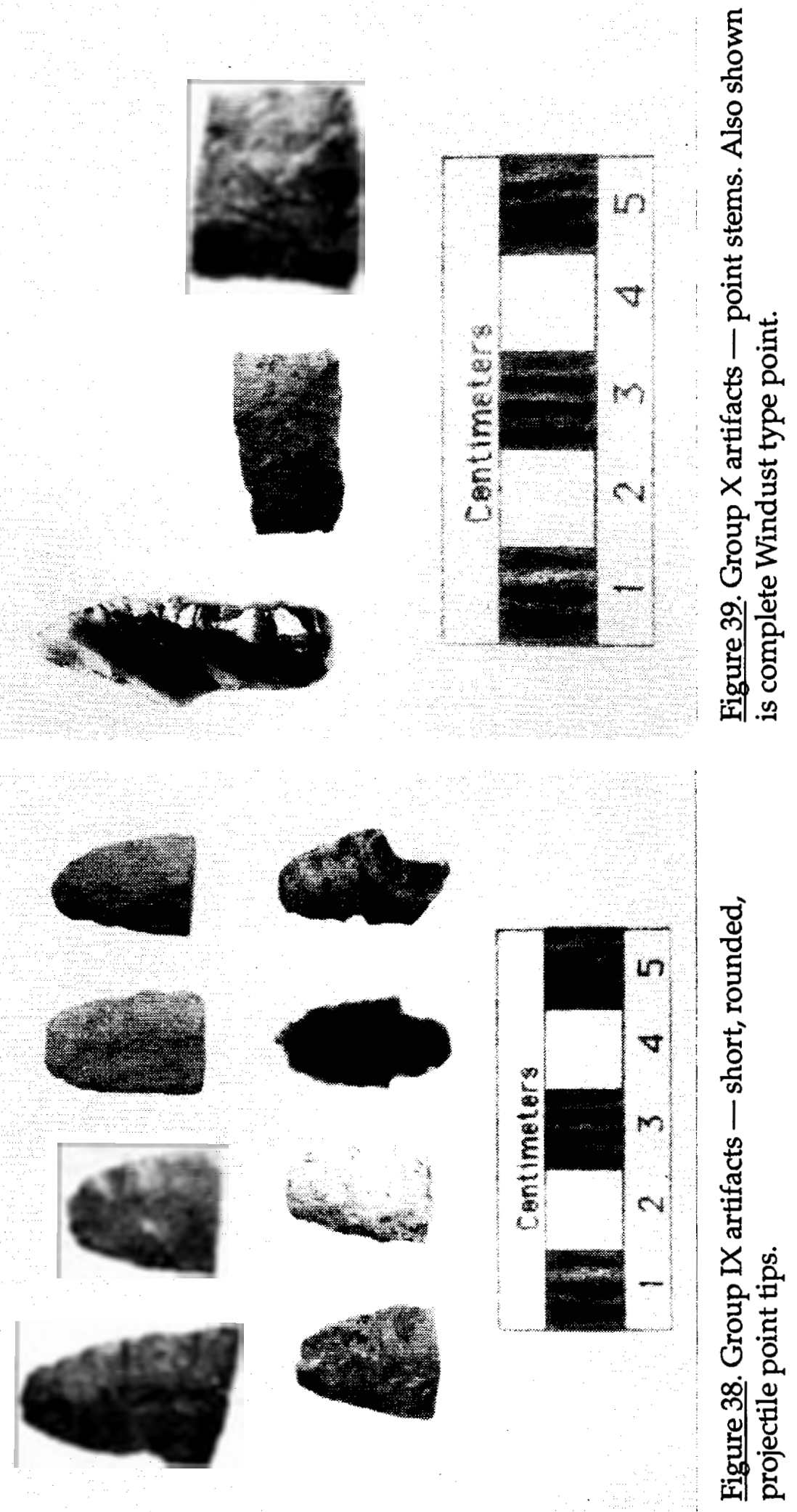

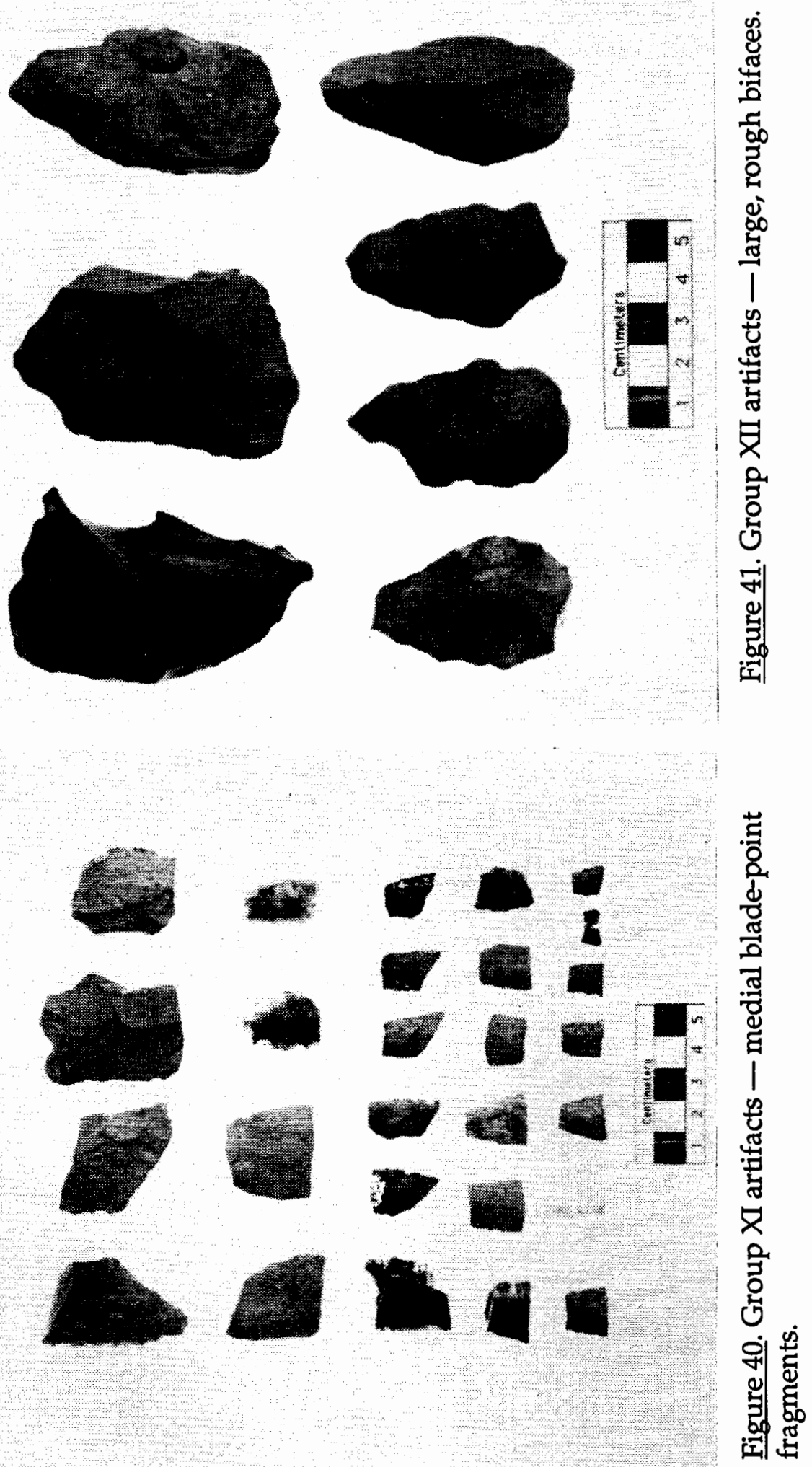

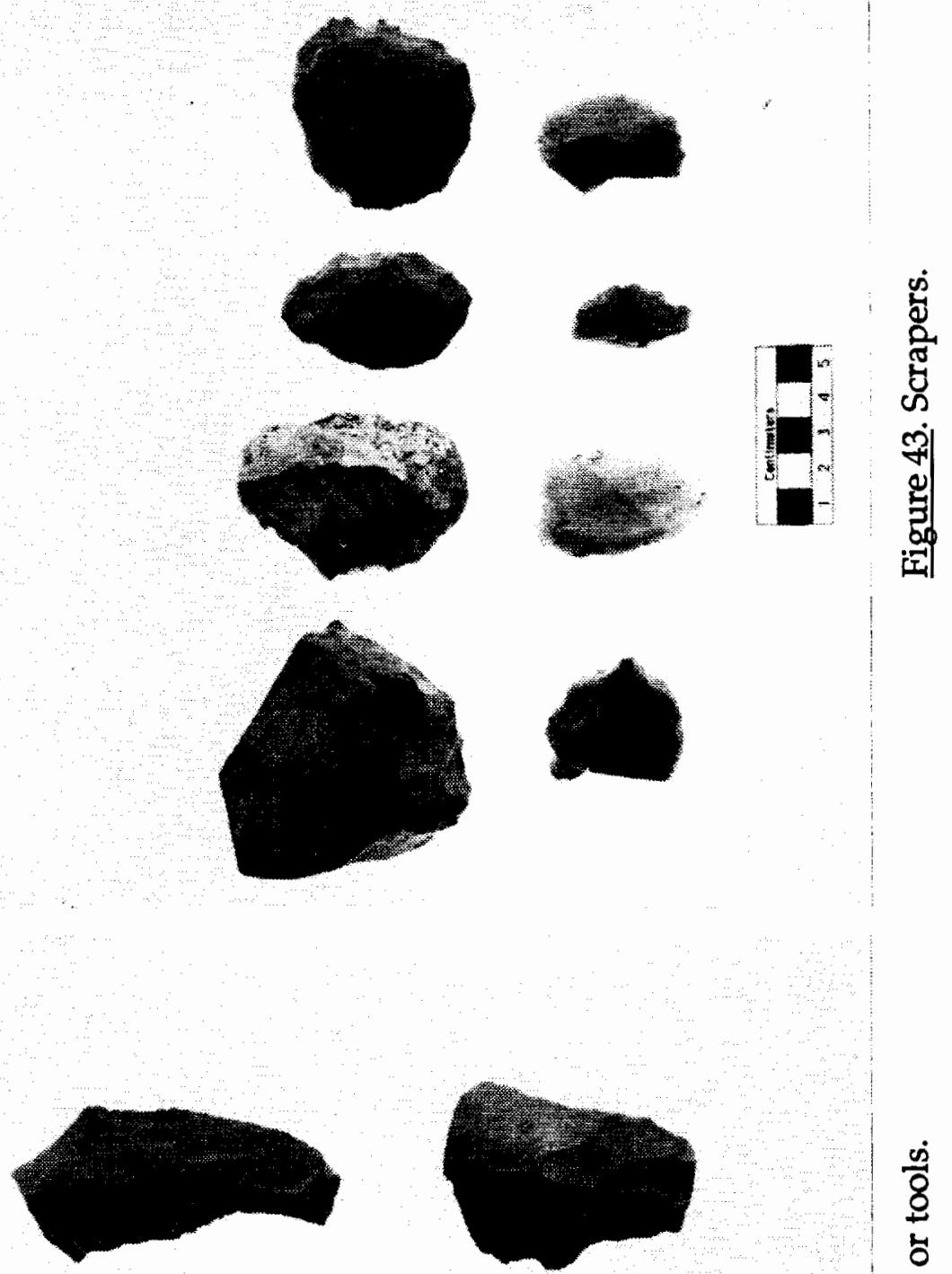

$\frac{5}{8}$
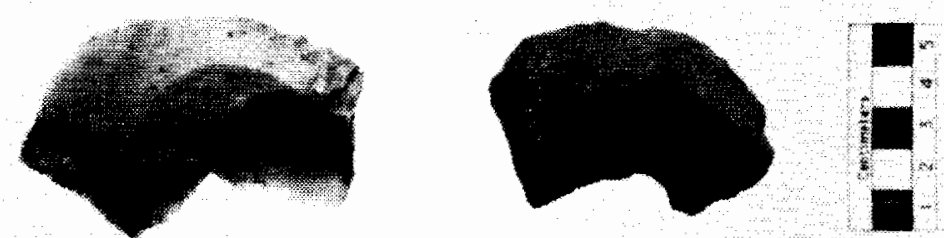

\%

F

O

苛

辣
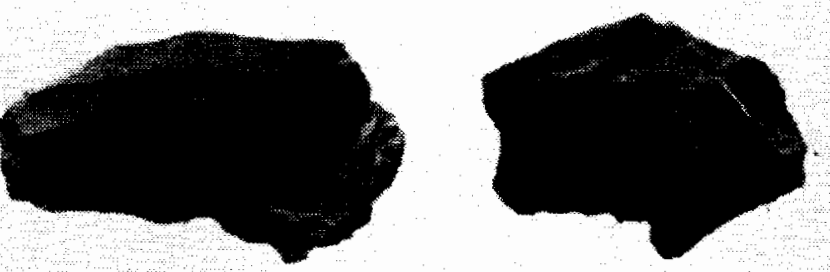

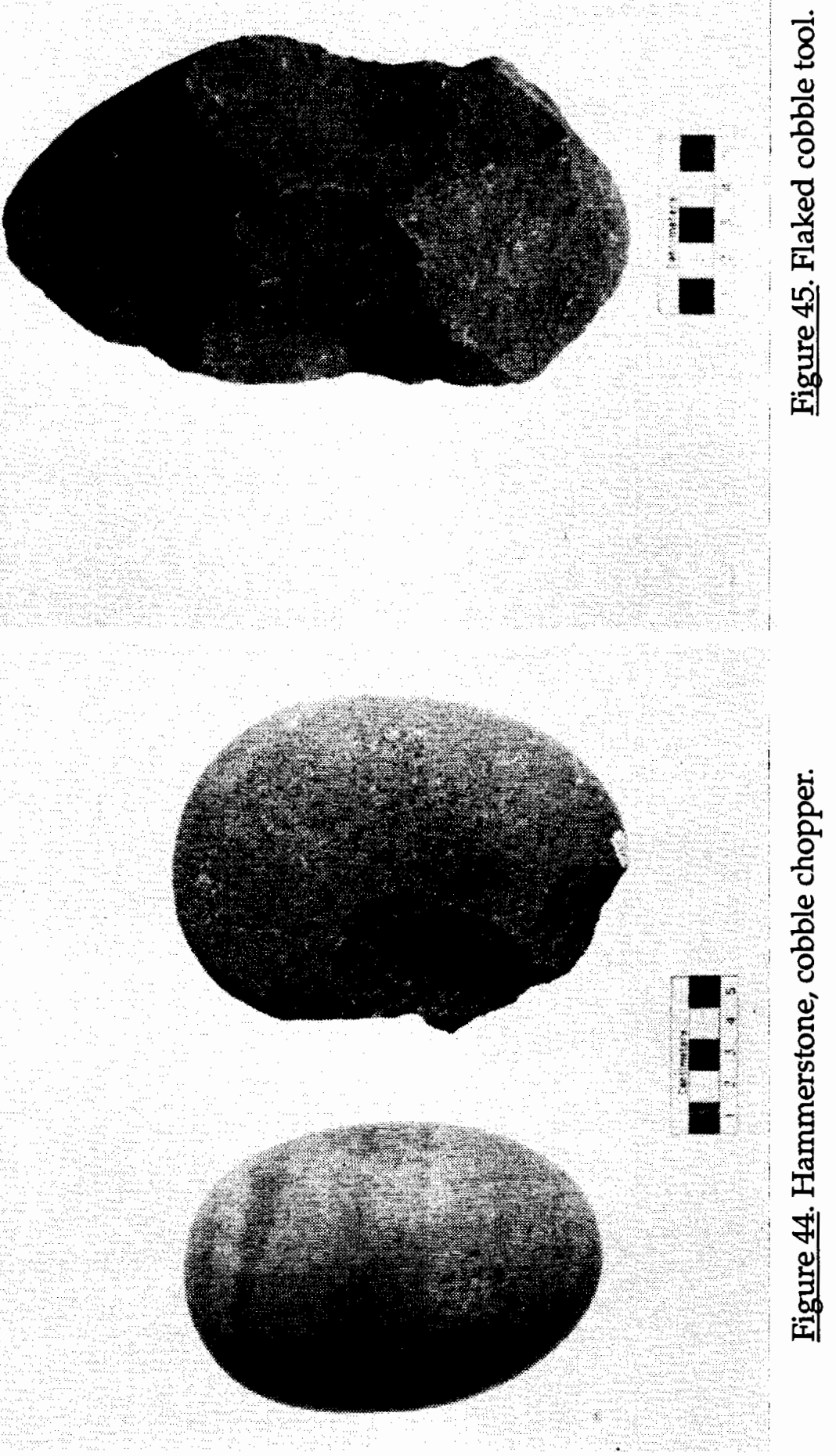

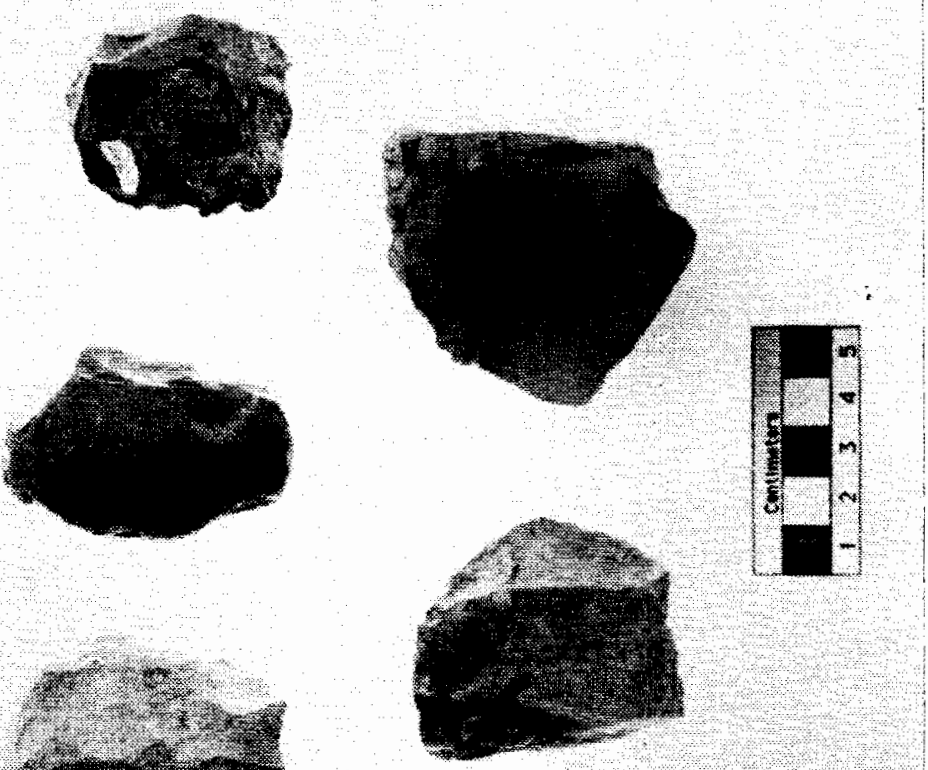

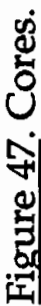
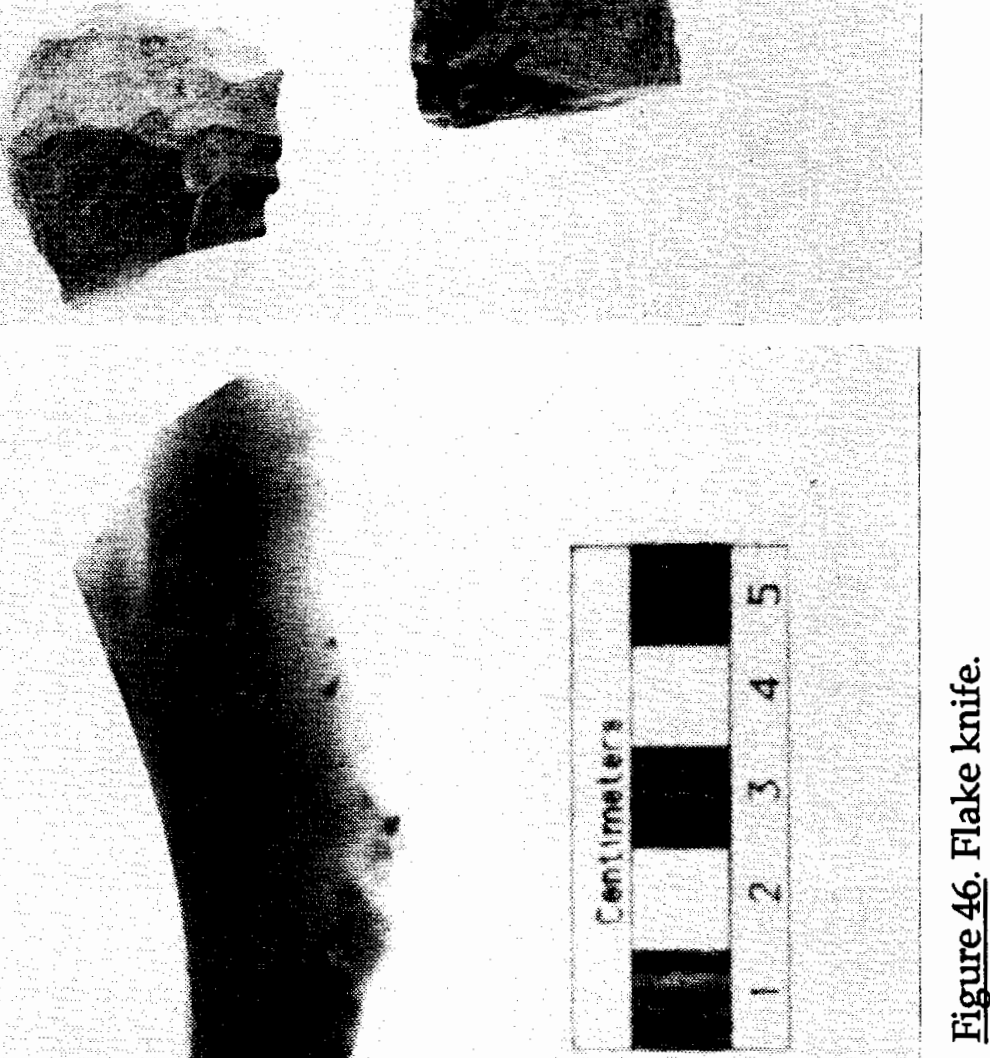

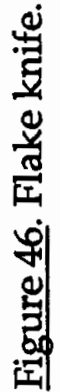

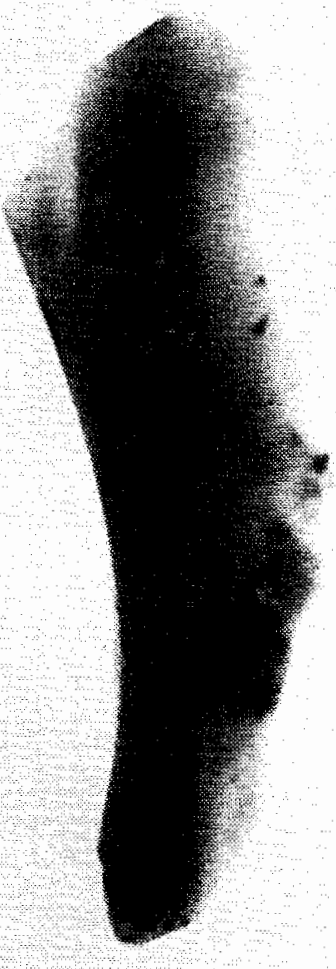




\section{CHAPTER IV}

\section{CASCADE AND WINDUST TYPE PROJECTILE POINTS}

Since 1961, when B. Robert Butler published his theory that the Old Cordilleran culture represented an early period in human occupation of the Pacific Northwest, the leaf-shaped "Cascade" projectile point has been widely used as a marker to identify archaeological sites with dates of around 8,0004,500 B.P. Leonhardy and Rice (1970) later defined the Windust and Cascade phases as the first two of six occupational phases proposed for the Lower Snake River region of eastern Oregon and Washington. They suggest dates of approximately 8,000 to 5,000 B.P. for the Cascade Phase and 10,000 to 8,000 B.P. for the Windust Phase. As the projectile point assemblage from the Burnett site contains primarily lanceolate "Cascade" type points, Butler's concept as it applies to western Oregon, Washington and British Columbia is considered here.

The Cascade Phase concept has since been extended to areas west of the Cascade Mountains where it has been cited as representing Butler's Old Cordilleran Culture (Daugherty, Flenniken, Welch 1987). Manifestations of the Old Cordilleran were found at the Glenrose Cannery site in British Columbia and dated to $8,500-5,500$ B.P by Matson (1976) who sees it as distinguished from earlier cultures by the rarity of stemmed projectile points. Fladmark (1982) characterizes major Old Cordilleran components dating between about 5,000 and 9,000 B.P. on the southern British Columbia coast as 
producing leaf-shaped and occasionally contracting stem bifaces and points, flake tools and cores, large blade-like flakes, pebble tools, cortical spalls and rare abrasive stones. He also includes the apparent absence of microblades and any significant pecked or ground stone.

Butler, in his theory published in 1961 and only slightly modified since then, views the Pacific Northwest as inhabited during the early period by a people with a common culture and adaptation. He theorizes that the culture arrived in the Pacific Northwest not more than 12,000 years ago and persisted relatively unchanged until the end of the Altithermal period about 4,000 B.P. Its identifying feature is the leaf-shaped Cascade-type projectile point which appears "to have been the chief diagnostic implement of an unspecialized hunting-gathering culture which appeared on the scene in the Pacific Northwest at or near the end of the Late Pleistocene" (Butler 1961).

While the basic culture is marked primarily by the bipointed Cascade projectile point, Butler notes that other evidence includes a "generally nondistinctive assortment of cutting, chopping and scraping instruments, all made of stone." To this he adds bone tools, edge ground cobbles and a broadbased diet that included deer, elk, birds, fish, mussels and root crops (Butler 1965). Cascade and northern side-notched points of the period between 8,0003,000 B.P. often occur together but Cascade points are believed to have appeared considerably earlier on the Columbia Plateau (Aikens 1986). Butler's hypothesis came under heavy criticism, especially for its connotations of a widespread culture. His recognition of the Cascade type projectile point and its place in human chronology in the Northwest still forms a basis for study of early archaeology of this area. 


\section{THE CASCADE POINT IN WESTERN OREGON}

While much of the attention to the Cascade point and the Old Cordilleran concept has been focused on the Columbia Plateau and the areas east of the Cascade Mountains in Oregon, the presence of the points on the western side of the Cascades is receiving increased interest.

Evidence of man's earliest presence in western Oregon, ascribed to around 11,000 B.P. or earlier, is based primarily on a Clovis-type projectile point found near Springfield, and one or two other putative finds of a similar nature (Aikens 1986). In general, however, the sites of greatest antiquity in the area are dated by the Cascade point, primarily by reference to Newman's (1966) radio carbon date of $7910+-280$ produced by material from the lower levels of Cascadia Cave. In the western Cascades area, it is the only point representing the period 8,000-6,000 B.P. ( Newman 1966, White 1979, Woodward 1972), again generally based on morphological similarities with points found in the dated context of Cascadia Cave.

Sites in the southwestern mountains of Oregon also have produced Cascade points typologically dated to 8,000 B.P. by comparison to points of that period from the Columbia Plateau (Aikens 1986). They are also found, together with other point types, in sites carbon dated 6,000 B.P. and later in the Willamette Valley (White 1979, Pettigrew 1980, Toepel 1985). As White (1979) states, citing Cole (1968), Cascade and side-notched points may represent a long-standing cultural tradition that began early and persisted into more recent times in the Willamette Valley area.

The Portland Basin area has produced scattered evidence, but no sites, indicating occupation of this area long before 2,500 B.P., the date given the 
Marybell phase and marking the beginning of the formally-defined sequence (Aikens 1986). This pre-Marybell period has as one of its indicators a few large, lanceolate, leaf-shaped and stemmed points, including points similar to those of the Windust and Cascade phases of the Columbia Plateau. The Merrybell phase (2,500-1,750 B.P.) is characterized by medium sized sidenotched, corner-notched and lanceolate points with broad stems (Aikens 1986).

The two Western Oregon sites most important for assemblage comparisons to the Burnett site are Cascadia Cave and the Geertz site (Table VI).

\section{Cascadia Cave}

Cascadia Cave (Newman 1966) is the best documented of the three known sites in western Oregon which have components relating exclusively to the Cascade Phase of 8,000 to 6,000 B.P. Indeed, as Minor (1981:165) states, the cultural content of this period, which he calls the Cascadia Phase, is based almost entirely on the artifact assemblage from Cascadia Cave.

In 1981, Cascadia Cave, Baby Rockshelter (Olsen 1975) and the Geertz site (Woodward 1972) were the only Early Archaic assemblages in the Willamette basin. Early Archaic sites in the area now include those reported by Snyder (1981); Cheatham (1988); O'Neill (1989); and Peterson (1989), but as Baxter(1989) notes, Cascadia Cave remains the best known and best dated early occupation in the Willamette Basin and would still be selected as the type site for the Cascadia Phase. Given its premier position in western Oregon archaeology, Cascadia Cave is vital to the investigation of the Burnett site.

The site is on a terrace above the South Santiam River east of Sweet Home, Oregon. It was first tested by Dr. L. S. Cressman of the University of 
Oregon in 1937. Excavations by Dr. Thomas M. Newman of Portland State University in 1964 (Newman 1966) provided basic data and the site was reexamined in 1988 by Paul Baxter of Heritage Research Associates, Inc. as part of a National Register of Historic Places nomination (Baxter 1989).

Newman found the site considerably disturbed but his excavations to a depth of 2.1 meters below the surface produced approximately 400 artifacts, and more than 300 modified flakes. The artifact assemblage from all levels includes Cascade-type, side-notched and stemmed projectile points, knives, drills, scrapers and a few ground stone objects (Newman 1966).

Newman established the initial occupation of the cave at 8,000 B.P. based on a carbon date of $7910+-280$. The dated charcoal was found immediately above the cave floor in exclusive association with Cascade-type projectile points. The radiocarbon date for the charcoal at Cascadia Cave "is consistent with the majority of other dates associated with Cascade points" (Newman 1966:23).

The most common and principal diagnostic artifacts found by Newman at Cascadia Cave are what he identifies as Butler's (1961) Cascade projectile points. This point was recovered from all areas of the site and in all levels excavated, but is the only point type found in the lower 80 centimeters of the excavations.

Newman also recovered 27 side notched points, one stemmed point and one lanceolate point from Cascadia Cave. He states that the Cascade point is early and is stratigraphically lower than the side notched points. While he does not give specific figures, he does say that the side notched points first appear in small numbers in the middle levels and become numerically more important in the more recent levels (Newman 1966). The date when the 
side-notched point was introduced at Cascadia Cave is not well established. Newman cites Cressman (1960) and Butler (1961) as authorities that sidenotched points are later than the Cascade points at most sites in the Northwest and that the Cascade point may have been widespread in the region by approximately 6,000 B.P. The concentration of side-notched points in the upper six levels of the shelter and in another test area just outside the shelter, combined with their appearance elsewhere in the Northwest as cited above, lead Newman to estimate that side notched points may be dated at 6,000-5,000 B.P. (Newman 1966). Side notched points became common the the Columbia Plateau after 6,900 B.P.

In short, in the lower 80 centimeters of the Cascadia Cave excavation only Cascade-types were found. Above 80 centimeters, both Cascade-type and side-notched were recovered.

In his report on a 1988 excavation at Cascadia Cave, Baxter(1989) notes that the team excavated a total of 5.4 cubic meters from a $1 \times 2$ meter test pit. (One half of the test pit was excavated to 1.7 meters, the other half to 3.7 meters.) Thirteen auger holes also were bored in searching for undisturbed areas. Baxter recovered 396 tools and 10,349 pieces of debitage from his excavation (Baxter 1989).

Radiocarbon analysis of charcoal produced dates of $4920+-120$ B.P at a depth of 170 centimeters and 6,360+-210 B.P from composite samples taken from the three lowest levels excavated at 350,360 and 370 centimeters. The project revealed that the site contained extensive undisturbed cultural deposits to a depth of nearly four meters and perhaps deeper. The two radiocarbon dates add a perspective on the occupational dates of the site and the study verifies the continuing archaeological importance of Cascadia Cave. 
The collection included seven projectile points and 36 fragmentary specimens. The assemblages from Cascadia Cave and the Geertz site will be compared with 35CL96 in a later section of this thesis.

\section{Geertz Site}

Less well known than Cascadia Cave, but important in its own right, the Geertz site is near the town of Sandy about 20 miles southeast of Portland. The site is in an open field at an elevation of 560 to 605 feet above sea level. It was excavated in 1971 by archaeology students from Mt. Hood Community College (Woodward 1972).

The excavations recovered 319 stone artifacts and more than 2,000 waste flakes, including 54 identifiable complete and fragmentary projectile points, 37 of which are classified as "a rather homogeneous collection of finely bifacially flaked Cascade-type willow leaf to bipointed forms" (Woodward 1972). Also recovered were scrapers, drills, knives choppers, cores, a chisel graver, a cleaver, used flakes and miscellaneous flaked stone pieces, many of them fragments of tools. Woodward suggests that the Geertz site was not occupied after 4,000 B.P. and may be as much as 8,000 years old, based on the presence of Cascade-type points and the absence of large side-notched points or other forms (Woodward 1972).

\section{Other Sites}

The Ripple site in the Upper Clackamas River area is given an initial occupation date of between 8,000 and 7,000 years B.P. and a probable terminal date of 6,000 B.P. (Lebow 1985). These dates are based on what Lebow calls the remarkable similarity between the projectile point assemblage from Cascadia Cave and nine of the 14 complete points recovered from the Ripple Site. The 
morphological similarities between points found there and those of Cascadia Cave, the predominance of lanceolate points and the relative scarcity of sidenotched points are factors cited in dating the Ripple site.

Other important regional sites include Layser Cave and the Judd Peak rockshelters in the western foothills of the Cascade Mountains in southwestern Washington. These sites produced earliest radiocarbon dates of 6,650+-120 B. P and 5,970+-100 B. P., respectively. Similar assemblages of microcores, microblades and dart points were found at both sites (Daugherty, Flenniken, Welch 1987).

Points found at Judd Peak rockshelters included Windust-type, Cascadetype and small triangular arrowheads. The scarcity of the Windust-type points and their scattered distribution in the site lead to the belief that they are evidence of an early Windust stemmed point culture in the area. Points from the culture could have been found and used by later occupants. The Late Cascade type points were in use at Judd Peak and Layser Cave for perhaps 7,000 years. Small, triangular arrowheads were introduced sometime after 2,000 years ago (Daugherty, Flenniken, Welch 1987).

\section{CHRONOLOGY AND PROJECTILE POINT COMPARISONS}

Where features such as cooking hearths, firepits or other burned cultural material are found in an archaeological context, the age of the site can often be determined with reasonable accuracy through radiocarbon analysis of the accompanying charcoal. At Cascadia Cave, the date of 7910+280 B.P was obtained from charcoal recovered from near the bottom of the excavation (Newman 1966). 
At the Burnett site and the Geertz site, archaeological excavations uncovered no features that could provide charcoal to be used for radiocarbon dating. While obsidian hydration also can be used to date artifacts, funds for this analysis have not been available for use on Burnett site specimens.

Sites also can be dated by comparing the assemblage to other reported assemblages on the basis of chronologically sensitive artifact types (Pettigrew 1980). Newman, in the Cascadia Cave report, states that projectile points are the most important artifact type for comparative dating because they are diagnostic, can be compared with similar distinctive forms found elsewhere in the Northwest and have chronological and cultural significance.

Cascadia Cave's most distinctive type, the Cascade point, is of particular value because it is earlier and stratigraphically lower than the side-notched points found there and in other parts of the Northwest.

Butler (1961:28) describes Cascade points as:

generally long, narrow, leafshaped or bipointed items which tend to be quite thick in proportion to their width and are usually thickest above the butt end; none shows evidence of basal thinning. A number have a fairly prominent bulb of percussion at or near the butt end, which may indicate these had been made from a flake that was struck from a prepared core. Most of the points are diamond shaped in cross section, particularly above the butt end....

However, as Sampson (1985) points out:

Butler's Cascade Point allows wide variation in size and shape: bases may be rounded or pointed and cross sections may be lenticular or diamond shaped. Slight shouldering is also permitted. There are no specific limitations placed on length, weight or other metric ratios. This is broad enough to accommodate almost any bifacially worked unstemmed point and it can be used as a catch-all for any but the smallest and broadest specimens. Its breadth/length ratio grades into the Blade/Knife categories, and specimens as short as $37 \mathrm{~mm}$ have been admitted to the category. 
This section compares Cascade-type projectile points from Cascadia Cave, Geertz and Burnett sites on the basis of form, material, size and technology.

\section{Form}

Cascadia Cave. Newman describes the Cascadia Cave Cascade points as having at least four forms with the following characteristics:

1--Plano-convex in cross section. 2--Thicker, diamond-shaped or thickly lensatic in cross section--most have this type of cross section. 3--Tips not necessarily sharply pointed, bases are usually distinctly rounded, conforming generally to the form of "willow leaf"; a majority of the points are made in this outline form. Points are smoothly curved from base to tip, have serrated or even edge. 4--Lack even outline, have insets and irregularities, many apparently deliberate. Most are quite thick. He suggests that this is a variant of the more characteristic Cascade point. The majority have moderately even edges, but nine are serrated. Points are made with care and many show small, distinct, approximately parallel flake scars.

Geertz Site. The Geertz site point assemblage (Woodward 1972) is called a rather homogeneous collection of finely bifacially flaked Cascade-type willow leaf to bipointed forms. Woodward noted edge serration on 19 of the 54 specimens. The cross sections range from lenticular to prismatic; most points appear to have been made on prismatic flakes which were thinned by pressure flaking. Basal thinning is not extensive; two examples show slight basal grinding.

Burnett Site. Many of the fragmentary tips-bases recovered from the 
Burnett site are rounded as Newman noted of the points at Cascadia Cave. In contrast, most of the complete Cascade-type points recovered are bipointed. Only one, catalog number 208 , has a rounded base. In shape, the points range from willow leaf to bipointed, as at the Geertz site. Based on form alone, projectile points from the Burnett site belong to the Cascade-type category as defined by Newman for Cascadia Cave and Woodward for the Geertz site (Table VII).

\section{Comparisons: Raw Material}

The projectile point-biface assemblage from the Burnett site varies from that of the Geertz site and Cascadia Cave in its material (Table IX). At the Geertz site, 1.85 per cent of the points were of basalt, while there are no basalt points in the extant Newman collection or in the Baxter collections from Cascadia Cave. Basalt points make up an average of 58.08 per cent of the 250 Furnace St. excavated point-biface assemblage, while both CCS and obsidian point percentages are less than those of the Geertz and Cascadia Cave sites. Remarkable are the very similar percentages of the projectile point raw material in the Geertz site collection and extant Newman collection from Cascadia Cave. This similarity may reflect the upland locations of these two sites and the availability of similar raw material. The Burnett site, on the other hand, is at a lower elevation where basalt is the most abundant raw material (Table 8).

\section{Comparisons:Size}

Burnett site complete points tend to be larger than those at Cascadia 
Cave and the Geertz site in both length and width, but comparable in thickness ( Table IX).

In analyzing the style of the Ripple points, Lebow (1985) compared their length/width ratio with the same ratio of what he called "true" Cascade points from Granite Point in the Southern Columbia Plateau and points from Cascadia Cave, Cougar Mountain Cave and site 35JA52 in southwestern Oregon as shown in Table XVI. The length/width ratio of complete lanceolate points from the Burnett site is included for comparison (Table 10).

Among the sites studied, Lebow (1985) states that only the Cougar Mountain Cave lanceolate points are similar to the "true" Cascade points from Granite Point. He sees the Ripple, Cascadia Cave and 35JA52 points as not similar to the Granite Point and Cougar Mountain points, but similar to each other. Lebow notes as especially interesting what he calls the extremely low level of similarity between the Ripple site points and the Granite Point and Cougar Mountain points and the high level of similarity between the Ripple points and the Cascadia Cave points.

From these differences in length/width ratios, Lebow concludes that the Ripple site does not contain Cascade points, but does contain points that are very similar to the lanceolate projectile points from Cascadia Cave which date to 8,000 years B.P.

The difference between the length/width ratio of the points from the Burnett site and the "true" Cascade points from Granite Point is .67. The difference between the Ripple points and those from Granite Point is .64. Following Lebow's reasoning, this would exclude the Burnett site points from the "Cascade" category because they are as much larger than those of Granite Point as the Ripple points are smaller. 
However, Nelson (1969), in establishing the characteristics of the "true" Cascade point, found that the length/width ratio commonly ranges from 2.4 to 4.0, although specimens occasionally have a length/width index as low as 2.2 and as high as 4.4. Points from the Ripple site, Cascadia Cave, Cougar Mountain Cave, 35JA52 and the Burnett site all fall within the range established by Nelson. Under the Nelson length/width ratio system, Burnett site points can be considered as fitting the Cascade category.

On the other hand, use of the length/width ratio method of analysis to compare and categorize points is somewhat questionable unless the degree of completion of the points analyzed is taken into account. An unfinished point, for example, may have a length/width ratio considerably different from the average of the finished points common to a particular locality. Also to be considered is the likelihood that the length/width ratio is a function of the extent that points are reworked or resharpened after the original point is damaged or broken. Workability of the raw material also may be a factor in establishing the length/width ratio of points. The ratio system may not be a valid test in cases in which the point has been worked down from its original size.

\section{Lithic Technology}

Geertz site. Woodward (1972) describes the flaking methods as including both percussion and pressure techniques. Projectile points show evidence of refined pressure flaking which allowed the controlled removal of small parallel chips to produce either an even or serrated edge. Tools were manufactured from prismatic and tabular flakes and the surface of many chalcedony artifacts indicates heat treating. 
Cascadia Cave. Newman (1966) concludes that there is no evidence that prepared cores were extensively used at Cascadia Cave. He states that flakes intended to be made into points or tools may or may not have been struck from cores, but some were made on plano-convex flakes that have a marked curvature and a series of ripple marks. Flakes of this type are not likely to have been struck from a prepared core. Few cores were recovered and those that were did not bear evidence of a prepared striking platform. Newman believes that it is more probable that flakes or blanks were imported and final flaking accomplished at the site. The majority of the points could have been made on lamellar flakes, although Newman saw no direct evidence to support this theory. Scrapers and knives also are generally made on plano-convex flakes (Newman 1966).

A significant number of the points are pressure flaked. Newman concludes that the larger pieces and those made from basalt or other intractable material were percussion flaked and have little pressure retouch. The smaller points and those of obsidian tend to be pressure retouched. The points are made with care and many show small distinct flake scars which are approximately parallel (Newman 1966). Most points have moderately even edges, but nine are serrated. The serrated points, with one exception, have serrations applied by pressure flaking (Newman 1966).

Burnett Site. Several reduction sequences were used in manufacturing the tools and points at the Burnett site. Many of them result from biface manufacture from split cobble flakes, but bipolar reduction, core-flake production, core reduction and microblade techniques also were used. Percussion flaking is evident on the larger pieces of both basalt and CCS. 
Many of the points and fragments, particularly the smaller examples, exhibit pressure flaking scars which are roughly parallel.

Basalt points predominate and many of them appear to have been severely eroded by soil chemical reaction and water. In addition, the workmanship of the basalt points is less refined than that seen on the CCS and obsidian points from Cascadia Cave and the Geertz site.

Serrations are visible on a number of points, but are much less pronounced than those of Geertz and Cascadia Cave. A few flakes show some evidence of exposure to heat. Whether this indicates deliberate heat treatment of lithic material is conjectural. The cores are generally small, and 17 of the 26 specimens are of CCS.

From the above discussion, it can be concluded that, with the exception of the three possibly early Windust Phase items, all points recovered to date from the Burnett site are leaf shaped, bipointed, foliate, lanceolate forms generally known as Cascade or Cascade-type. The points fall in the size, material, and technology range of those from Cascadia Cave and the Geertz site, the only other known sites in Western Oregon containing components producing exclusively Cascade-type points.

However, there is a difference in the material preference seen at the Burnett site and the Geertz and Cascadia Cave sites. Basalt is preferred at the Burnett site while CCS dominates at the other two. Some basalt points exhibit cruder workmanship and some are badly eroded. Rice (1972) notes that while the early Windust subphase on the Lower Snake River favored lanceolate stemmed, basal notched points of CCS, the late subphase is dominated by lanceolate leaf-shaped points of basalt. These later points become the hallmark of the Cascade Phase. 
The Late Windust subphase is thought to be transitional between the Windust and the Cascade phases. The small number (3) of Windust-type points compared to the number of Cascade-type points suggests a Late Windust-Early Cascade phase occupancy.

The projectile point assemblage includes two stem fragments and one complete stemmed point that are similar to points representing the Windust Phase of 10,500-8,000 B.P. The phase is extensively documented east of the Cascade Mountains but is less well known on the western side.

Windust points are described by Rice (1972) as basically either stemmed with a pronounced shoulder and basal notch/concave base or nonstemmed with a basal notch/concave base. However, he also notes that 22 per cent of the 229 points examined were straight based and 22 per cent were convex based. Edge and basal grinding are both present.

Specimen No. 488 of the Burnett assemblage, a complete point, was found at a depth of 100-110 centimeters beneath the surface in the 1990 Headlee property excavation. The two basal fragments were recovered from 250 Furnace St. , one from the surface and the other from $45-50$ centimeters below datum.

The complete point, with a basal width of only .9 centimeters, is smaller than the basal fragments which are 2.2 and 1.9 centimeters wide. It is strikingly similar to the group 11 projectile points described by Rice (1972) as shouldered lanceolate projectile points with elongated stems. These points, as described and illustrated by Rice (1972), have convex sides, an acute 
tip, well defined shoulders, slightly convex sided stem, edge grinding on stem, convex base, lenticular cross section, and well-controlled pressure flaking. These attributes fit Specimen 488 of the Burnett collection. It is smaller than those described by Rice but there is considerable variation in size among Windust points. It appears to have been reworked from a larger point.

The two basal fragments are not as easily assigned to a Windust category. The fragments appear to be similar to Rice's group 2 shouldered lanceolate projectile points which are described as having stems which are slightly expanding to slightly contracting, edge grinding on the stem, some with basal grinding, base straight to slightly convex, lenticular cross section and well controlled pressure flaking. These descriptors, including basal grinding, apply to the Windust-type points found at the Burnett site(Table 11).

Aikens (1986) notes that at that time points of the Windust type had not been reported for the Willamette Valley, but had been found in southwestern Washington, as well as east of the Cascades. He adds that their occurrence in Western Oregon is probable and they presumably would date to between 8,000 and 10,000 B.P. as they do on the Columbia Plateau (Aikens 1986).

The Windust Phase has been divided into two subphases, Early and Late. The early Windust Phase represents the period between 10,000 and 9,000 B.P., while the late subphase is dated between 9,000 and 7,500 B.P. Lanceolate stemmed and basal notched points of CCS dominate the early subphase while lanceolate leafshaped basalt points are the primary type found in the late subphase. These leaf shaped basalt points become the hallmark of the following Cascade Phase (Rice 1972).

At the Burnett site, Cascade-type points are found from the surface to 125 centimeters and the three Windust-type points were recovered from the 
surface to 110 centimeters. This suggests a co-occurrence of Windust and Cascade points consistent with Rice's conclusion that the Late Windust subphase is a transition phase with overlapping culture elements between the Windust Phase and the Cascade Phase (Rice 1972).

Given the fact that the two basal fragments are incomplete, it is also possible that they represent points from a later period. However, the distinctive edge-grinding found on Windust bases and those from the Burnett site is not a common characteristic on broad-stemmed points found in the Willamette Valley and the Portland Basin.

\section{ASSEMBLAGE COMPARISONS}

While the Cascade-type projectile point is generally known as the chief identifying feature of the Cascade phase of $8,000-6,000$ B.P. on the Columbia Plateau, in western Oregon it is also found in more recent context and is not considered diagnostic unless it is the only point type found in the site or component under investigation. Identification of Cascade Phase sites is further based on the contents of the complete artifact assemblage, which also usually includes edge-ground cobbles and ovate knives (Leonhardy and Rice 1970).

At Cascadia Cave, Newman (1966) found Cascade points, knives, drills, scrapers, worked flakes, two "edge ground cobbles" and a few other ground stone objects. Newman focused on the Cascade point, side-notched point and other point forms and the petroglyphs as the only artifacts useful in establishing the relationship of Cascadia Cave to other sites and cultures in the Northwest. He dismisses other artifacts as "of little use as they are not 
sufficiently distinctive or are distributed so widely that apparent similarities are not instructive."

At the Geertz site near Sandy, Oregon, the excavation produced projectile points, scrapers, drills, knives, chisel gravers, choppers, a cleaver, used flakes, cores, end-battered cobbles, an anvil stone, a small nodule of ochre and 58 specimens which did not fit into any of the above categories. Woodward (1972) described the Cascade points and other artifacts as similar to those recovered from sites on the Columbia plateau attributed to the Cascade Phase of 8,000-6,000 B.P.

Connolly and Baxter (1986) identified projectile points, scrapers, blades and blade tools, hammer/anvil stones and edge ground cobbles as the five classes of artifacts at Cascadia Cave where the initial occupation was radiocarbon dated at $7,910+/-280$ B.P. They also found the same five major artifact classes at the Standley site in Camas Valley, which produced radiocarbon dates of 2400 B.P.-300 B.P: (Connolly, Baxter 1986). These artifacts are considered diagnostic of Cascade assemblages on the southern Columbia Plateau (Leonhardy and Rice 1970, Bense 1972, Nelson 1969). Baxter's 1988 excavation at Cascadia Cave produced an assemblage that included foliate and stemmed projectile points, bifaces, unifaces, drills and perforators, used flakes, cores and nodules, cobble tools, ground stone tools and grinding slab fragments.

The artifact assemblage at the Burnett site, which includes Cascade and Windust type projectile points, scrapers, blades and blade tools, cobble choppers, cores, bifaces and one hammerstone, is similar to that of the Geertz site. However, it varies significantly from that of Cascadia Cave and the 
Standley site, in its lack of edge-ground cobbles and the scarcity of hammer/anvil stones. 


\section{ATTRIBUTES OF CASCADIA CAVE, GEERTZ AND BURNETT SITES}

\section{Cascadia Cave Geertz}

Rockshelter

Foothills

Mixed

No. of artifacts

Newman

Baxter

Soil excavated

Newman

Baxter

Screen

Newman

Baxter
Unknown

5.4 cubic meters

ca.700

10,748
Unknown

$1 / 8$ inch
Burnett

Open

Foothills

Portland Basin

Cascade type

2,319

6,651

Cascade type Windust type

$65 \mathrm{cu}$. yards

$10.4 \mathrm{cu}$. meters

$1 / 4$ inch

Artifact density

Newman

Unknown

1990/cu. meter

Preferred

Obsidian

CCS

Basalt

point material

Dominant

Obsidian

CCS

CCS

flake material

Depth of excavation

Newman

2.1 meters

Baxter

3.7 meters

1.3meters 
TABLE VII

\section{PROJECTILE POINT MATERIAL PREFERENCES \\ FOR CASCADIA CAVE, GEERTZ AND BURNETT SITES}

Total No. Points,

Fragments

Basalt CCS

Obsidian

Geertz

Cascadia Cave

54

$1.85 \%$

$87.04 \%$

$11.11 \%$

Newman

$>200$ Cascade Material \% not known

Newman

extant

44

0

$88.64 \%$

$11.36 \%$

Baxter

10

0

$60.00 \%$

$40.00 \%$

Burnett

80

$58.08 \%$

$38.14 \%$

$3.73 \%$

(250 Furnace

excavated)

250 Furnace

surface

46

$53.33 \%$

$42.22 \%$

$4.44 \%$

Headlee

11

$45.45 \%$

$45.55 \%$

$9.1 \%$ 
TABLE VIII

RANGE OF SIZES FOR COMPLETE POINTS FROM

CASCADIA CAVE, GEERTZ AND

BURNETT SITES

Length centimeters Width Thick

Geertz

3.3--5.5(est.)

$1.1-2.0 \quad .4-.5$

Cascadia Cave

Newman

2.2--9.0

$1-3.5$

$.4--.9$

Cascadia Cave

Baxter

$2.4--6.98$

$1.12--2.03 \quad 42--1.1$

Burnett

$2.7--11.40$

$.9--4.2$

$.4-1.1$ 
TABLE IX

AVERAGE LENGTH/WIDTH RATIOS OF COMPLETE
LANCEOLATE POINTS

Burnett Cougar Granite 35JA52 Cascadia Ripple Mountain Point Cave

3.41

3.136

2.941

2.686

$2.492 \quad 2.3$ 
TABLE $X$

CHARACTERISTICS OF WINDUST-TYPE POINTS FROM BURNETT SITE

Cat. No.Material Length Width Thick Depth

$\begin{array}{lllllll}488 & \text { Obsidian } & 3.2 & 1.2 & .4 & 100-110 & \text { Comp. } \\ 390 & \text { CCS } & 1.8 & 2.2 & .5 & \text { Surface } & \text { Stem } \\ 447 & \text { CCS } & 1.1 & 1.0 & .5 & 45-50 \mathrm{~cm} & \text { Stem }\end{array}$




\section{CHAPTER V}

\section{CONCLUSION}

This thesis is designed to serve as a report on archaeological site 35CL96 and to determine if it represents a Late Windust-Early Cascade Phase occupation in the Portland Basin of the Lower Willamette Valley.

\section{HYPOTHESES}

The discovery of only two projectile point types at the site (stemmed and lanceolate) suggests the two major hypotheses to be tested in this thesis:

1-- The projectile point assemblage, made up exclusively of lanceolate and stemmed points, represents a two-component occupation of the site from 9,000 to 7,000 B.P.(Late Windust and Early Cascade phases).

2-Or, the co-occurrence of stemmed (Windust type) and lanceolate (Cascade type) points indicates a single component occupation during the transition period between the Late Windust and Early Cascade period of 9,000 to 7,000 B.P.

These hypotheses raise questions regarding the number of components contained in the site, soil creation processes and artifact distribution, use of the site, age determination and relation of the site to regional prehistory. 


\section{COMPONENTS}

\section{One Component}

The overlapping vertical distribution of two distinct projectile point types, Windust and Cascade, indicates that the site has a single component which represents the transition period between the Windust and Cascade phases. Other evidence pointing to a single component includes the presence of artifacts of the same methods of lithic manufacture (core reduction, split cobble flaking, bipolar flaking and microblades) from the surface to the the Bretz flood cobbles. This uniformity of stone tool technology combines with levels of artifact concentration to suggest multiple occupations by a single people. Similarities of artifact morphology, material preference and CCS/basalt ratios in the four units at 250 Furnace St. further support the single occupation theory. It could also be a single component site where natural processes have resulted in the concentrations of artifacts at certain levels.

\section{Two Components}

The levels of concentrated artifact density at 35CL96 offer another perspective on the possible number of components at the site. At least two levels of high artifact density are seen at the 250 Furnace St. However, the Headlee locale has only one level of artifact concentration. The presence of a bimodal curve of artifact distribution in one location and a unimodal in another presents an interesting anomaly and, although it is not conclusive, it does suggest that there could have been multiple components and/or 
occupations with a subsequent mixing of the artifacts by natural disturbance. Obsidian hydration testing would establish the validity of these hypotheses.

\section{Site Function}

The high density and the variety of flakes, projectile points and tools indicate that the early inhabitants were involved in a wide range of intensive manufacturing, hunting and processing activities while the absence of edge ground cobbles, ground slate and grinding tools such as morters, pestles and metates suggests that crushing and grinding of nuts, roots and other food was not a common activity. Obsidian found at the site indicates possible travel and trade, and it should be sourced to determine the range of these activities.

Some conclusions can be drawn from the condition of the projectile points recovered from the Burnett site. Many of the finished tips and bases have use breaks which suggests that they were broken during the hunt and returned to camp. Some unfinished pieces are in an early stage of manufacture while some finished pieces apparently were broken during resharpening.

The abundance of manufacturing debris in the form of cores, waste flakes and broken bifaces implies that this was a specialized site where Cascade-type points broken in use were replaced with newly-made points that were manufactured there. Most early sites are in caves or rockshelters but the Burnett site's open location may reflect adaptation to some unique environmental or subsistence requirements. The debitage density is high for an open site.

The location of the site at the top of a steep slope more than 100 feet above the river does not appear to provide the most convenient access to water. Springs may have existed in the area at the time of the occupation, but 
the area closer to Oswego Creek would seem to have been more convenient. It is also possible that the Bretz floods had filled the Willamette River with gravel and thus raised the water level closer to the top of the terrace where the site is located. Movement of these gravels downstream by the river current over thousands of years would have resulted in a subsequent lowering of the river to its present level.

\section{Material Preference}

Cryptocrystalline silicate artifacts predominate in all but four of the 43 excavation levels at 250 Furnace St., while basalt is second. Although the combined count of all artifacts gives CCS a lead in the overall figures, basalt is the favored material for projectile points. The similar percentages of basalt, CCS and obsidian artifacts in Units A, B, C, and D at 35CL96 are indicative of a single occupation.

At 35CL96, excavated artifacts from 250 Furnace St. display this pattern:

$$
\text { Material Points }
$$

$\begin{array}{lrr}\text { Basalt } & 41.20 \% & 58.08 \% \text { of the points } \\ \text { CCS } & 56.52 \% & 38.14 \% \text { of the points } \\ \text { Obsidian } & 2.29 \% & 3.73 \% \text { of the points }\end{array}$

This dominance of CCS flakes over basalt flakes, but the presence of more basalt points than CCS points, indicates that much of basalt point manufacturing was conducted away from the site.

The preference for basalt points contrasts with the point assemblages from Cascadia Cave and the Geertz sites, where CCS is the favored point material. This suggests a cultural relationship between the Geertz and 
Cascadia Cave sites, but also implies that the Burnett site may not share a cultural affinity with them.

\section{Artifact Distribution}

The excavations at the Burnett site (250 Furnace St. and the Headlee property) have no visible stratigraphy or evidence of modern disturbance except for a plow or lawn zone near the surface. However, as many of the flakes and tools recovered from the site were found on edge, the soil probably has been disturbed since the items were deposited. On the other hand, five of the six size categories analyzed show very similar patterns of vertical distribution in Unit $C$ and the pattern is essentially the same as that for all artifacts in this unit and in the other three. This could suggest that the site is relatively undisturbed, as some researchers believe that artifacts of varying sizes and weights will respond differently to disturbances. All artifact classes studied have essentially the same distribution pattern and heated flakes also have concentrations generally corresponding to those of all artifacts.

The four excavation units at 250 Furnace show little variation in material and numbers of tools and debitage found which further illustrates the horizontal uniformity of distribution.

\section{Soil Formation}

Soil has formed in sediments deposited by the Bretz glacial floods of 15,000-13,000 years B.P. These flood deposits are cited as beginning about 87 centimeters below the present surface (Langridge 1987) and no stratigraphy or layering is evident above the Bretz flood cobble layer except for a plow zone at the surface. 
No change is seen in lithic manufacturing techniques from surface to sterile layer as the site maintains its horizontal and vertical uniformity in this aspect. Core reduction, split cobble flaking, bipolar flaking and the microblade technique are all found distributed through the site. The 11 bipolar flakes and cores accounted for just .17 per cent of all artifacts, a figure which indicates that this was not a major technique employed at this site.

\section{Age Determination}

The one charcoal sample submitted for radiocarbon analysis provided a date of about 1,500 B.P., but is suspected of being a burned tree root and therefore of little use in determining the age of the site. Estimates of the time period of the site are therefore based on stylistic comparisons of projectile points from 35CL96 with those from other known dated sites.

As all but three of the points recovered are Cascade types, discussion of morphological similarity with those from other sites inevitably rests on Cascadia Cave, where the lower levels radiocarbon dated to about 7,900 B.P. produced only "Cascade type" points. As this is the only dated site in western Oregon containing exclusively Cascade-type components, it continues to be the benchmark against which other sites are measured.

The lanceolate points recovered from the Burnett site in general resemble the collection from Cascadia Cave and Geertz as well as other Cascade-type points from the Northwest. However, there also are recognizable differences. Basalt is favored for the projectile points at the Burnett site, while CCS predominates at Geertz and Cascadia Cave. 


\section{Prehistory}

Theories on the relationship of the site to regional prehistory are based on artifacts recovered from the surface and from the excavations at 250 Furnace St. and the Headlee property. The primary diagnostic artifacts are Cascade-type lanceolate projectile points. Two stem fragments and one complete point which appear to be of the Windust-type also are important clues to the regional affiliation of the site.

These two point types are the only varieties found to date and this evidence argues for the hypothesis that the site represents a Late WindustEarly Cascade occupation covering the period of about 9,000-7,000 B.P. The lanceolate Cascade-type points from the Burnett site fall in the form, material, size and technology range of those from Cascadia Cave and the Geertz site, the only other known sites in western Oregon containing components which produced exclusively Cascade-type points. These points are hallmarks of the Cascade Phase, a culture type found throughout the Northwest and dated at about 8,000--6,000 B.P. (Leonhardy and Rice 1970; Rice 1972).

The Windust-type specimens resemble points from the Windust Phase described as representing the earliest occupation of the Lower Snake River region and dated between 10,800-8,000 B.P. by radio carbon analysis (Rice 1972). Similar points have also been recovered from sites outside the Plateau.

At Judd Peak (Daugherty, Flenniken, Welch 1987) the introduction of small, triangular points is seen to have occurred sometime after 2,000 years ago, probably as the result of the advent of the bow and arrow. The absence 
of triangular points at the Burnett site suggests that it was not used after introduction of the bow and arrow.

Edge-ground cobbles are one of the diagnostic factors of the Cascade phase in the Columbia Plateau but no specimens were found at the Burnett site, perhaps because of the small area excavated. Radiocarbon analysis of feature-associated charcoal or obsidian sourcing and hydration dating would aid in fixing the site's place in regional prehistory.

\section{SUMMARY}

Archaeologists attempting to date early period sites in western Oregon face a formidable challenge, particularly in the case of open sites where tree falls and roots have destroyed most stratigraphic evidence over the thousands of years since artifacts were deposited. Additionally, the damp climate west of the Cascades in most cases results in decomposition and erosion of bone and floral material which might be radiocarbon dated.

In caves and rockshelters, on the other hand, conditions are more amenable to dating as sediments are generally drier and are only minimally disturbed by vegetation. The two known Cascade Phase sites in the Lower Willamette-Portland Basin area (Geertz and Burnett sites) are both open sites and have produced no material suitable for radiocarbon dating.

Cascadia Cave, the only other site in western Oregon containing a purely Cascade Phase component, is a rockshelter containing suitable charcoal and some undisturbed stratigraphy. Analysis of material from this site has provided a date of about 8,000 B.P. for the Cascade Phase in western 
Oregon (Newman 1966). As other dated sites of this age have not been reported, Cascadia Cave stands as the site against which others are measured.

The Geertz site near Sandy, which produced only Cascade-type points and no datable charcoal, is given a possible date of $8,000-4,000$ years B.P. on the basis of point similarities between its assemblage and that of Cascadia Cave (Woodward 1972).

The Ripple site in the Clackamas River area also is dated at around 8,0006,000 B.P., again because the assemblage and Cascade-type points found there are seen as similar to those of Cascadia Cave.

At the Judd Peak site in southwestern Washington, the suggested date of around 7,000 B.P. for the earliest occupation of the south rockshelter is based upon comparative cultural material from nearby Layser Cave, which was radiocarbon dated (Daugherty, Flenniken,Welch 1987).

The practice of comparing sites on the basis of artifact similarity when more objective methods are not possible is thus well established archaeologically and its utility in relation to Cascadia Cave and other early sites has been demonstrated. Charcoal found at the Burnett site has been radiocarbon dated to about 1,500 B.P., but as the sample analyzed was not associated with any cultural feature, it is not considered to be a reliable indicator of the site's age.

With the absence of means for reliable objective dating, concepts about cultural relationships and age of the site are based on comparison of artifacts found there with those from dated contexts elsewhere. The combination of Windust-type points and Cascade-type points, with the Cascade-type predominating, suggests that this is a Late Windust-Early Cascade site. Distinguishing the Early and Late Cascade phases is the side-notched 
projectile point which is present only in the later phases. As no sidenotched or triangular points have been found at this site, the Early Cascade designation appears most appropriate.

Rice (1972) notes that the Early Windust subphase is characterized by predominantly lanceolate stemmed and basal notched points of cryptocrystalline silicate and the Late Windust subphase is dominated by lanceolate leafshaped projectile points of basalt. One of the three Windust type specimens from the Burnett site is obsidian and the other two are of CCS, but their presence in conjunction with the later Cascade-style points supports the argument for a Late Windust-Early Cascade site. This period is considered to be a transition phase with overlapping culture elements between the Windust and Cascade phases.

Bryan (1965) points out that dating sites by comparing their projectile points with other dated sites is not an infallible method. He states that sites with tools known to be ancient, if not associated with local types known to be later, were presumably occupied before the latter types were innovated. He stresses that every effort should be made to verify the age by more objective means whenever possible as most projectile points have a long history.

Connolly and Baxter (1986) also caution against dating sites by comparing Cascade-type points as this style was used over a long period of time in the Pacific Northwest. The ubiquity and long temporal presence of the Cascade-type point underscores the need for further excavation and radio carbon and obsidian hydration dating at the Burnett site.

The Burnett site has all the attributes of a single component site, including unchanged technology and similarity of artifacts throughout the horizontal and vertical dimensions. The site is probably considerably 
disturbed by tree falls and other forces and is probably the result of multiple occupations.

The situation could be similar to that encountered at Judd Peak in southwestern Washington where the combination of Cascade and sidenotched points was taken to indicate that it was used by one group which used both type points at same time. The Judd Peak site is placed in the Late Cascade Phase because Cascade-type points, side-notched and later styles. were found there. It appears that the Burnett site may be earlier because it has produced Windust and Cascade points only, with no later points seen. The Burnett site appears to have either one or two components. In either case, the evidence favors an Early Cascade Phase, and this may explain the differences between its artifacts and those of Cascadia Cave.

If the site is of a single component, the many Cascade points and the few stemmed points means that most of the occupation occurred during the Early Cascade Phase. If there are two components, such as separate Late Windust and Early Cascade Phases, the absence of side-notched points still weights the case toward the Early Cascade period. Obsidian hydration would answer the component question. Adequate obsidian is available to provide for hydration dating, but acquiring appropriate charcoal for radio carbon dating will require additional excavation and the discovery of features. This is a large, complex site that will require considerably more investigation to completely understand.

If the hypothesized dates are valid, the Burnett site would be the oldest site in the Lower Willamette River-Portland Basin area. The site's importance warrants further investigation to obtain definitive answers to the questions of age, components and the place of the site in regional prehistory. 


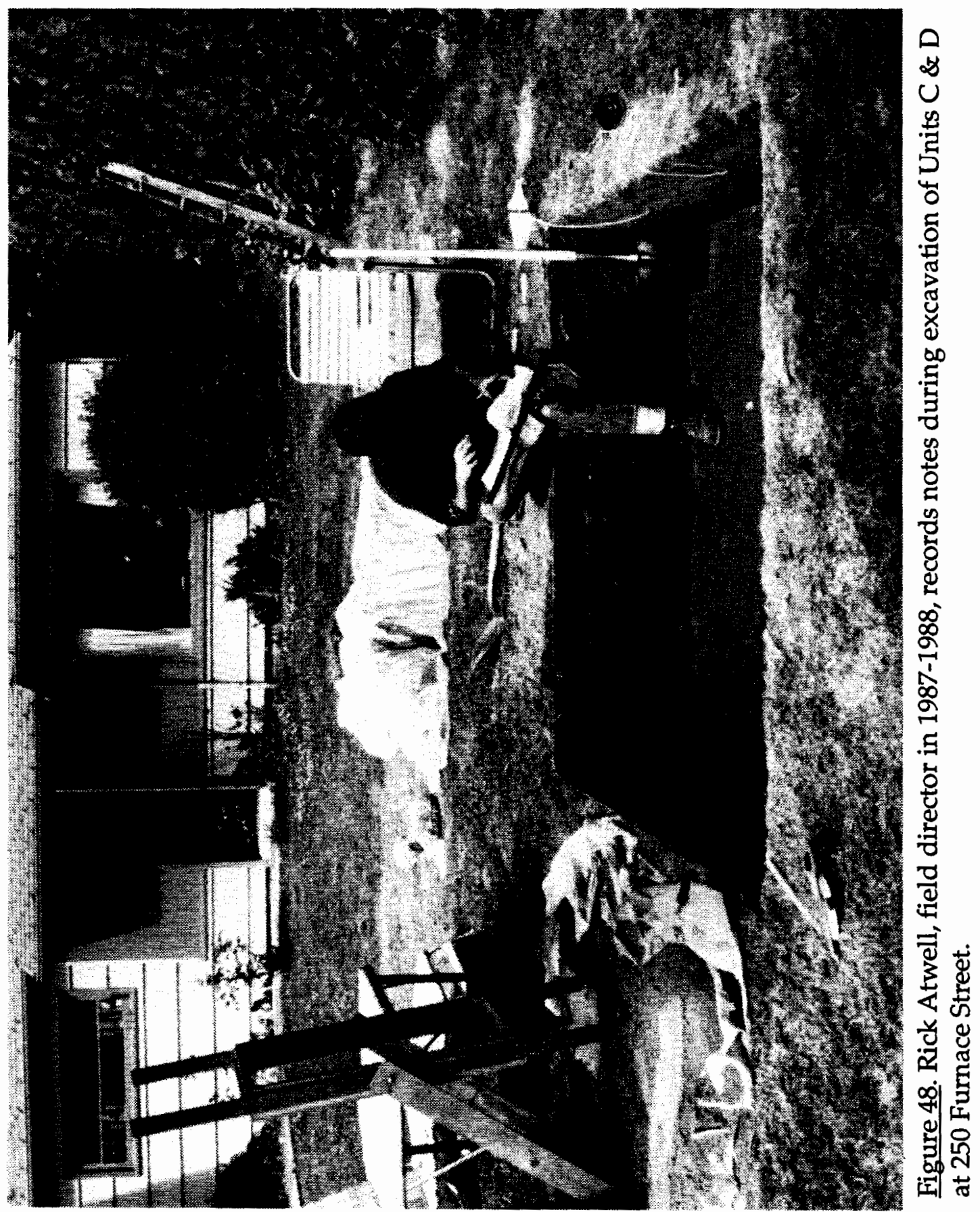




\section{REFERENCES}

Aikens, Melvin. 1986. Archaeology of Oregon. U. S. Department of Interior, Washingon, D. C.

Allen, John, Marjorie Burns and Sam C. Sargent. 1986. Catadysms on the Columbia. Timber Press, Portland, Oregon.

Baxter, Paul. 1989. A Preliminary Report of Investigations at Cascadia Cave, Linn County, Oregon. Submitted to State Historic Preservation Office, Salem.

Beckham, Stephen Dow, Rick Minor and Kathryn Ann Toepel. 1981. Prehistory and History of BLM Lands in West-Central Oregon: A Cultural Resources Overview. Anthropological Papers No. 25. University of Oregon, Eugene.

Bense, Judith Ann. 1972. The Cascade Phase: a Study of the Effect of the Altithermal on a Culture System. Unpublished Ph. D. dissertation, Department of Anthropology, Washington State University, Pullman. University Microfilms, Ann Arbor.

Brown, Lionel A. 1960. A Typology and Distribution of Projectile Points from Sauvie Island, Oregon. Unpublished Master's thesis, Department of Anthropology, University of Oregon, Eugene.

Bryan, Alan Lee. 1965. Paleo-American Prehistory. Occasional Papers No. 16. The Idaho State University Museum, Pocatello.

Butler, B. Robert. 1961. The Old Cordilleran Culture in the Pacific Northwest. Occasional Papers No. 5. The Idaho State College Museum, Pocatello.

Butzer, Karl. 1982. Archaeology as Human Ecology. Cambridge University Press.

Cheatham, Richard D. 1988. Late Archaic Settlement Pattern in the Long Tom Sub-Basin, Upper Willamette Valley, Oregon. Anthropological Papers No. 39. Department of Anthropology, University of Oregon, Eugene. 
City of Lake Oswego. 1976. Physical Resources Inventory. City of Lake Oswego, Oregon.

Cole, David L. 1968. Archaeology of the Fall Creek Dam Reservoir. Final report to the National Park Service. Ms. on file, Museum of Natural History, University of Oregon.

Connolly, T. J. and Paul W. Baxter. 1986. New Evidence on a Traditional Topic in Pacific Northwest Prehistory. In Contributions to the Archaeology of Oregon, 1983-86. Edited by K. M. Ames, pp. 120146. Occasional Papers No. 3. Association of Oregon Archaeologists.

Cressman, Luther S. 1977. Prehistory of the Far West. University of Utah Press, Ogden.

Cressman, Luther S., David L. Cole, Wilbur A. Davis, Thomas A. Newman, and Daniel J. Scheans. 1960. Cultural Sequences at The Dalles, Oregon. American Philosophical Society Transactions, New Series 50(10). Philadelphia.

Daugherty, Richard D., J. Jeffrey Flenniken and Jeanne M. Welch. 1987. A Data Recovery Study of Judd Peak Rockshelters (45-LE-222) in Lewis County, Washington. Studies in Cultural Resource Management No. 8. U. S. Forest Service, Portland, Oregon.

Dunnell, R. C. and S. K. Campbell. 1977. Aboriginal Occupation of Hamilton - Island, Washington. Reports in Archaeology No. 4. Department of Anthropology, University of Washington, Seattle.

Fagan, John, Jo Reese and David V. DeLyria. 1991. Archaeological Survey of the Camas Meadows Development Project. Final report to Vanport Manufacturing, Inc. Report No.10. Archaeological Investigations Northwest, Portland, Oregon.

Fladmark, Knut R. 1982. An Introduction to the Prehistory of British Columbia. Canadian Journal of Archaeology No. 695-156.

Follansbee, Julia. 1975. Archaeological and Historical Survey of the Kruse Way Corridor. Clackamas County, Oregon City. 
Gerig, Allen J. 1985. Soil Survey Clackamas County Area, Oregon. United States Department of Agriculture, Soil Conservation Service. In cooperation with United States Department of the Interior Bureau of Land Management and Oregon Agricultural Experiment Station.

Goodall, Mary. 1958. Oregon's Iron Dream. Binfords and Mort, Portland, Oregon.

Langridge, Russ. 1988. Report on Soils at Burnett Site. U. S. Soil Conservation Service, Albany, Oregon.

Lebow, Clayton. 1985. Archaeological Investigations at the Ripple Site (35CL55) in the Mount Hood National Forest, Clackamas County, Oregon. Report to the Mount Hood National Forest. Department of Anthropology, University of Oregon, Eugene.

Leonhardy, Frank C., and David G. Rice. 1970. A Proposed Culture Typology for the Lower Snake River Region, Southeastern Washington. Northwest Anthropological Research Notes No. 4.

Mackey, Harold. 1974. The Kalapuyans. Mission Hill Museum, Salem,Oregon.

Matson, R. G. 1976. The Glenrose Cannery Site. Archaeological Survey of Canada Paper 2. National Museum of Man Mercury Series. Ottawa.

Nelson, C. M. 1969. The Sunset Creek Site and its Place in Plateau Prehistory. Report of Investigations No. 47. Laboratory of Anthropology, Washington State University, Pullman.

Newman, Thomas M. 1966. Cascadia Cave. Occasional Papers No. 18. The Idaho State University Museum, Pocatello.

Olsen, Thomas. 1975. Baby Rock Shelter. In Archaeological Studies in the Willamette Valley, Oregon. Edited by C. M. Aikens. Anthropological Papers No. 8. Department of Anthropology, University of Oregon, Eugene. 
O'Neill, Brian L. 1989. A Cultural Chronology of the Umpqua Basin, Southwest Oregon. Unpublished Ph. D. dissertation, Department of Anthropology, University of Oregon, Eugene.

Peterson, Lynn. 1989. 9,000 Years of Human Occupation in Relation to Geomorphic Features and Processes in the Long Tom River Subbasin, Willamette Valley, Oregon. Unpublished Master's thesis, Department of Anthropology, University of Oregon, Eugene.

Pettigrew, Richard M. 1977. A Prehistoric Culture Sequence in the Portland Basin of the Lower Columbia Valley. Unpublished Ph. D. dissertation, Department of Anthropology, University of Oregon, Eugene.

.1980. The Archaeological Investigations at Hager's Grove, Salem. Anthropological Papers No. 19. Department of Anthropology, University of Oregon Eugene.

.1990. Prehistory of the Lower Columbia and Willamette Valley. In Northwest Coast_edited by Wayne Suttles, pp. 518-529. Handbook of North American Indians. Vol. 7. William C. Sturtevant, general editor Smithsonian Institution, Washington, D.C.

.Undated. (Work performed 1977-1980). Archaeological Investigations in Mill Creek Valley, Crook County, Oregon. Anthropological Papers No. 26. Department of Anthropology, University of Oregon, Eugene.

Reckendorf, Frank F. and Roger B. Parsons.1966. Soil Development Over a Hearth in the Willamette Valley, Oregon. Northwest Science 40:46-54.

Rice, David G. 1972. The Windust Phase in Lower Snake River Region Prehistory. Report of Investigations No. 50. Laboratory of Anthropology Washington State University, Pullman.

Saleeby, Becky and Richard Pettigrew. 1983. Seasonality of Occupation of Ethnohistorically Documented Villages on the Lower Columbia River. In Prehistoric Places on the Southern Northwest Coast, edited by Robert E. Greengo, pp.169-193. Thomas Burk Memorial Washington State Museum, University of Washington, Seattle.

Sampson, C. Garth. 1985. Nightfire Island: Late Holocene Lakemarsh Adaptation on the Western Edge of the Great Basin. Anthropological Papers No. 33. Department of Anthropology, University of Oregon, Eugene. 
Snyder, Sandra L. 1981. Medicine Creek: Pre-and-Post Mazama Occupations in the Cascades. Tebiwa 23: 1:13.

Toepel, Kathryn A. 1985. The Flanagan site: 6,000 years of Occupation in the Upper Willamette Valley, Oregon. Ph. D. dissertation, Department of Anthropolgy, University of Oregon, Eugene.

Trimble, G. E. 1963. Geology of Portland, Ore. and Adjacent Areas. U.S. Geological Survey Bulletin 1119.

Villa, Paola. 1982. Conjoinable Pieces and Site Formation. American Antiquity 47: 276:290.

White, John R. 1979. A Chronology of Upper Willamette Valley, Oregon, Prehistory. American Antiquity 44: 556-566.

Woodward, John A. 1972. The Geertz Site: An Early Campsite in Western Oregon. Tebiwa 15:55-62.

.1974. Salmon, Slaves and Grizzly Bears: The Prehistoric Antecedents and Ethnohistory of Clackamas Indian Culture. Unpublished Ph. D. dissertation, Department of Anthropology, University of Oregon, Eugene.

Zenk, Henry B. 1976. Contributions to Tualatin Ethnography, Subsistence and Ethnobotony. Unpublished Master's thesis, Department of Anthropology, Portland State University, Portland, Oregon. 
APPENDIX 
Soil Report on the Burnett Site

Taxonomic Class:

Fine-silty, mixed, mesic Ultic Argixerolls LOCATION:

Robert M. Burnett property-250 Furnace St., Lake

Oswego, OR 97034

PEDON:

\section{Hillsboro silt loam}

A1- 0 to $6 \mathrm{~cm}$; very dark grayish brown (10YR 3/2) silt loam, grayish brown (10YR 5/2) dry; weak very fine subangular blocky structure; slightly hard, friable, slightly sticky and slightly plastic; common very fine roots; neutral (pH6.6); abrupt smooth boundary.

A2- 6 to $16 \mathrm{~cm}$; very dark grayish brown (10YR 3/2) gravelly silt loam, grayish brown (10YR 5/2) dry; moderate medium and coarse granular structure; slightly hard, friable, slightly sticky and slightly plastic; common very fine roots; 30 per cent 1-2 mm hard iron concretions; neutral ( $\mathrm{pH} 6.8$ ); clear smooth boundary.

$A B-16$ to $26 \mathrm{~cm}$; very dark grayish brown (10YR 3/2) gravelly silt loam, grayish brown (10YR5/2); weak moderate subangular blocky structure parting to weak coarse granular; slightly hard, friable, slightly sticky and slightly plastic; very few fine roots; 20 per cent $1-2 \mathrm{~mm}$ hard iron concretions; neutral (pH 7.0f); clear smooth boundary.

Bt1- 26 to $45 \mathrm{~cm}$; dark brown (7.5YR 4/4) silt loam; weak fine and medium prismatic structure; slightly hard, friable, slightly sticky and slightly 
plastic; few very fine roots; few thin brown (10YR 4/3) clay coatings on ped faces and in pores; very few coarse and medium krotovinas; 5 per cent 1-2 $\mathrm{mm}$ hard iron concretions; neutral ( $\mathrm{pH} 7$ ); clear wavy boundary.

Bt2- 45-70 cm; dark brown (10YR 4/3) silty clay loam; weak coarse prismatic structure; hard, friable, slightly sticky and plastic; common very fine and fine roots; common thin dark yellowish brown (10YR 4/4) clay coatings on ped faces and in pores; 2 per cent 1-2 mm maganese concretions; neutral (pH 7.2); gradual wavy boundary.

Bts3 -70 to $87 \mathrm{~cm}$; dark brown (10YR 4/3) clay loam; weak coarse prismatic structure; hard, friable slightly sticky and plastic; moderately thick dark yellowish brown (10YR 4/4) clay coatings on ped faces and in pores; 2 percent 1-2 mm maganese concretions; neutral ( $\mathrm{pH}$ 7.2); abrupt wavy boundary.

2BC- 87 to $98 \mathrm{~cm}$; dark brown (10YR 4/3) loam; weak medium and coarse prismatic structure; slightly hard, friable, slightly sticky and slightly plastic; common moderately thick dark yellowish brown (10YR 4/4) clay coatings on ped surfaces and in pores; 2 per cent hard concretions; neutral ((pH 6.6); abrupt wavy boundary.

3c- 98-120 cm; dark brown (10YR 4/3) extremely cobbly loam; massive; slightly hard, friable, slightly sticky and slightly plastic; few thin dark yellowish brown (10YR 4/4) clay coatings on ped faces; 30 per cent gravel, 30 per cent cobble and 5 per cent stones; neutral (pH 6.6). 
NOTES:

Using elevation and reconsidering profile characteristics, the soil described at the site correlates most closely to the Hillsboro soil series rather than the Willamette.

There were a variety of profile characteristics which just did not fit the Willamette series nor the Senecal geomorphic surface on which this soil is associated.

These characteristics include: (a) the absences of a Pachic epipedon(dark surface layer over 20 inches thick), (b) the abundance of concretions found in the profile, (c) the sandy and cobbly underlying soil layers beginning at $87 \mathrm{~cm}$, (d) and the elevation of approximately 130 to 140 feet which is somewhat lower than the Senecal geomorphic surface in this area where the Willamette series should be found.

Consideration of these differences results in the Burnett site actually being correlated to the Champoeg geomorphic surface and the Hillsboro soil series.

The Champoeg surface (1) is directly related to the Spokane or Missoula Flood deposits of the Portland delta and the Willamette Valley referred to as the Portland Sand and Gravel. This surface is underlain by these deposits and truncates older geomorphic surfaces such as the Senecal. In the profile described, the soil layers beginning at $87 \mathrm{~cm}$ would represent this material.

It is currently recognized that there were several floods associated with the damming of Lake Missoula (2) and that the age of the last major flood is about 13,000 years ago (3). It is this last flood deposit which is believed to have formed the Champoeg geomorphic surface (4) in the Portland delta area. 
The Hillsboro series represents a soil formed in silty alluvial deposits over a coarse textured discontinuity.

I do hope this description provides what you need. If you have an questions, please don't hesitate to call either Jerry Latshaw or myself.

Russ Langridge

Area Soil Scientist

SCS-Albany, Or.

\section{LITERATURE CITED}

1. Balster, C. A., and R. B. Parsons. 1968. Geomorphology Soils, Willamette Valley, Oregon. Oregon State Univ. Agric. Exp. Stn. Special Rep. 265.

2. Parsons, R. B. 1972-76. Quaternary Soil Development and Geomorphology, Willamette Valley, Oregon. Unpublished.

3. Parsons, R. B. 1981. The Soil Sequence of Late Pleistocene Glacial Outwash Terraces from Spokane Floods in the Idaho Panhandle. Soil Sci. Soc. Am. 45: 925-930.

4. Parsons, R. B., and G. L. Green. 1982. Geomorphic Surfaces and Soil Development. In Soil Survey of Multnomah County, Oregon. U. S. Government Printing Office, Wash. D. C. 